\title{
Volatility and asymmetric dependence in Central and East European stock markets
}

\author{
Nathan Lael Joseph ${ }^{1}$ (D) Thi Thuy Anh Vo ${ }^{2}$ (D) Asma Mobarek ${ }^{3} \cdot$ Sabur Mollah $^{4}$
}

Published online: 18 March 2020

(c) The Author(s) 2020

\begin{abstract}
We study the effects of contagion around the global financial crisis (GFC) and the Eurozone crisis periods using German and UK returns, each paired with returns from Central and East European (CEE) stock markets that recently joined the European Union (EU). Using bivariate vector error-correction models (VECMs) estimated in $\operatorname{GARCH}(1,1)$, we find strong support for long-run equilibrium conditions. This finding suggests that tests of tail dependence using differenced VARs may be mis-specified when long-run equilibrium conditions apply. Past news has more persistence on current volatility in CEE markets than in the developed markets. Past volatility has more persistence in the developed markets compared to the CEE markets. The T-V symmetrized Joe-Clayton (T-V SJC) copula outperforms all other copulas in goodness-of-fit, including, the T-V Gaussian and Student $t$ copulas. This result is supported by a differenced VAR-GARCH $(1,1)$. For CEE and developed market returns, no more than half of our market pairs exhibit significant increases in lower tail dependence, under the T-V SJC copula. Given the number of paired comparisons, the evidence on joint extreme dependence is weak. As such, CEE stock markets experienced little contagion effects during the GFC and Eurozone crisis periods, contrary to prior results. We find that the legal environment negatively impacts financial development, perhaps causing CEE and the EU markets to be isolated.
\end{abstract}

Keywords Cross-country contagion - Global financial crisis · Eurozone crisis · GARCH · Vector error-correction models · Time-varying copula functions

JEL Classification $\mathrm{G} 1 \cdot \mathrm{G} 11 \cdot \mathrm{G} 14 \cdot \mathrm{G} 15$

Nathan Lael Joseph

n.1.joseph@aston.ac.uk

Thi Thuy Anh Vo

vothuyanh@due.edu.vn

1 Aston Business School, Aston University, Birmingham, UK

2 University of Economics, University of Danang, Danang, Vietnam

3 Cardiff Business School, Cardiff University, Cardiff, UK

4 University of Sheffield, Western Bank, Sheffield S10 2TN, UK 


\section{Introduction}

Over the past two decades or so, academic researchers, practitioners and regulators have developed renewed interest in low-probability events associated with the dependence structure of asset returns. Both the global financial crisis (GFC) of 2007-2009 and the Eurozone crisis of 2010-2018 demonstrate the economic problems associated with financial linkages and contagion effects. ${ }^{1}$ One interesting area relates to the dependence structure of pairs of equity market returns around economic shocks or crisis events. Indeed, Erb et al. (1994) and Longin and Solnik (2001) report that pairs of stock market returns exhibit stronger correlations during market declines compared to market upturns. A more complete approach to test for extreme dependence is to decompose the multivariate joint distribution of stock returns into their marginal distribution functions and a copula part that describes the dependence structure between the pairs of returns. A copula approach provides more information regarding dependence in returns than linear correlation, especially when the joint distribution of the returns is nonelliptical (Patton 2006). Prior studies (Caporale et al. 2014; Mollah et al. 2016) tend to estimate joint dependence using the dynamic conditional correlation (DCC) of Engle (2002). However, this approach has important econometric limitations, since the DCC has no testable regularity conditions and asymptotic properties (Caporin and McAleer 2013). It turns out that the copula approach is a useful way to examine contagion and spillover effects, especially for stock markets that experience episodes of crises.

We therefore examine the dependence structure of stock returns for a set of nine Central and East European (CEE) stock markets, seven of which are based in economies that joined the European Union (EU), having satisfied the convergence criteria of the Maastricht Treaty. ${ }^{2}$ By examining the dependence structure during tranquil and crisis periods, we show how dependence in returns varies under long-run equilibrium conditions for a set of countries that operate under common economic conditions. Since the EU's Financial Services Action Plan of 1999 was designed to achieve full integration of financial markets, through the harmonization of rules on financial transaction, we predict that these stock markets are likely to experience strong market integration and contagion effects during the crisis periods. Indeed, Kalemli-Ozcan et al. (2010) show that a primary facilitator of EU integration was the elimination of currency risk such that the introduction of the euro increased cross-border bilateral bank holdings and transactions by around $40 \%$ for euro area countries. For the accession countries examined in our paper, market integration implies less home bias, more risk sharing, and a lower cost of capital for firms operating in the area (see Kwabi et al. 2016). However, Chambet and Gibson (2008) show that many emerging markets are segmented because they are less open to international trade and that trade openness positively relates to stock market integration. Furthermore, Wu (2000) shows that strong intra-regional trade and liberalization are an important source of contagion effects (see Wu et al. 2003). As such, it is possible that our accession countries

\footnotetext{
${ }^{1}$ European leaders declared an end to the Eurozone crisis in August 20, 2018 (Brunsden and Khan 2018).

${ }^{2}$ Following the signing of the Treaty of Accession of April 16, 2003, ten countries, including Malta and Cyprus, joined the EU on May 1, 2004. Five of our nine CEE countries (Czech Republic, Estonia, Hungary, Poland and Slovenia) that joined on May 1, 2004, belong to the "eight first-wave accession countries." Bulgaria and Romania joined the EU in January 1, 2007 (second-wave). Croatia joined in July 1, 2013 in the third-wave (see https://en.wikipedia.org/wiki/Central_and_Eastern_Europe). We exclude Bulgaria and Lithuania because of the shorter history of their MSCI data. Price observations for Latvia and Slovakia are unavailable as MSCI data in Datastream. The Russian and Ukrainian stock indices are included as benchmarks.
} 
may not have achieved the high level of market dependence and integration reported by some DCC studies (Syllignakis and Kouretas 2011), especially since new evidence indicates that DCC estimates may unreliable predict market dependence and contagion effects (Caporin and McAleer 2013). Following Chambet and Gibson (2008), we should expect a lower level of extreme dependence between CEE stock markets paired with the UK stock market, compared to CEE stock markets paired with the German stock market, perhaps because the level of UK imports/exports of goods and services to CEE countries is much lower compared to the level of trade between CEE countries and Germany. ${ }^{3}$ Nevertheless, the UK and euro area are the dominant sources of external bank finance for CEE countries, and the UK has the more dominant financial center compared to the German financial center (Lane and Milesi-Ferretti 2007). Thus, the larger size and higher liquidity level in the UK stock market might also influence the level of dependence between CEE and UK stock market returns.

Market integration, however, has important negative effects. They include fewer opportunities for portfolio diversification, increases in contagion risks and spillover effects (Goetzmann et al. 2005). Increased financial integration and frictionless capital markets can even undermine a country's macroeconomic policy (Blanchard and Dell'Ariccia 2010). Even so, contagion and herding effects do not affect all countries and markets with the same level of intensity (Donadelli and Paradiso 2014; Dias and Ramos 2014). Overall, these apparently conflicting economic conditions make CEE markets an interesting case for testing extreme dependence. Our paper also contributes to the debate on the relative contribution of country factors, compared to industry factors, in determining the extent of volatility and diversification opportunities for investors (Heston and Rouwenhorst 1994; Cavaglia et al. 2000; Bekaert et al. 2009).

This paper makes two main contributions. To the best of our knowledge, this is the first paper to use bivariate vector error-correction models (VECMs) in GARCH $(1,1)$, hereafter, VECM-GARCH, in order to extract dynamic conditional correlations (DCCs) as inputs into time-varying (T-V) copula functions. We predict that the long-run equilibrium properties of the VECM-GARCH will constrain price movements, causing more dependence between pairs of markets, compared to the differenced VAR-GARCH $(1,1) .{ }^{4}$ Therefore, we predict that the VECM-GARCH will exhibit more extreme dependence compared to the differenced VAR-GARCH. This is because, under the error-correction specification, the variables will not move too far apart when long-run equilibrium conditions apply (Engle and Granger 1987). As such, we argue that failure to use a correctly specified VAR may explain the weak evidence for return dependence reported by Baruník and Vácha (2013), for CEE stock markets and for stock markets in non-Euro countries (Bartram and Wang 2015), on the assumption that a VECM is the preferred model specification. Furthermore, Bollerslev and Engle (1993) put forward the idea of co-persistence in conditional variances, where combinations of variables can contain a long-run component in co-persistence that can have a generalized interpretation similar to Engle-Granger cointegration (Engle and Granger 1987). An error-correction framework is useful in our setting since it allows us to interpret the short-run and long-run dynamics of stock markets that operate

\footnotetext{
${ }^{3}$ UK exports of goods and services to CEE countries during the 10 years to 2014 are a mere $£ 16$ billion, representing $3 \%$ of the region's imports. German exports to the region are almost 15 times larger. http:// waterbriefing.org/home/company-news/item/8816-uk-ti-leads-drive-to-double-trade-to-central-and-easterneurope. Accessed 28 July 2017.

${ }^{4}$ For simplicity, we state VECM-GARCH and differenced VAR-GARCH, accordingly.
} 
in countries that have common macroeconomic policies and common financial market regulations. ${ }^{5}$ An error-correction framework also improves estimation consistency when long-run conditions apply. Prior studies tend to estimate DCCs using a differenced VARGARCH, which, in turn, ignores long-run conditions (see Mollah et al. 2016). Syriopoulos and Roumpis (2009) and Caporale et al. (2014) estimate VECMs and find support for longrun equilibrium conditions. Caporale et al. (2014), in particular, find support for increases in the DCCs during the GFC period. An important limitation of both studies is that copula functions are not estimated. Our estimates focus on sample periods that constitute crisis and non-crisis periods, since volatility persistence in the underlying GARCH will be less sensitive to parameter changes and model misspecification (see Lamoureux and Lastrapes 1990), compared to the case of a full sample study.

Under VECM-GARCH, we find strong support for long-run equilibrium conditions, especially for pairs of CEE and UK market returns, during the Eurozone crisis period. ${ }^{6}$ We attribute the strong support for the long-run conditions of the Eurozone crisis period to the increase in global and Euro-area financial flows, since the end of the GFC (see ECB 2012). We also take the view that during the Eurozone crisis period, CEE, UK and German investors attributed more certainty and stability to UK economic conditions than economic conditions in Germany, perhaps, reflecting a weaker connection between the UK and the Eurozone crisis. This would increase financial flows to the UK market. ${ }^{7}$ We find that EU membership does not necessarily imply the presence of long-run equilibrium conditions. For example, German and UK stock markets have no long-run equilibrium relationship with the Czech Republic stock market, nor do the Slovenian and German stock markets have long-run equilibrium relations. Indeed, both the Czech Republic and Slovenia joined the EU during the first wave. Even so, this has not facilitated the presence of long-run conditions with the developed markets. In contrast, both the Croatian and Russian markets have long-run equilibrium conditions with the German and the UK stock markets during the non-crisis period, even if Croatia and Russia are non-EU members. These findings suggest that common financial regulation and economic policies alone are insufficient to bring about long-run equilibrium relationships across financial markets.

Our second main contribution is to establish the time-varying symmetrized Joe-Clayton (T-V SJC) copula as the best function to describe the dependence structure of CEE and the developed market returns. Related work favors the Student $t$ copula over other copulas, such as the Gaussian copula (Breymann et al. 2003; Jondeau and Rockinger 2006). The T-V SJC copula allows tail dependence to determine the presence or absence of asymmetry. This

\footnotetext{
5 The Maastricht Treaty criteria do not apply to stock market conditions. The treaty requires convergence in price stability (nominal inflation), exchange rate stability, durable convergence of long-term interest rates and sustainability on certain fiscal measures. However, the EU's Financial Services Action Plan of 1999 aims to harmonize rules on securities, banking, insurance, mortgages and other financial transactions. We argue that satisfying both requirements would imply stronger stock market interdependence.

6 Although different in specification, many econometricians interpret the Engle-Granger, Johansen cointegration tests and the $t$-ratio of the error-correction model (ECM) as measures of long-run equilibrium conditions (see Banerjee et al. 1998).

7 The GFC has its source in the US subprime credit market, whereas the Eurozone Crisis has its source in Portugal, Italy, Ireland, Greece and Spain (Frieden and Walter 2017). We do not treat Portugal, Italy, Ireland, Greece and Spain as sources of contagion since they have relative small stock markets and economic links with the CEE countries. Germany dominates the UK in terms of its economic association with the Eurozone Crisis and economic links with CEE countries. Therefore, we treat Germany as the main economy to carry the cost of the Eurozone Crisis. However, the UK dominates Germany as a financial centre and as an important source of contagion during the GFC.
} 
limits an important weakness of the basic Joe-Clayton copula when determining upper and lower tail dependence (Patton 2006). Since Fantazzini (2009) shows that marginal and copula misspecifications can lead to biases in skewness and volatility estimates, we estimate four copula functions under both the VECM-GARCH and the differenced VAR-GARCH. Using the T-V SJC copula, we find weak evidence that joint negative extremes dominate joint positive extremes. This finding holds across both the VECM-GARCH and the differenced VAR-GARCH specifications. Using CEE and UK returns, no more than five of our ten market pairs exhibit significant increases in lower tail dependence during the Eurozone crisis period (compared to the non-crisis period). For CEE and German returns, no more than five market pairs exhibit significant increases in lower tail dependence during the Eurozone crisis period (compared to the GFC period). We also find weaker support for upper tail dependence.

Overall, our findings are inconsistent with the results of prior DCC studies. Our findings also go against the observation that stock markets tend to decline together, but do not boom together (Longin and Solnik 2001; Ang and Chen 2002). Given the slow speed of adjustment to steady-state equilibrium conditions under our VECM-GARCH, we suggest that this feature may explain the weak result regarding tail dependence. The slow speed of adjustment to steady-state equilibrium in the VECM-GARCH may also explain the inability of the VECM-GARCH to outperform the differenced VAR-GARCH in tests of tail dependency. The T-V SJC outperforms the T-V Student $t$ copula and all other copulas. The T-V Gaussian and the T-V Student $t$ copula provide poor fit to the data because they lack the ability to capture tail dependence in heavy-tailed distributions. While long-run equilibrium conditions ensure that the variables do not move too far apart, this feature does not improve the performance of the VECM-GARCH over the VAR-GARCH for our copula estimates. ${ }^{8}$

There is an extant body of empirical work on stock market contagion (e.g. Kenourgios et al. 2011; Mollah et al. 2016; Horváth et al. 2018). These studies report that contagion effects are more pronounced during crisis periods. A common estimation approach is the DCC approach of Engle (2002), assuming one or more country sources for contagion effects. ${ }^{9}$ A new body of work demonstrates that we should not be over-reliant on DCC estimates to determine the dependence structure of returns. Several econometric issues, including asymptotic properties and regularity conditions, are unresolved in the DCC setting, thereby making certain econometric inferences unreliable (Caporin and McAleer 2013; Fermanian and Malongo 2018). This means that we should not treat the DCC approach as an ultimate indicator of contagion effects. As indicated in Embrechts et al. (2002), copula dependence does not suffer from shortcomings associated with correlation coefficients. We contribute to the literature by using properly specified VARs to extract the conditional variances for the copula estimates, in the context of economies that are

\footnotetext{
8 There are critical econometric issues associated with the use of the differenced (stationary) VAR for DCC estimation when long-run conditions apply. The stationary properties of DCCs and the finiteness of their moments also create important econometric problems. These specific issues are unresolved in the literature (see Caporin and McAleer 2013; Fermanian and Malongo 2018). Caporin and McAleer (2013, p. 116), for example, state: "most published papers dealing with dynamic correlations simply do not discuss stationary of the model, the regularity conditions, or the asymptotic properties of the estimators." Our concern is at a simpler and more practical level and relates to the problems associated with model misspecification when they affect estimation consistency.

9 Mollah et al. (2016), for example, use the US as the source of contagion for CEE stock markets even though the economic and trade links of CEE countries with the US are minimal.
} 
supposed to have reached some level of economic convergence. We find little support for market dependence, contrary to prior work. Contagion effects are of interest to investors seeking to exploit diversification opportunities (Boyer et al. 1999; Durante and Jaworski 2010) and policymakers, who implement macroeconomic policies to avert financial crises. An important economic implication of our results is that EU financial markets have not achieved the level of integration anticipated under the Financial Services Action Plan of 1999. A practical implication of our results is that investors can still exploit portfolio diversification opportunities in CEE markets. However, CEE capital markets will experience higher cost of capital compared to developed markets. We find that the legal environment has a decreasing effect on financial development, perhaps causing CEE and the EU stock markets to be segmented. Our results are robust against the diagonal BEKK model.

The rest of the paper is organized as follows. Section 2 reviews prior work. Section 3 describes the research methodology and the data set. We present our empirical results in Sects. 4, 5 and 6. The paper concludes in Sect. 7.

\section{Related prior work}

Guidi and Ugur (2014) test for cointegration using five South-Eastern European (SEE) stock markets in terms of German, UK and US returns over the 2000-2013 period. They find support for cointegration between SEE and German stock markets, and SEE and UK stock markets, but not between SEE and US stock markets. They provide DCC estimates for their sample period, but they do not estimate VECMs nor copula functions. Using the Johansen (1988) technique, Gilmore and McManus (2002) find no support for pair-wise cointegration between three CEE (Czech Republic, Hungary and Poland) stock markets and the US market, during the 1995-2001 period. Lucey and Voronkova (2008) find no support for cointegration using four CEE stock markets (Russia, Hungary, Czech Republic, Poland) and developed markets, over the 1995-2004.

Syllignakis and Kouretas (2011) find evidence for shifts in the DCC estimates of CEE and US stocks and CEE and German stocks, during the GFC period. Their results suggest that CEE markets are exposed to external shocks that alter their joint conditional correlations. Voronkova (2004) finds cointegration between three CEE stock markets (Czech Republic, Hungary, and Poland) and developed stock markets (UK, French, German and US) as well as evidence for long-run equilibrium relations, using error-correction models (ECMs).

Using the US as the source of contagion, Mollah et al. (2016) find support for contagion effects based on fifty-five equity markets, including six of the CEE stock markets used in our sample. Their DCC estimates suggest that the GFC spread from the US to other markets, in line with previous results. Pragidis et al. (2015) propose a correction to the DCC to allow for structural breaks in the correlation dynamics. Using this test, they find no support for contagion using the 10-year Greek government bond yield. Jawadi et al. (2015) use smooth transition autoregressive and threshold autoregressive models which capture more dynamics in the data compared to Pragidis et al.'s (2015) approach. Jawadi et al. (2015) find that while the US equity market leads the UK, French and German stock markets during overlapping trading hours, regional contagion is more pronounced during non-overlapping trading hours. Furthermore, they show that jump contagion exhibits asymmetry and nonlinearities, and varies according to regimes. Anastasopoulos (2018) finds evidence for contagion in relation to the Greek debt crisis and the devaluation of the Chinese yuan 
of 2015. The yuan devaluation gave rise to more persistence in contagion effects than the Greek debt crisis. Baharumshah and Wooi (2007) provide evidence to support foreign currency volatility and asymmetric effects for South Korea and ASEAN-5 currencies during the Asian Financial Crisis. Using the VECM-GARCH, Syriopoulos and Roumpis (2009) find evidence for long-run equilibrium conditions using German and US market returns, each paired with Romanian, Bulgarian, Croatian, Turkish, Cypriot and Greek market returns. Their approach is closely related to ours but they do not estimate copula functions.

Given the limitations of the DCC model (Caporin and McAleer 2013; Fermanian and Malongo 2018), it is better to test the dependence structure of returns using both the marginal and copula part of the distribution. Brechmann et al. (2013) derived Archimedeantype vine copulas to tests for contagion during the GFC period. They report that bank failure constitutes a larger component of systemic risk compared to the failure of insurance firms. Mensah and Premaratne (2017) find support for asymmetric dependence among Asian banking sector stocks, using copula functions. Poshakwale and Mandal (2017) use a copula approach to show that Indian stock returns and developed market returns are more responsive to economic downturns than to economic upturns. Ait-Sahalia et al. (2015) propose an excitation model where jumps in one region increase the intensity of jumps in that region as well as other regions of the world. They claim that the US market has more influence on the jump intensity of other world markets. Su (2017) examines jumps in the context of tail dependence. Chollete et al. (2009) find support for asymmetric dependence in G5 and Latin American stock returns. Cubillos-Rocha et al. (2019) find support for asymmetric dependence but mostly during periods of currency appreciations. Kenourgios et al. (2011) use both the regime-switching Gaussian copula and asymmetric DCCs to test for dependence between Brazilian, Russian, Indian and Chinese (BRIC) stock markets each paired with the UK and US markets. They find support for contagion. Their use of the Gaussian copula function is unlikely to provide the best fit to data, due to the imposition of symmetry on the joint distribution. Our study extends this work in the context of CEE markets. We estimate both the bivariate VECM-GARCH and differenced VAR-GARCH as there may be model misspecification issues in terms of the VAR specification. Furthermore, we estimate four T-V copulas including the commonly used Student $t$ and Gaussian copulas, but in $\mathrm{T}-\mathrm{V}$ form.

\section{Methodology and data set}

\subsection{Methodology}

Our first methodological application is the Johansen cointegration technique. This technique enables us to test whether each pair of developed and CEE stock markets is cointegrated over each sub-period. Theory suggests that a pragmatic approach to generate an error correction model (ECM) is to use a priori information from a static model or autoregressive distributed lag (ADL). As such, we estimate the Engle-Granger cointegrating regression using OLS, equation by equation and incorporate each time series of the residuals in a differenced VAR to generate the VECM. This approach is in line with Engle and Granger (1987) but also recognizes that in the context of developed and developing stock markets, the rate of adjustment to long-run equilibrium would not be similar for each equation in the bivariate VECM. As such, we argue against using the same error-correction term based on Johansen for each VAR, as it may not fully capture variation in the long-run 
adjustment process for each equation. Indeed, Banerjee et al. (1998) and de Boef and Granato (1999) show that the $t$-ratio in the ECM has good power against alternative tests for cointegration. Furthermore, Banerjee et al. (1998, p. 279) argue that the ECM is a special case of the Johansen cointegration where "... the cointegrating vectors appear only in the equation of interest." We also estimate a differenced VAR as this specification is commonly used in contagion and DCC studies. Both the VECM and the differenced VAR are estimated using GARCH which we refer to as VECM-GARCH and differenced VARGARCH, respectively.

Denote $R_{1 t}$ and $R_{2 t}$ as the natural logarithms of the stock market indices (in levels) of each CEE market and a developed stock market, respectively. $R_{1 t}$ and $R_{2 t}$ are both nonstationary. The Engle and Granger (1987) cointegrating regressions are

$$
\begin{aligned}
& R_{1 t}=c_{1}+\vartheta_{2} R_{2 t}+\varepsilon_{1 t} \\
& R_{2 t}=c_{2}+\vartheta_{1} R_{1 t}+\varepsilon_{2 t} .
\end{aligned}
$$

In Eqs. (1a) and (1b), $c_{1}$ and $c_{2}$ are constants and $\varepsilon_{1 t}$ and $\varepsilon_{2 t}$ as the respective residuals. Following Engle and Granger (1987), we use $\varepsilon_{1 t}$ and $\varepsilon_{2 t}$ as the error-correction term. ${ }^{10}$ Thus $E C T_{1 t}=\varepsilon_{1 t}$ and $E C T_{2 t}=\varepsilon_{2 t}$. Denote $r_{1 t}$ and $r_{2 t}$ as the log returns associated with $R_{1 t}$ and $R_{2 t}$, respectively. Thus, the pair of mean equations for the bivariate VECM-GARCH, with $(p, q)$ lags is,

$$
\begin{aligned}
& r_{1 t}=a_{1}+\sum_{i=1}^{p} b_{1 i p} r_{1 t-p}+\sum_{i=1}^{q} c_{1 i q} r_{2 t-q}+\gamma_{1} E C T_{1 t-1}+\mu_{1 t} \\
& r_{2 t}=a_{2}+\sum_{i=1}^{p} b_{2 i p} r_{2 t-p}+\sum_{i=1}^{q} c_{2 i q} r_{1 t-q}+\gamma_{2} E C T_{2 t-1}+\mu_{2 t}
\end{aligned}
$$

where $\mu_{1 t}$ and $\mu_{2 t}$ are the conditional errors based on the past information sets, $\Omega_{1 t-1}$ and $\Omega_{2 t-1}$ in Eqs. (2a) and (2b), respectively, for country $i$. A lag is imposed on each errorcorrection term as it is customary. We assume the Student $t$-distribution for the conditional errors since it accommodates heavy-tailed marginals better than normal margins and improves the quality of the joint distribution, even if the chosen copula is sub-optimal (Junker and May 2005). $\gamma_{1}$ and $\gamma_{2}$ are predicted to be negative and significant if long-run equilibrium conditions exist. Since the returns in Eqs. (2a) and (2b) are I(0), the inclusion of $E C T_{1 t-1}$ and $E C T_{2 t-1}$ in the respective equations should increase estimation consistency. Furthermore, it is always better to include an error-correction term in a differenced (stationary) VAR as opposed to excluding it, since in theory, its inclusion causes no harm in the differenced VAR (Banerjee et al. 1993).

The variance equations of the $\operatorname{GARCH}(p, q)$ process corresponding to Eqs. (2a) and (2b) are respectively,

\footnotetext{
10 The literature adopts different approaches in order to generate the error-correction term. We use the residuals of the cointegrating regression as suggested by Engle and Granger (1987). Syriopoulos and Roumpis (2009) appear to generate their error-correction term from the Johansen technique.
} 


$$
\begin{aligned}
& h_{1 t}^{2}=\omega_{1}+\sum_{i=1}^{p} \alpha_{1 i} \mu_{1 t-p}^{2}+\sum_{i=1}^{q} \beta_{1 i} h_{1 t-q}^{1} \\
& h_{2 t}^{2}=\omega_{2}+\sum_{i=1}^{p} \alpha_{2 i} \mu_{2 t-p}^{2} \sum_{i=1}^{q} \beta_{2 j} h_{2 t-q}^{2} .
\end{aligned}
$$

Here, $h_{1 t}^{2}$ and $h_{2 t}^{2}$ are the conditional variances of $\mu_{1 t}$ and $\mu_{2 t}$, respectively. $\omega_{1}$ and $\omega_{2}$ capture the long-term (average) conditional variances. Also, $\alpha_{1}$ and $\alpha_{2}$ capture past news (ARCH), whereas $\beta_{1}$ and $\beta_{2}$ capture past volatility $(\mathrm{GARCH})$. Certain inequality constraints must be satisfied for the $\operatorname{GARCH}(p, q)$ to be valid (Bollerslev 1986). Thus, in Eq. (3a): (i) $\omega_{1} \geq 0$; (ii) $\alpha_{1} \geq 0$; (iii) $\beta_{1} \geq 0$; and, (iv) $\alpha_{1}+\beta_{1}<1$. Similar inequality constraints apply to Eq. (3b).

\subsection{Copula estimates for bivariate distributions}

The copula approach provides separate estimates of the marginal and dependence structures of multivariate probability distributions. Using Sklar's (1959) theorem, there is only one expression for an $n$-dimensional $C$ copula with a continuous $\left(X_{1}, \ldots X_{n}\right)$ random vector. Thus,

$$
F\left(x_{1}, \ldots x_{n}\right)=C\left(F_{1}\left(x_{1}\right), \ldots, F_{N}\left(x_{n}\right)\right) .
$$

In Eq. (4), $F_{1}(*), \ldots, F_{N}(*)$ and $F(*, \ldots, *)$ represent the marginal and joint distribution functions respectively of $x_{1}, x_{2}, \ldots, x_{n}$ random variables.

It is well-known that financial asset returns are time-varying, with fat-tails, long memory and heteroscedasticity. Poon et al. (2004) show that heteroscedasticity is an important contributing factor to extreme price movement. ARMA-ARCH/GARCH processes are able to capture these stylized features reasonably well (Bollerslev 1986). GARCH-type processes normally assume that the conditional multivariate distribution follows a Gaussian or Student $t$-distribution. Copula-GARCH models avoid this distributional constraint (Jondeau and Rockinger 2006; Patton 2006). They allow the combination of different marginal distributions in the dependence structure (Dias and Embrechts 2010) and facilitate estimation of T-V higher moments. The copula approach also allows some control over fattailedness and asymmetry. Thus, our copulas are of the GARCH-type, and we use different copula functions.

Starting with Engle's (2002) DCC approach, the correlation $R_{t}$ evolves over-time such that the $\mathrm{DCC}(1,1)$ is denoted by,

$$
Q_{t}=(1-\alpha-\beta) \bar{Q}+\alpha \epsilon_{t-1} \hat{\epsilon}_{t-1}+\beta Q_{t-1} .
$$

$R_{t}=\tilde{Q}_{t}^{-1} Q_{t} \tilde{Q}_{t}^{-1}$, where $\bar{Q}$ is the sample covariance of $\epsilon_{t}, \tilde{Q}_{t}$ is a square $p \times q$ matrix containing zeros as off-diagonal elements and with diagonal elements of the square root of $Q_{t}$. The DCC parameter constraints are the same as those of the univariate $\operatorname{GARCH}(1,1)$. We specify four copula functions below.

\subsubsection{Student $t$ copula}

The log likelihood of the Student $t$ copula (see Vogiatzoglou 2016) is written as, 


$$
\begin{aligned}
\mathcal{L}_{S t}\left(R, d, u_{t}\right)=-T \log \frac{\Gamma\left(\frac{d+p}{2}\right)}{\Gamma\left(\frac{d}{2}\right)}-p T & \log \frac{\Gamma\left(\frac{d+1}{2}\right)}{\Gamma\left(\frac{d}{2}\right)}-\frac{d+p}{2} \sum_{t=1}^{T} \log \left(1+\frac{\epsilon_{t}^{\prime} R^{-1} \epsilon_{t}}{d}\right) \\
& -\sum_{t=1}^{T} \log |R|+\frac{d+1}{2} \sum_{t=1}^{T} \sum_{i=1}^{p} \log \left(1+\frac{\epsilon_{i t}^{2}}{d}\right) .
\end{aligned}
$$

$\epsilon_{t}$ is the vector of the transformed standardized residuals that depends on the copula function. $\epsilon_{t}$ is defined as $\epsilon_{t}=\left(t_{d}^{-1} u_{1, t}, \ldots, t_{d}^{-1}\left(u_{p, t}\right)\right) \cdot t_{d}^{-1}$ denotes the inverse Student $t$-distribution using $d$ degrees of freedom and $R$ correlation matrix of $\epsilon_{t}$.

\subsubsection{Gaussian copula}

The Gaussian copula is a dependence function associate with bivariate normality (Patton 2006) and is defined by,

$$
\begin{aligned}
C(u, v \mid \rho)= & \int_{-\infty}^{\Phi^{-1}(u) \Phi^{-1}(v)} \int_{-\infty} \frac{1}{2 \pi \sqrt{\left(1-\rho^{2}\right)}} \exp \left\{\frac{-\left(r^{2}-2 \rho r s+s^{2}\right.}{2\left(1-p^{2}\right)}\right\} d r d s \\
& -1<\rho<1
\end{aligned}
$$

where $\Phi^{-1}$ denotes the inverse of the standard normal cumulative density function. We follow Patton's (2006) proposed evolution of $\rho_{t}$ such that,

$$
\rho_{t}=\tilde{\Delta}\left(\omega_{\rho}+\beta_{\rho} \rho_{t-1}+\alpha \frac{1}{10} \sum_{j=1}^{10} \Phi^{-1}\left(u_{t-j}\right) \Phi^{-1}\left(v_{t-j}\right)\right)
$$

where $\tilde{\Delta} \equiv\left(1-e^{-x}\right)\left(1+e^{-x}\right)^{-1}=\operatorname{tahn}(x / 2)$ is a modified logistic transformation to keep $\rho_{t}$, the correlation parameter in the density Gaussian, within $(-1,1)$ at all times. This copula has $\tau^{U}=\tau^{L}=0$ for correlations less than one (Embrechts et al. 2002), where $\tau^{U}$ and $\tau^{L}$ denote upper and lower tail dependence, respectively. $\rho_{t-1}$ captures persistence in the dependence parameter, while the mean of the product of the last ten observations of the transformed variables, $\Phi^{-1}\left(u_{t-j}\right)$ and $\Phi^{-1}\left(v_{t-j}\right)$ captures variation in dependence.

\subsubsection{Clayton copula}

The log likelihood of the Clayton copula (Vogiatzoglou 2016) is given by,

$$
\mathcal{L}_{\text {Clayton }}\left(d, u_{t}\right)=\sum_{t=1}^{T} \log \left((1+d)\left(u_{1 t} u_{2 t}\right)^{-1-d}\left(u_{1 t}^{-d}+u_{2 t}^{-d}-1\right)^{-2-\frac{1}{d}}\right) .
$$

This copula function has more left tail than right tail dependence. The evolution of the Clayton copula takes the form,

$$
\tau_{t}=\Lambda\left(\omega+\beta \tau_{t-1}+\alpha\left|u_{t-j}-u_{2 t-j}\right|\right) .
$$




\subsubsection{Symmetrized Joe-Clayton (SJC) copula}

A particular Laplace transformation of the basic Joe-Clayton copula is given by,

$$
\left.C_{J C}\left(u, v \mid \tau^{U}, \tau^{L}\right)=1-\left(1-\left\{\left[1-(1-u)^{k}\right]^{-\gamma}+\left[1-(1-v)^{k}\right]^{-\gamma}\right)-1\right\}^{-1 / \gamma}\right)^{1 / k} .
$$

In Eq. (9a), $k=1 / \log _{2}\left(2-\tau^{U}\right) ; \gamma=-1 / \log _{2}\left(\tau^{L}\right) ; \tau^{U} \in(0,1) ; \tau^{L} \in(0,1)$. The two parameters of the Joe-Clayton are $\tau^{U}$ and $\tau^{L}$ capture upper and lower tail dependence, respectively. The basic Joe-Clayton copula imposes a degree of asymmetry even when dependence is similar in both tails. On the other hand, the SJC copula allows both upper and lower tail dependence to range freely from zero to one, such that the extreme tails of the joint distribution are independent (Patton 2006). Under the SJC copula, tail dependence determines the presence or absence of dependence and nests the symmetry case when $\tau^{U}=\tau^{L}$ (Patton 2006). Thus, the SJC copula is written as,

$$
C_{S J C}\left(u, v \mid \tau^{U}, \tau^{L}\right)=0.5\left[C_{J C}\left(u, v \mid \tau^{U}, \tau^{L}\right)+C_{J C}\left(1-u, 1-v \mid \tau^{L}, \tau^{U}\right)+u+v-1\right] .
$$

Patton (2006) proposes an evolution for the SJC copula using,

$$
\begin{aligned}
& \tau_{t}^{U}=\Lambda\left(\omega_{U}+\beta_{U} \tau_{t-1}^{U}+\alpha_{U} \frac{1}{10} \sum_{j=1}^{10}\left|u_{t-j}-v_{t-j}\right|\right) \\
& \tau_{t}^{L}=\Lambda\left(\omega_{L}+\beta_{L} \tau_{t-1}^{L}+\alpha_{L} \frac{1}{10} \sum_{j=1}^{10}\left|u_{t-j}-v_{t-j}\right|\right) .
\end{aligned}
$$

Patton (2006) shows how upper and low tail dependence can be such that the parameter $\Lambda(x) \equiv\left(1+e^{-x}\right)^{-1}$ is a logistic regression that keeps $\tau^{U}=\tau^{L}$ within $(0,1)$ at all times. The SJC copula does not impose symmetry, as is done in the Gaussian copula. The evolution of tail dependence [Eqs. (9c) and (9d)] contains the autoregressive terms $\beta_{U} \tau_{t-1}^{U}$ and $\beta_{L} \tau_{t-1}^{L}$ and a forcing variable for the absolute mean difference between $u_{t-j}-v_{t-j}$ over the past 10 observations. In effect, the past 10 observations capture the dynamics of upper and lower tail dependence, in something akin to a restricted ARMA $(1,10)$.

\subsection{Data set}

To conduct the analysis, we use daily closing MSCI stock market indices from DataStream. The full sample spans the period July 1, 2003 to August 17, 2018. We use nine CEE (developing) and two developed stock markets (Germany and the UK). These stock markets are identified in Table 1. Our choice of CEE stock market indices reflects the availability of data and the fact that some of the stock markets operate in countries that joined the EU during the sample period. We include the Russian and Ukrainian stock markets in the sample, even if they operate in non-EU countries. The non-crisis period spans July 1 , 2003 to August 8, 2007. The GFC period spans the period August 9, 2007 to December 31, 2009. We use August 9, 2007, as the start of the GFC since BNP Paribas ceased trading on that date (see Ahmed et al. 2012). Our Eurozone crisis period begins May 2, 2010 as this is the date of the first Greek bailout by the European Central Bank and the IMF. European 


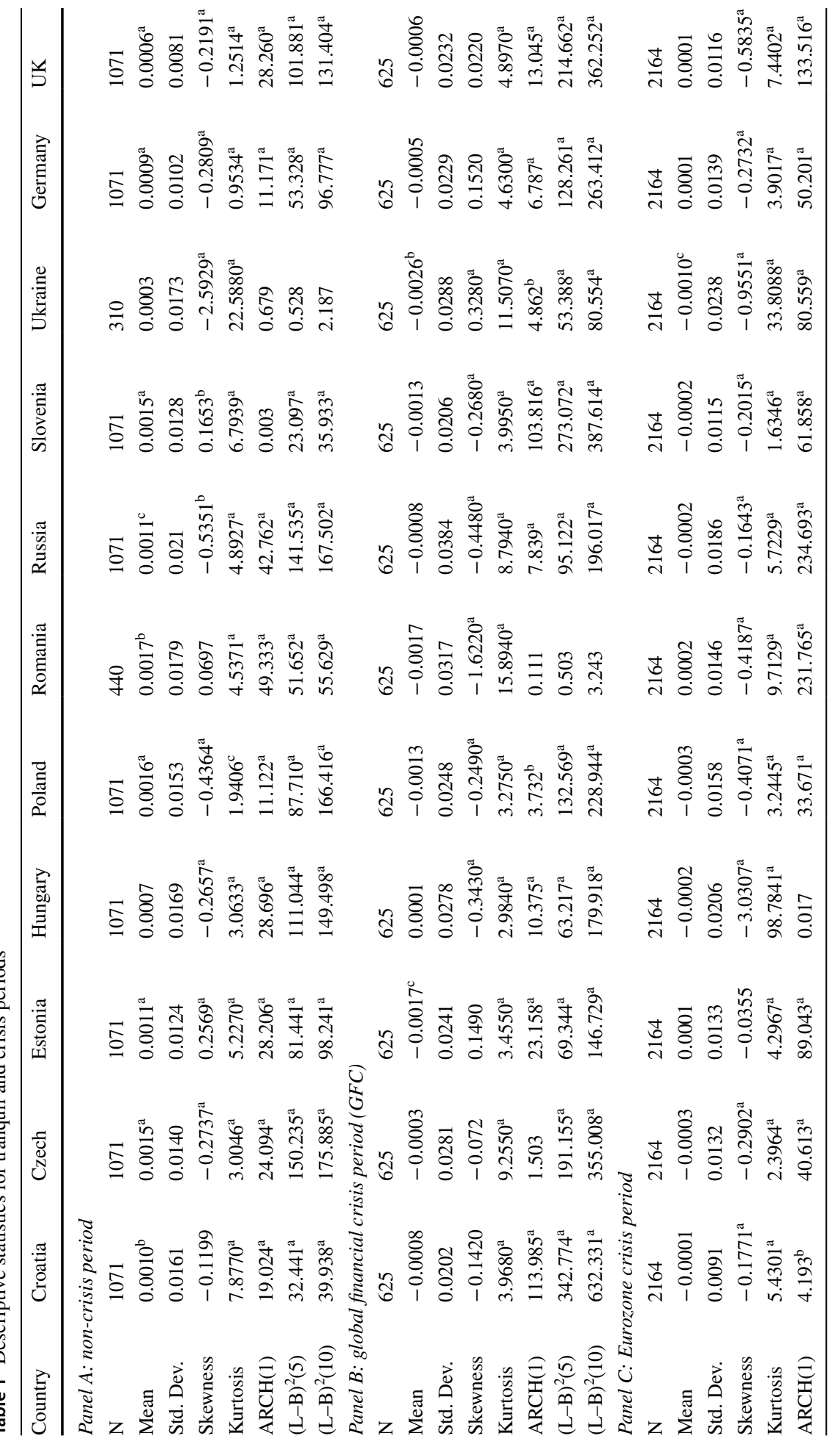




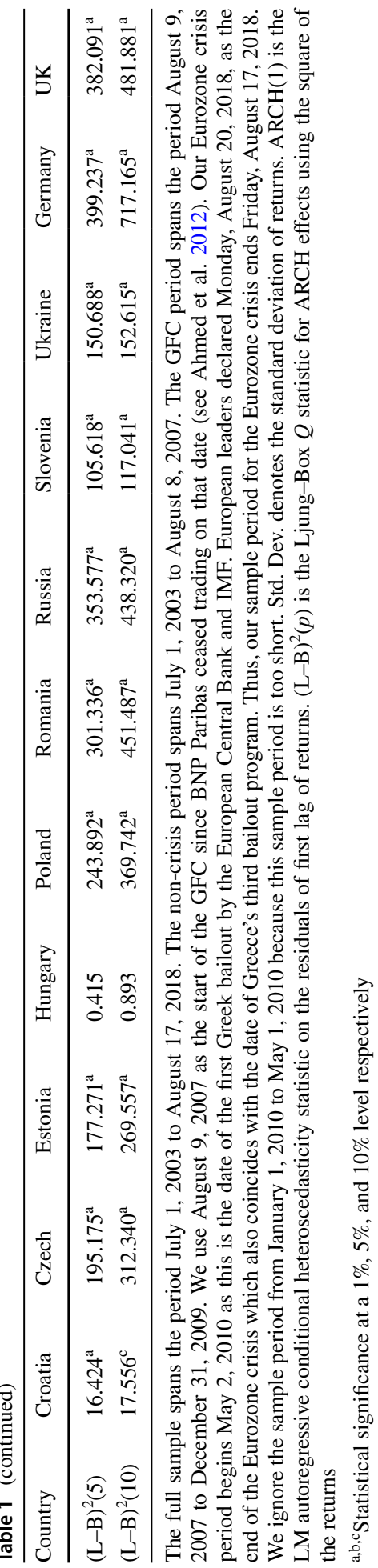


leaders declared Monday, August 20, 2018, the end of the Eurozone crisis, which also coincides with the date of the third bailout program for Greece. ${ }^{11}$ As such, we use Friday, August 17, 2018 as the end of the Eurozone crisis. We ignore the sample period January 1, 2010 to May 1, 2010 because it is too short for statistical analysis.

\section{Empirical results}

\subsection{Descriptive statistics and unit root tests}

Table 1 shows the descriptive statistics for the market index returns across all three regimes. The mean log returns are positive during the non-crisis period and are often significantly different from zero $(p$ value $\leq 0.10$ ). The mean log returns are mostly negative and insignificant for both crisis periods. The exceptions are Estonia and Ukraine for the GFC periods, and Ukraine for the Eurozone crisis period. For these stock markets, the mean $\log$ returns are negative and significant ( $p$ value $\geq 0.10$ ). Skewness is mostly negative and significant for the non-crisis period. Only Estonia and Slovenia have positive and significant skewness for the non-crisis period ( $p$ value $\leq 0.05$ ). Skewness is negative for the GFC when significant, except for Ukraine where it is positive ( $p$ value $\leq 0.10)$. Skewness is negative and significant for the Eurozone crisis period ( $p$ value $\leq 0.10)$, except for Estonia, where it is insignificant.

Table 1 also shows strong variation in the level of kurtosis across the sub-periods and across markets. Excess kurtosis is significant $(p$ value $\leq 0.10)$ for all markets. Romanian stock returns have more kurtosis during the GFC period than at any other period. Hungarian returns have the most kurtosis during the Eurozone crisis period whereas, Ukrainian returns have the most kurtosis during the non-crisis period. In general, the presence of kurtosis provides evidence for volatility clustering and fat-tailedness, making GARCH-type estimation more appropriate compared to OLS estimation.

As an initial test for volatility clustering (ARCH effects), we estimate the Ljung-Box (L-Q) statistic using the square of the log returns for up to ten lags. The $(\mathrm{L}-\mathrm{B})^{2}$ statistic is significant ( $p$ value $\leq 0.10$ ), except for Ukraine (for the non-crisis period), Romania (for the GFC period) and Hungary (for the Eurozone crisis period). As a further test, we run the log returns on its first lag with a constant. Table 1 shows that $\mathrm{ARCH}(1)$ is present in the returns of almost all markets.

As a simple test of dependence, we estimate the Kendell $\tau$ correlation for the log returns. We use the $\tau$ correlation rather than the Pearson correlation because it is more robust to outliers and insensitive to nonlinearities. The $\tau$ correlation is commonly used as a benchmark against the elliptical copula family, such as the Student $t$ (Dias and Embrechts 2010). Our results indicate that the correlations are positive and highly significant for all market pairs ( $p$ value $\leq 0.01) .{ }^{12}$ They increase during the GFC period but decrease slightly during the Eurozone crisis period (compared to the GFC period). The $\tau$ correlations are consistently lowest for Ukraine and highest for Poland. To illustrate, the correlations are lowest at $\tau=0.109$ and $\tau=0.164$ for Ukrainian-German and Ukrainian-UK returns, respectively,

\footnotetext{
11 Brunsden and Khan (2018), Financial Times. https://www.ft.com/content/aeb930e0-a475-11e8-926a$7342 \mathrm{fe} 5 \mathrm{e} 173 \mathrm{f}$. Accessed 21 June 2019.

12 These and other untabulated results are available from the authors.
} 
during the non-crisis period. For this same period, the correlations are highest at $\tau=0.297$ and $\tau=0.293$ for Polish-German and Polish-UK returns. $\tau$ is higher during the GFC period but is still lowest for Ukrainian-German and Ukrainian-UK returns at $\tau=0.165$ and $\tau=0.172$, respectively. $\tau$ is still highest for Polish-German and Polish-UK returns at $\tau=0.502$ and $\tau=0.469$, respectively, for the GFC period. It is noteworthy that there are slightly lower correlations for the Eurozone crisis period (compared to the GFC period). However, the relative ranks of the correlations of Ukrainian and Polish returns remain unchanged. The patterns in the correlations are in line with prior work for crisis and tranquil periods (Boero et al. 2010). For the non-crisis period, pairs of CEE-UK returns tend to have higher correlations compared to pairs of CEE-German returns. Conversely, the pairs of CEE-German returns tend to have higher correlations than pairs of CEE-UK returns, during the crisis periods. As such, we should expect some variation in return dependence across the sub-periods.

The Augmented Dickey-Fuller (ADF) statistic cannot reject the null of a unit root in the $(\log )$ level of the univariate returns (with a drift). ${ }^{13}$ This result is untabulated. The optimal lag is determined using the Akaike Information Criteria (AIC). Performing the test on the first difference of each series does not alter the conclusion of a unit root. The unit root hypothesis also holds with both drift and trend terms included in the equations. Since we find that each level series contains a unit root, economic shocks have a permanent effect on the data generating process. The result that the first difference of each level series is $\mathrm{I}(0)$ allows us to test for cointegration (Granger 1986). We do so below, using both the Johansen technique and the $t$-ratio of the VECM-GARCH (see below).

\subsection{Cointegration results of CEE and developed markets}

Since we find that the first difference of the univariate series is stationary, we proceed to test for cointegration between each pair of CEE and developed stock markets, using the Johansen technique. ${ }^{14}$ The optimal lag structure is determined using the AIC after running an unrestricted $\operatorname{VAR}(p, q)$ in levels of up to 20 lags. Since we rely on the stationary hypothesis (with drift), we incorporate a restricted constant in the Johansen estimation but exclude a deterministic trend. The Johansen technique requires sequential identification of the number of cointegrating vectors. The Trace statistic tests the null hypothesis of at most $r$ cointegrating vectors, whereas the maximum eigenvalue ( $\lambda \max )$ statistic tests the null hypothesis of exactly $r$ cointegrating vectors against an alternative of $r+1$. The critical values are from MacKinnon et al. (1999).

The statistical results are untabulated but are summarized in Appendix I. We find weak support for cointegration. The Hungarian, Polish, and Slovenian stock markets are each cointegrated with the German stock market during the non-crisis period. Only the Hungarian and Slovenian markets are each cointegrated with the UK stock market during the non-crisis period. The Croatian stock market is cointegrated with both the German and UK

\footnotetext{
13 Since we assume specific economic regimes for each sub-period, there is no point in testing for structural breaks. The commonly used Perron (1989) test for structural breaks assumes the break point takes place at a known date with innovations in the disturbance treated as an ARA $(p, q)$. Such a test is only useful for the full sample period.

14 We also performed the Johansen tests for the full period. Evidence for cointegration is also weak. Following Lamoureux and Lastrapes (1990), such an analysis is not reliable since the data contains different regimes of volatility.
} 
stock markets during the GFC period, even if Croatia only joined the EU in 2013. No other stock market exhibits cointegration during the GFC period, except for the German-UK market pair. The Romanian, Slovenian and Ukrainian markets are each cointegrated with the German stock market during the Eurozone crisis period whereas, the Hungarian and Slovenian markets are each cointegrated with the UK market during the same period. The $\lambda \max$ statistic indicates that there is at most one cointegrating vector. A larger number of cointegrating vectors would have suggested a tighter bound between each pair of variables.

According to the Granger representation theorem, if two or more variables are integrated of order I(1), then it is possible that they are cointegrated and have an error-correction representation, if their difference in levels is $\mathrm{I}(0)$. Thus as another cointegration test, we perform the Engle-Granger cointegration test on $E C T_{1 t}=\varepsilon_{1 t}$ and $E C T_{2 t}=\varepsilon_{2 t}$, obtained from Eqs. (1a) and (1b), respectively. This is essentially a unit root test on the residuals, using the ADF statistic. ${ }^{15}$ For the CEE and German stock market pairs, for example, there are 18 univariate series per sub-period. The same applies to CEE and UK stock markets. Using the Engle-Granger test, four (three) of the univariate series confirm cointegration for CEEGerman (CEE-UK) stock markets, during the non-crisis period. The Engle-Granger test provides stronger support for cointegration during the GFC period. Finally, four (eleven) univariate series exhibit cointegration for CEE-German (CEE-UK) pairs, during the Eurozone crisis period. This evidence indicates that the markets have become more integrated during the crisis periods, in line with prediction. We proceed to test for long-run relations using the $t$-ratios of error-correction terms in each VECM-GARCH.

\subsection{VECM-GARCH of CEE and developed markets}

Using the AIC, the optimal lag structure for each pair of CEE and developed market returns is based on the differenced VAR. Since the error-correction term is imposed in the differenced VAR, the VECM-GARCH and differenced VAR-GARCH have the same lag structure. Between one and four lags apply. However, for some VAR specifications, the optimal lag is increased or decreased to achieve computation convergence. ${ }^{16}$ Only the estimates for the VECM-GARCH are tabulated since the differenced VAR-GARCH only omits the error-correction term.

We summarize the VECM-GARCH results in Appendix I. The VECM-GARCH provides much stronger support for long-run equilibrium conditions than the Johansen technique. Using the VECM-GARCH, fewer market pairs exhibit long-run relations during the non-crisis period compared to the crisis periods. Up to nine market pairs have long-run equilibrium conditions for CEE-UK returns during the Eurozone crisis period. While this is our strongest result, there is a stronger tendency for error-correction conditions to prevail when we regress the returns of developed markets on CEE market returns. This evidence provides further justification for using equation by equation error-correction terms. The $t$-ratio of the error-correction term therefore provides stronger support for long-run equilibrium conditions than both the Johansen technique and the Engle-Granger cointegrating regression. This is in line with previous work (see Banerjee et al. 1998; de Boef and

\footnotetext{
15 These results are untabulated. Banerjee et al. (1998) show that both the Engle-Granger cointegration and the Cochrane-Orcutt cointegration tests suffer in finite samples. Banerjee et al. (1998) and de Boef and Granato (1999) show that the $t$-ratio of the ECM has more power.

${ }^{16}$ It must be emphasized that the differences in the values of the AIC for sequential lags are very small. As such, altering the suggested optimal lag by one or two lags does not affect the results.
} 


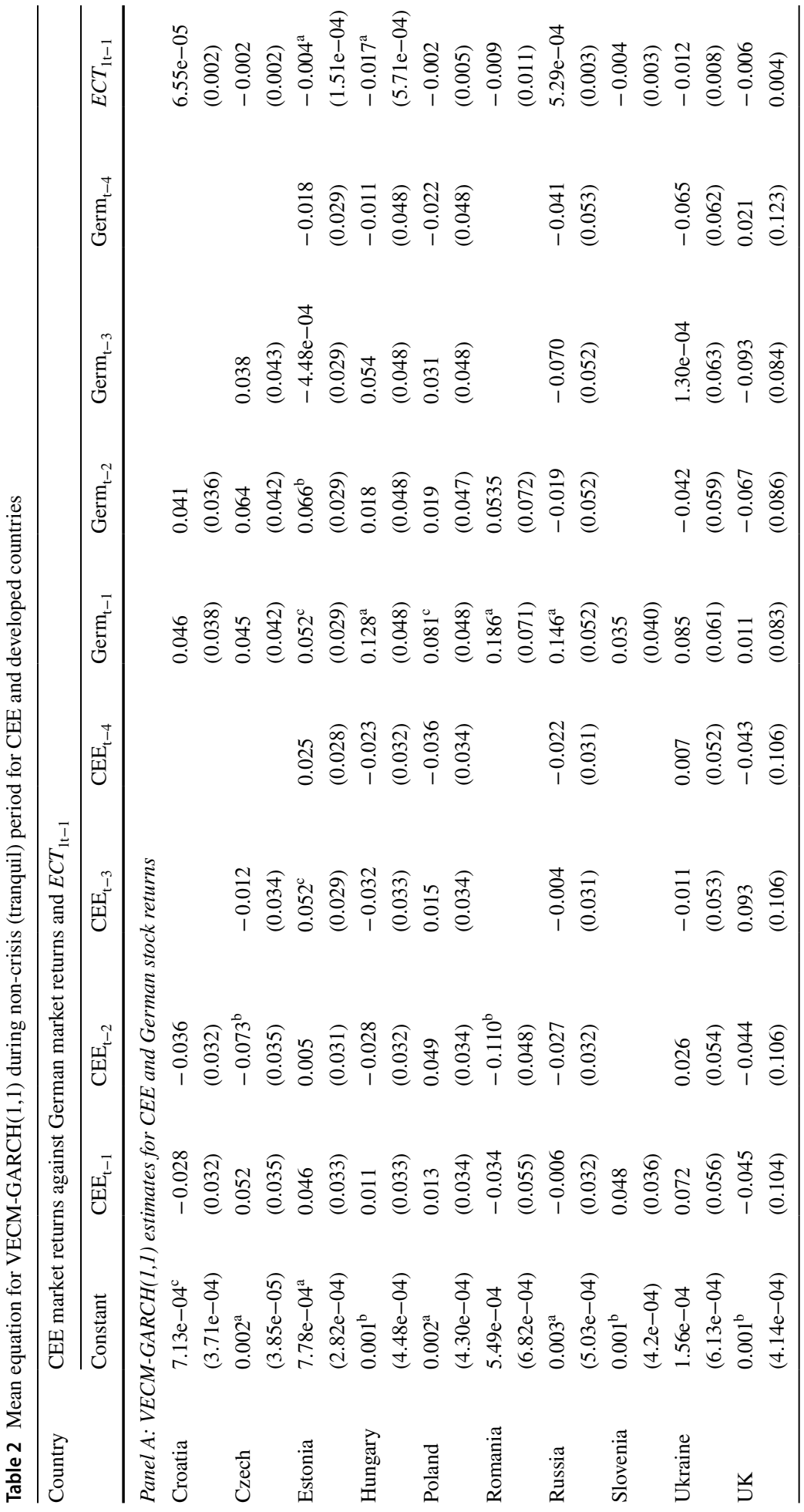




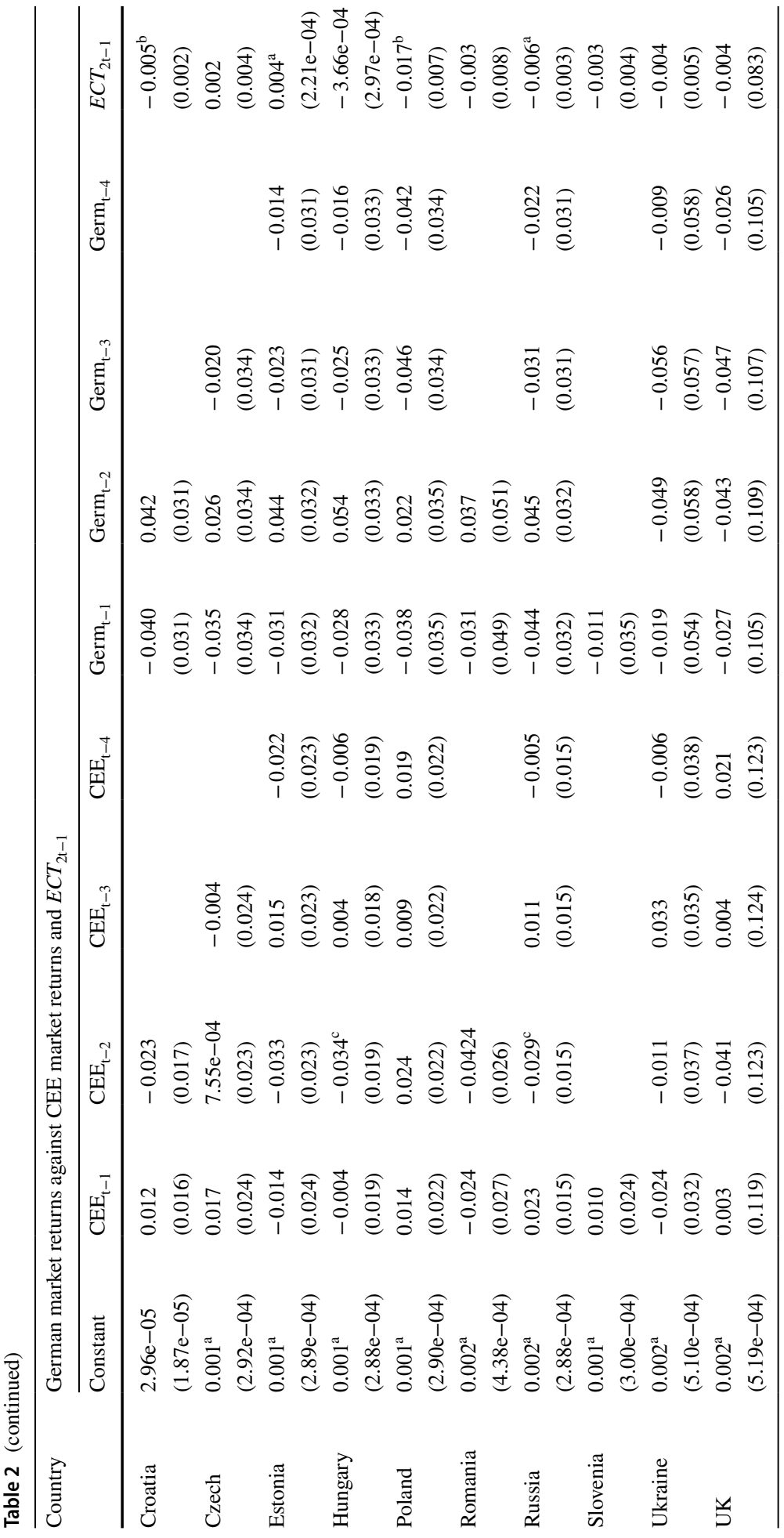




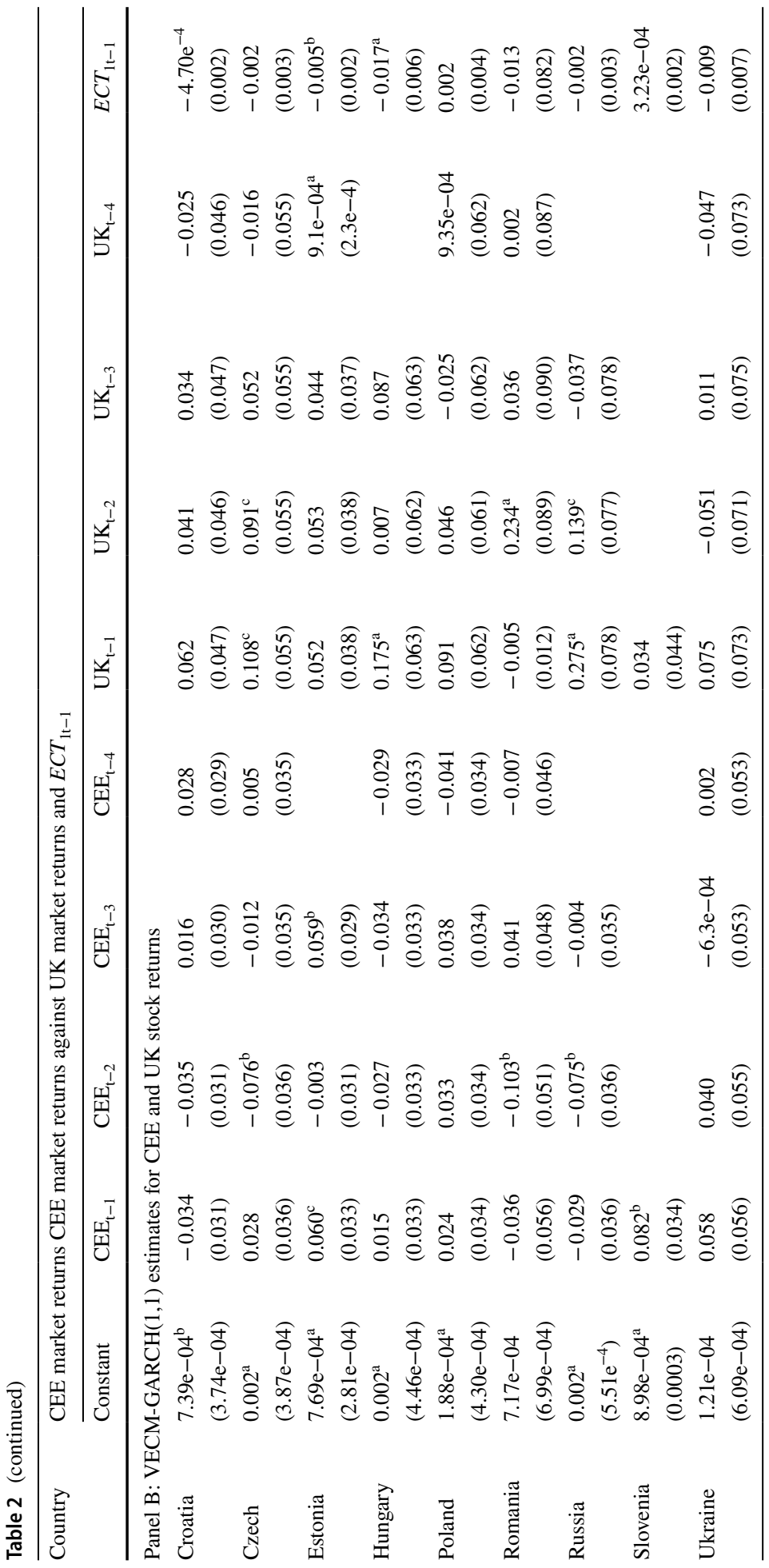




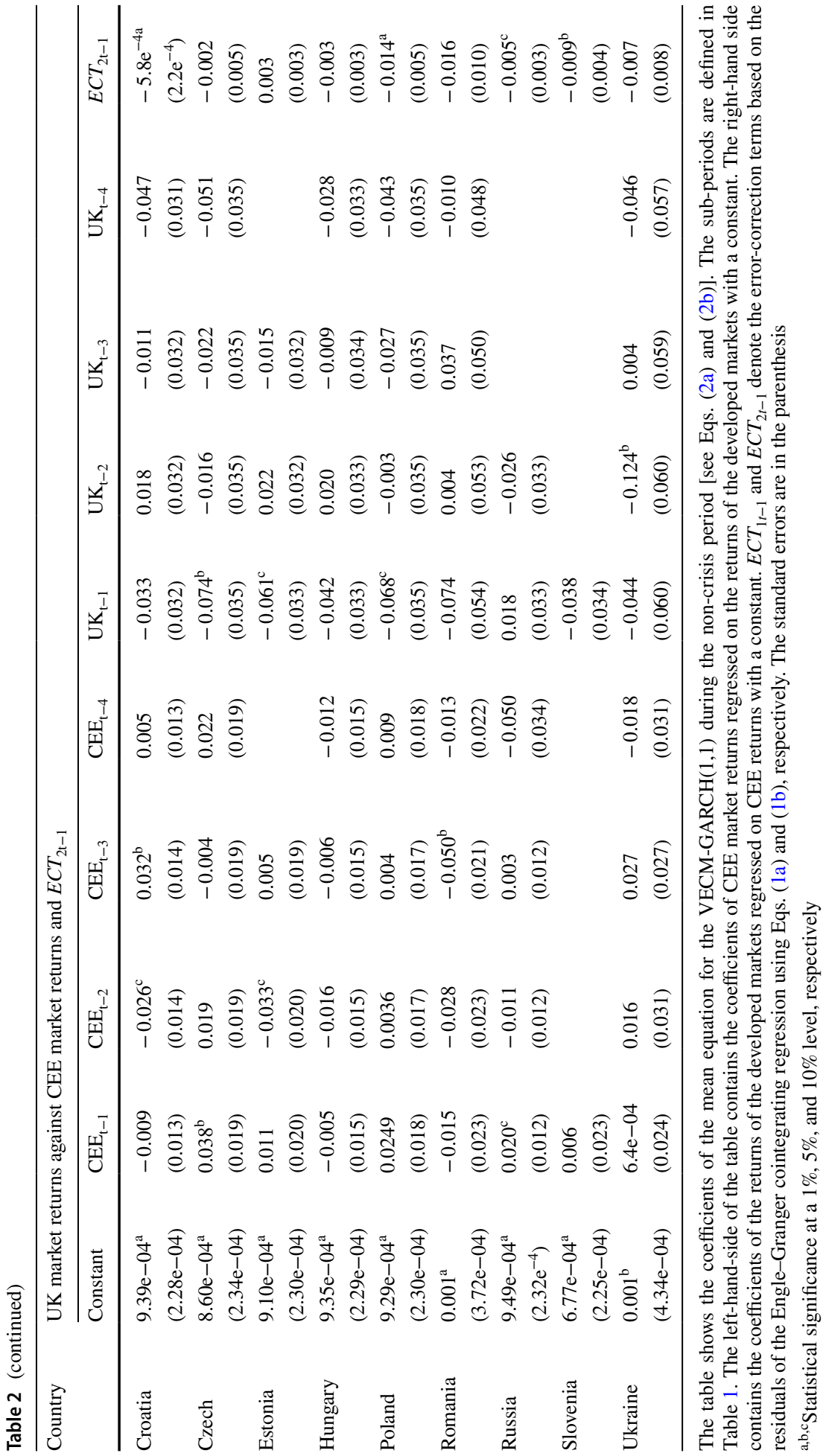




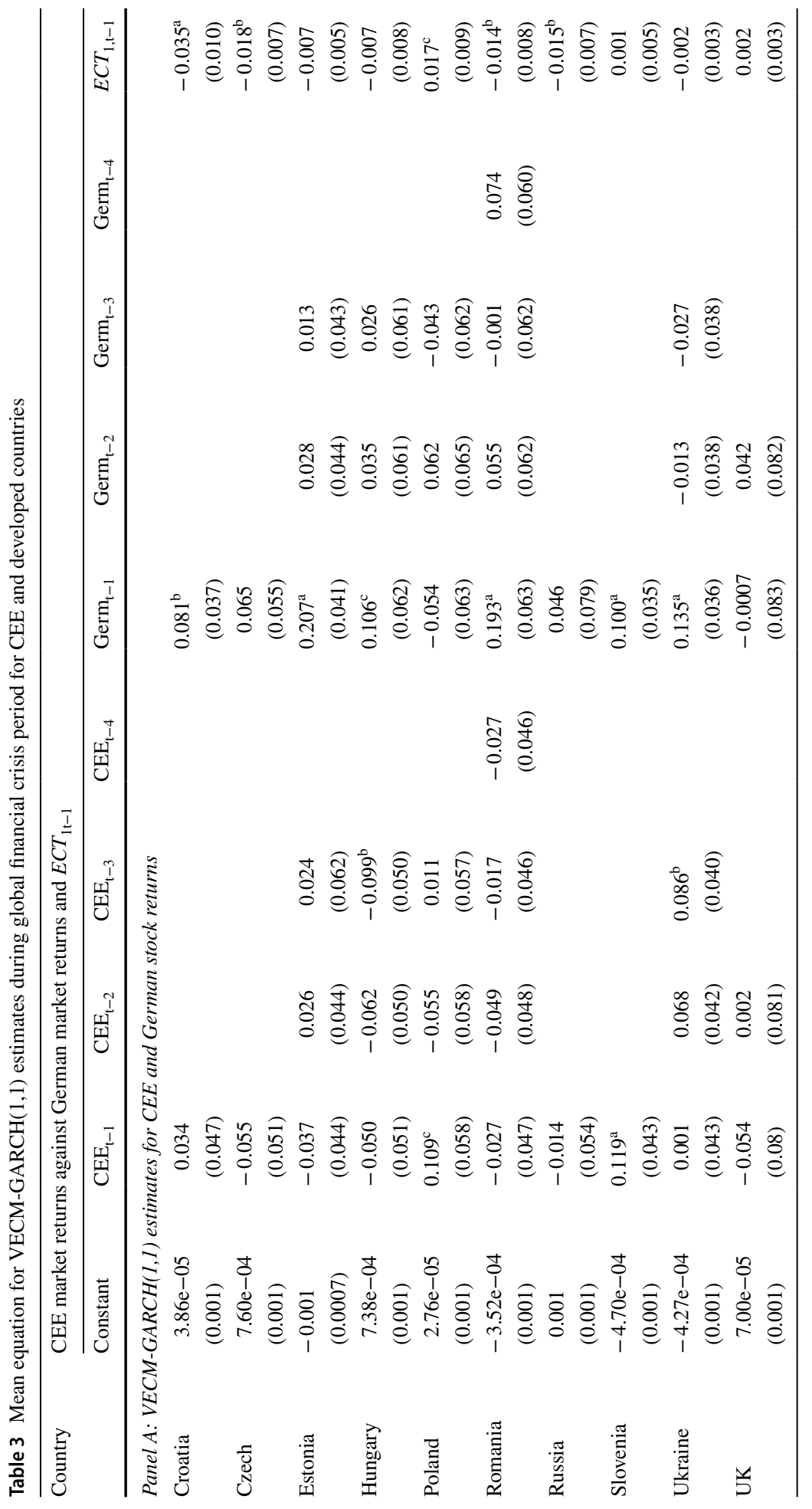




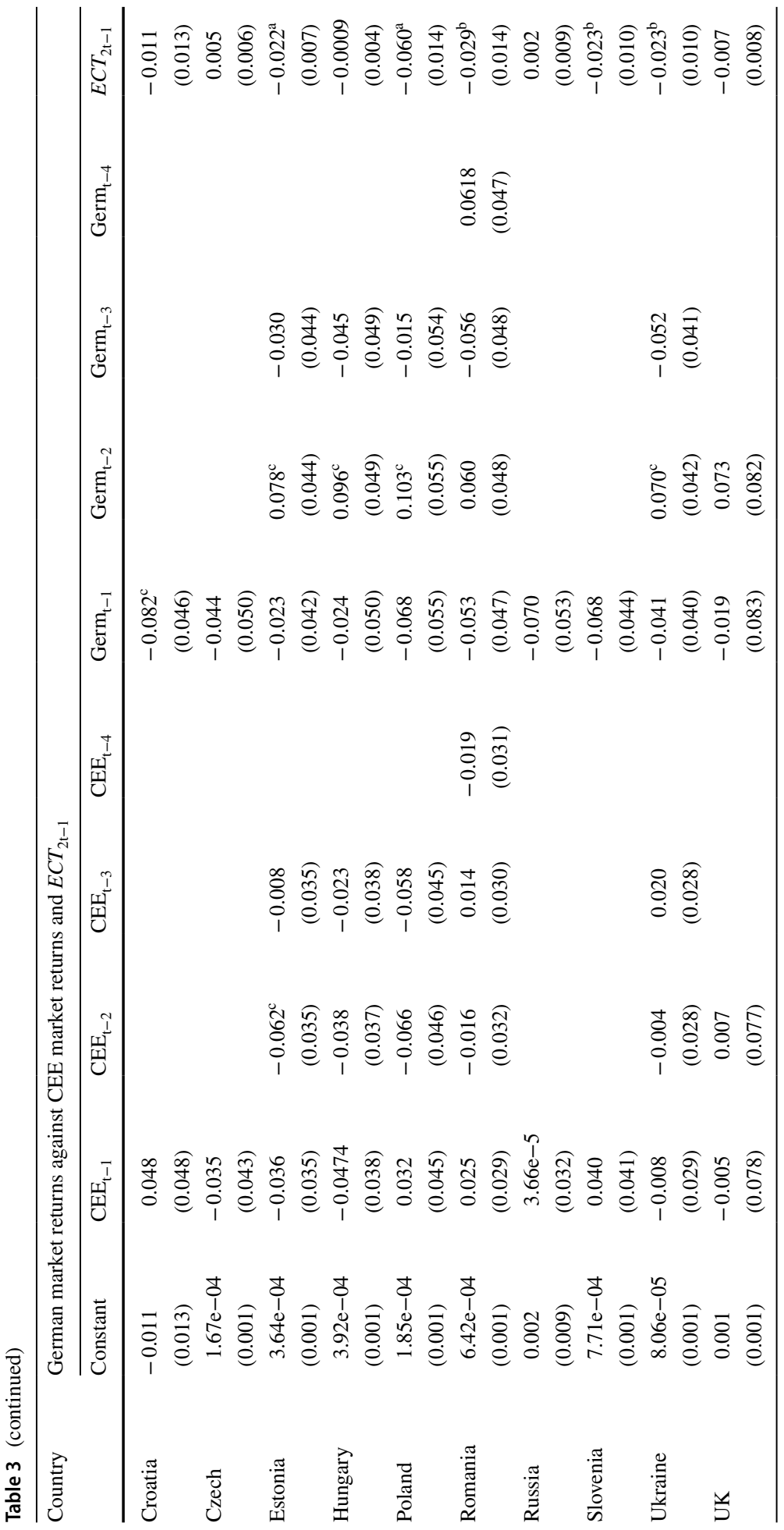




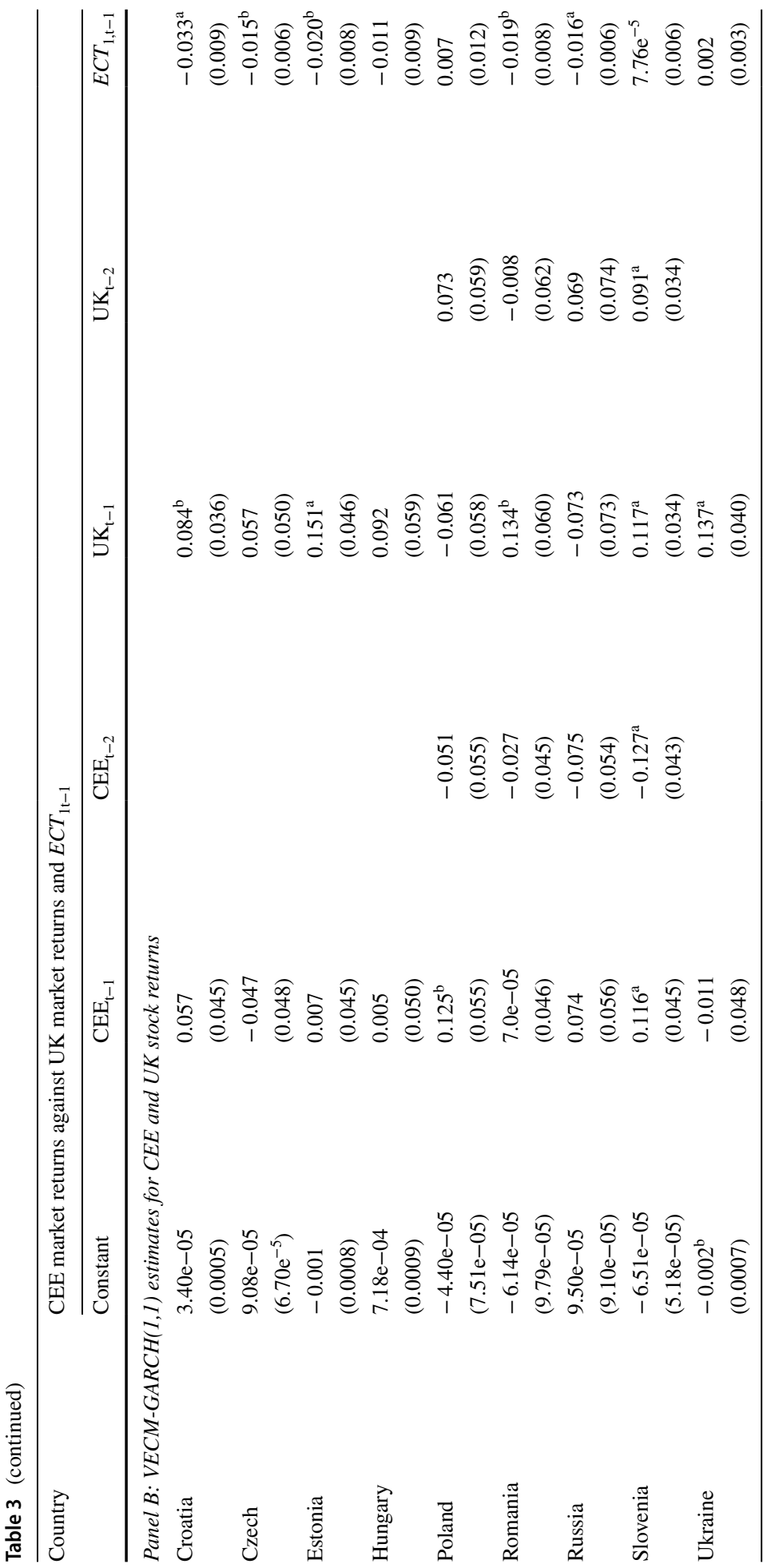




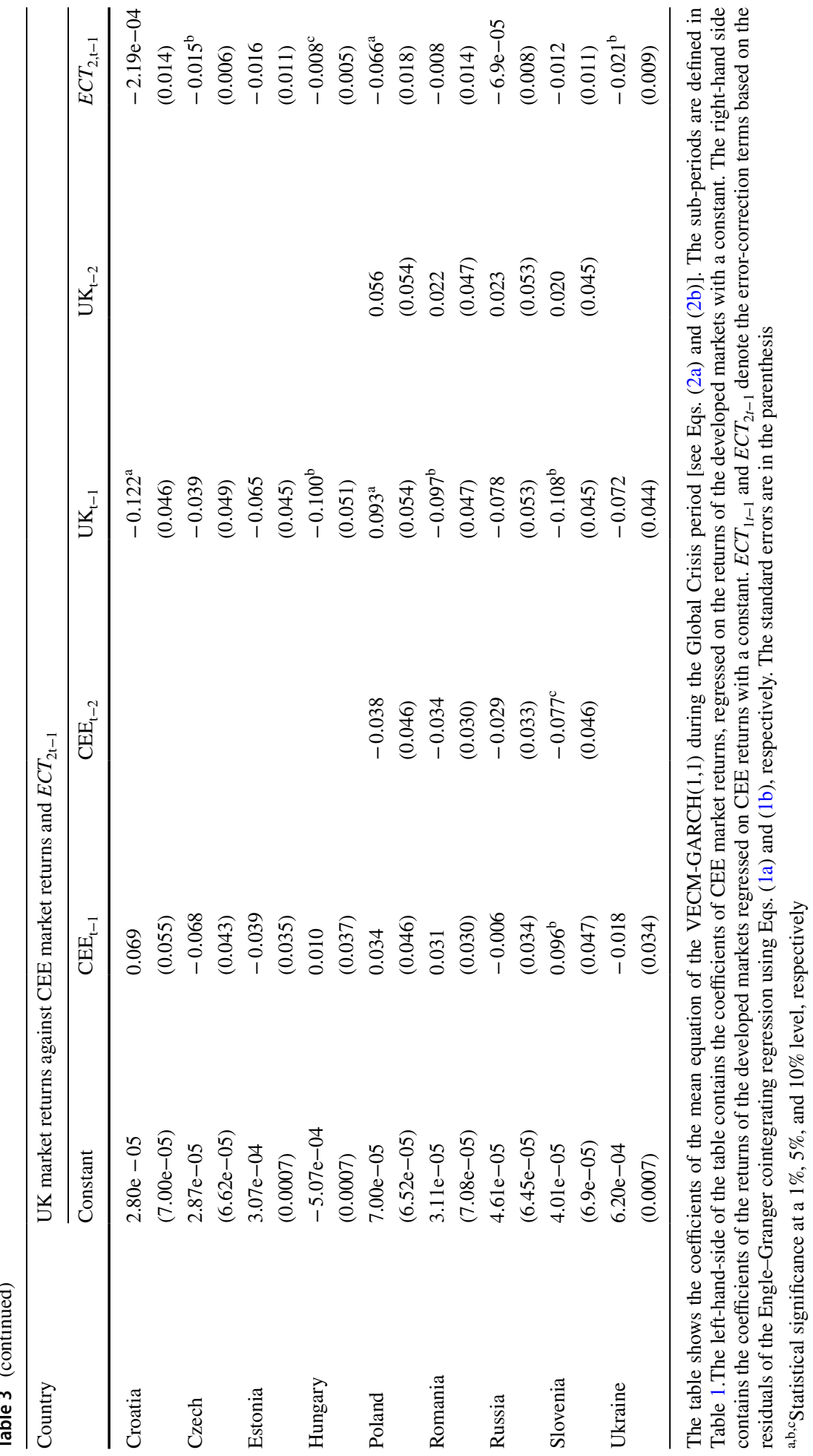




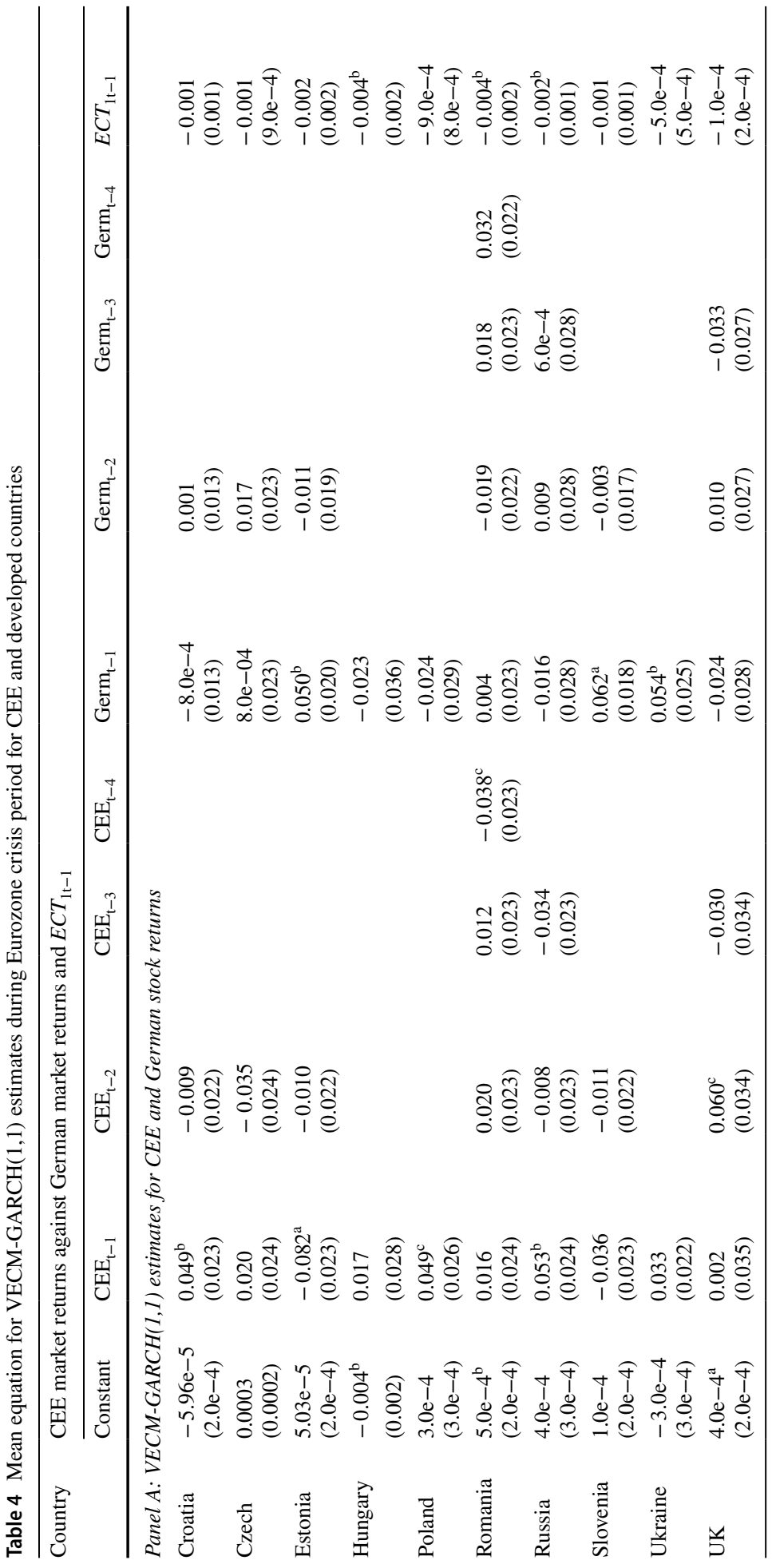




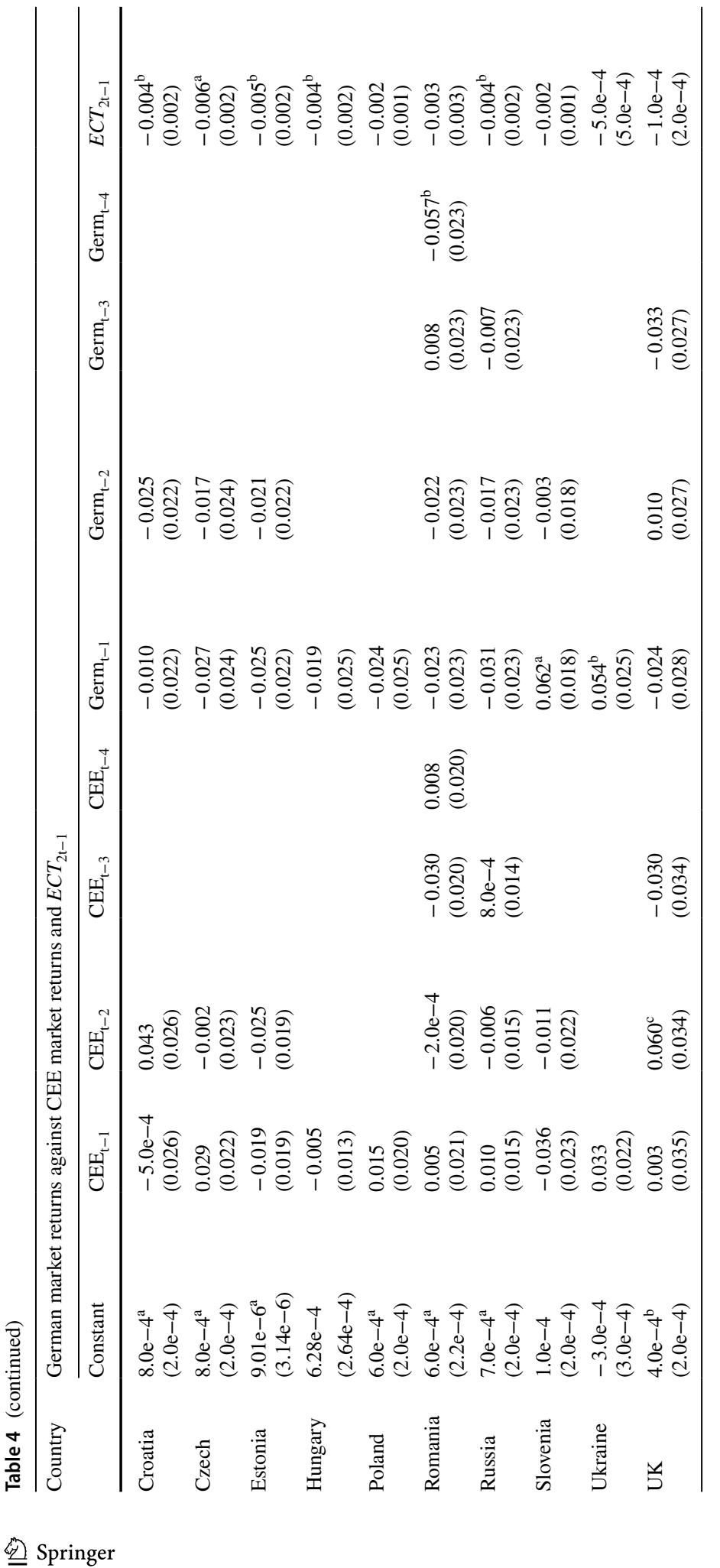




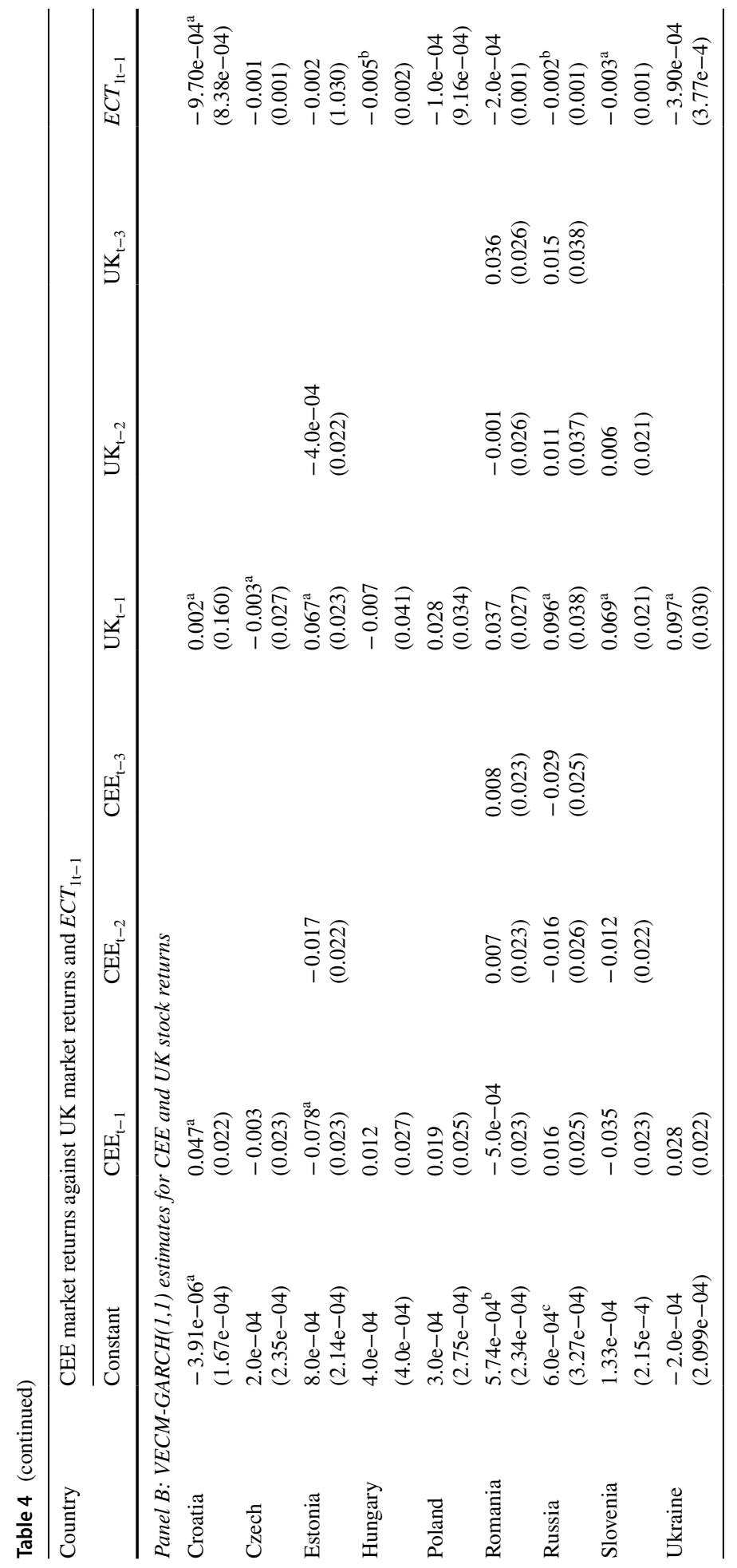




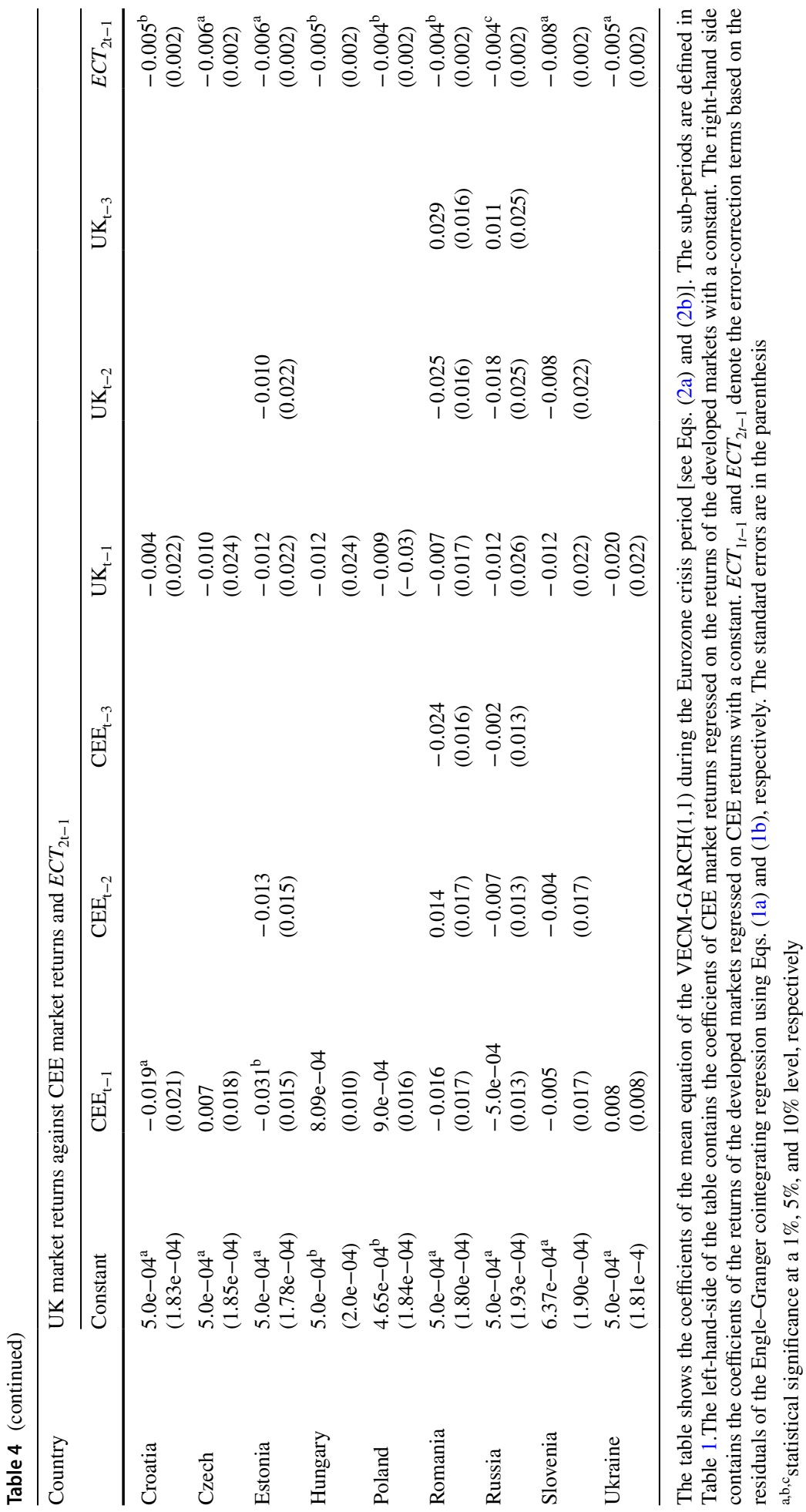


Granato 1999). There is also some tendency for adjustment to long-run equilibrium to be quicker during the crisis periods. The results are presented in Tables 2, 3 and 4 and summarized in Appendix I.

\subsubsection{Non-crisis period and CEE and developed markets}

Table 2 shows the VECM-GARCH results for the non-crisis period. Panel A shows that the Estonian-German and Hungarian-German pairs, have a significant error-correction coefficient for $\gamma_{1}$ in each case ( $p$ value $\leq 0.01$ ). The Croatian, Estonian, Polish and Russian markets also have long-run relations with the German market, based on $\gamma_{2}$ ( $p$ value $\leq 0.05$ ). $\gamma_{2}$ therefore, provides stronger support for long-run relations than $\gamma_{1}$ although the $\gamma_{2}$ for Estonia has the unexpected positive sign. The positive coefficient sign indicates movement away from equilibrium conditions. However, since the same Estonian-German pair has opposite signs for $\gamma_{1}$ and $\gamma_{2}$ and their coefficients have the same (absolute) magnitude, there seems to be a cancelling out of the equilibrium conditions across both markets. ${ }^{17}$ Under the Johansen technique, only the Hungarian, Polish and Slovenian stock markets are cointegrated with the German stock market. Thus, the superior performance of the $t$-ratio approach is consistent with the arguments in the literature (Banerjee et al.1998; de Boef and Granato 1999). Hungary and Poland have the largest absolute coefficient value of -0.017 ( $p$ value $\leq 0.05$ ) for both $\gamma_{1}$ and $\gamma_{2}$. This value predicts that $1.70 \%$ of the disequilibrium will be dissipated before the start of the next period, with $98.30 \%$ remaining. The $t$-ratios therefore indicate very slow adjustment to long-run conditions, as represented by the economically small absolute values of $\gamma_{1}$ and $\gamma_{2}$, although significant. These small (absolute) values are in line with those reported by Syriopoulos and Roumpis (2009) for daily stock returns during the 1998-2007 period. ${ }^{18}$ The first lag of CEE returns has no influence on (current) own CEE returns and German current returns. CEE second lag influences German current returns to a very limited extent, whereas, German first lag and second lag (to a limited extent) influence CEE current returns. German first lag returns have no influence on own current returns. In general, CEE market returns tend to be influenced, more by German returns than by their own returns, in line with the stronger result for $\gamma_{2}$, compared with $\gamma_{1}$.

Panel B of Table 2 shows the corresponding results for CEE and UK stock returns. $\gamma_{1}$ is significant for the Estonian-UK and Hungarian-UK pairs. These same markets have significant $\gamma_{1}$ for CEE on German returns. Croatia, Poland, Russia and Slovenia have long-run relations with UK returns, using $\gamma_{2}$. The tendency for $\gamma_{2}$ to provide stronger support for long-run relations corroborates the CEE-German results. For CEE and UK returns, $\gamma_{1}$ is in the range of -0.005 ( $p$ value $\leq 0.05$ ) for Estonia to -0.017 ( $p$ value $\leq 0.01$ ) for Hungary when significant. $\gamma_{2}$ is in the range of -0.000578 ( $p$ value $\leq 0.01$ ) for Croatia to -0.014 ( $p$ value $\leq 0.01$ ) for Poland when significant. It is tempting to suggest that the speed of longrun adjustment is quicker for $\gamma_{1}$, but the error-correction coefficients are economically very small.

\footnotetext{
17 An alternative but simpler explanation for the positive coefficient can be model misspecification and the presence of structural breaks, not accounted for in our sub-periods.

18 Specifically, Syriopoulos and Roumpis (2009, p. 576) find error-correction coefficients for the Balkan and developed equity markets of -0.0255 ( $p$ value $\leq 0.10$ ) for the DAX and of 0.0383 ( $p$ value $\leq 0.05$ ) for Romania. They also report a tendency for some $t$-ratios to be positive.
} 
Across our VECM-GARCH estimates, the Czech Republic, Romanian and Ukrainian returns have no long-run equilibrium conditions with neither German nor UK returns (see Appendix I). In addition, Slovenian and German returns have no long-run equilibrium relations. Besides these cases, all other market pairs have long-run equilibrium relations in terms of, either $\gamma_{1}$ or $\gamma_{2}$ or both $\gamma_{1}$ and $\gamma_{2}$. Croatia, Russia and Ukraine were non-EU members during the non-crisis period. However, both Croatia and Russia exhibit long-run relations with the developed markets. ${ }^{19}$ The result for Russian returns might reflect the fact that Russia has the largest non-EU economy and that the EU is by far the largest foreign investors in Russia (De Souza 2008). These factors may contribute to the result we find. Indeed, Lucey and Voronkova (2008) report that the US and German stock markets are more important sources of spillover effects for the Russian stock market, whereas the German and the UK stock markets are more important sources of spillover effects for other CEE stock markets. We also find that German and UK returns have no long-run relations even if they are established EU members. Our results suggest that future DCC studies should place less reliance on the differenced VARs since they are mis-specified when longrun conditions apply. ${ }^{20}$

\subsubsection{Global financial crisis and CEE and developed markets}

Panel A of Table 3 shows that for the GFC period, $\gamma_{1}$ is significant for five pairs of CEE (Croatia, Czech Republic, Poland, Romania, and Russia) and German stock markets ( $p$ value $\leq 0.10) . \gamma_{1}$ is positive for the Poland-German pair. $\gamma_{2}$ is significant for five pairs of CEE (Estonia, Poland, Romania, Slovenia and Ukraine) and German markets. Except for the Hungary-German and UK-German pairs, at least one error-correction term is significant in each VECM-GARCH (see Panel A of Table 3 and Appendix I). Thus, long-run equilibrium conditions are more common during the GFC period compared to the noncrisis period. This evidence is in line with the reported tendency for market correlations to increase during turbulent conditions causing markets to be more integrated. While $\gamma_{1}$ and $\gamma_{2}$ have opposite signs for Poland, $\gamma_{2}$ is sufficiently large to absorb the positive effect of $\gamma_{1}$. We suggest that the German stock market (rather than the Polish stock market) has stronger influence on adjustment to long-run equilibrium condition. For Romania, both $\gamma_{1}$ and $\gamma_{2}$ are negative and significant, thereby allowing us to infer long-run adjustment in both directions. Across the estimates, $\gamma_{1}$ is in the range -0.014 ( $p$ value $\leq 0.05$ ) for Romania to -0.035 ( $p$ value $\leq 0.01$ ) for Croatia (ignoring the positive $\gamma_{1}$ for Poland). $\gamma_{2}$ is in the range of -0.022 ( $p$ value $\leq 0.01$ ) for Estonia to -0.060 ( $p$ value $\leq 0.01$ ) for Poland. The magnitudes of $\gamma_{1}$ and $\gamma_{2}$ suggest quicker adjustment to long-run equilibrium relative to the non-crisis period. Similar to the non-crisis period, the first lag of German returns has strong influence on current CEE returns. Very few own lags of CEE returns influence current CEE returns.

Panel B of Table 3 shows the CEE and UK results for the GFC period. Overall, five $\gamma_{1}$ and four $\gamma_{2}$ coefficients are significant. Except for Slovenia, at least one error-correction term is significant in each VECM-GARCH. Unlike CEE and German returns, all the errorcorrection coefficients for CEE and UK returns are negative when significant. Both $\gamma_{1}$ and

\footnotetext{
19 Romania and Croatia joined the EU in January 2007 and July 2013, respectively. Only Croatia has longrun relations with the developed stock markets.

${ }^{20}$ As stated before, most prior studies estimate a VAR in differences to generate the conditional correlations (Ahmed et al. 2012). Whether or not the stock returns of countries experience long-run equilibrium conditions is an empirical matter.
} 
$\gamma_{2}$ are significant for Czech Republic indicating equilibrium adjustments in both directions. EU membership does not determine the presence or absence of long-run relations since Croatia, Russia and Ukraine have long-run relations in at least one regression that includes UK and German returns (see Appendix I). For these markets, $\gamma_{1}$ and $\gamma_{2}$ have values within similar ranges to those of EU members.

\subsubsection{Eurozone crisis period and CEE and developed markets}

The results for the Eurozone crisis period are shown in Table 4. Panel A shows that $\gamma_{1}$ is significant for three CEE (Hungarian, Romanian and Russian) and German market pairs ( $p$ value $\leq 0.05$ ); $\gamma_{2}$ is significant for five CEE (Croatian, Czech Republic, Estonian, Hungarian, Russian) and German market pairs ( $p$ value $\leq 0.05$ ). The Polish, Slovenian and Ukrainian stock markets have no long-run conditions with the German stock market, even if two of these markets exhibit cointegration using the Johansen technique. For the significant cases, $\gamma_{1}$ is largest (in absolute value) at -0.004 ( $p$ value $\leq 0.05$ ) for both Hungary and Romania. $\gamma_{2}$ is largest at -0.006 ( $p$ value $\leq 0.01$ ) for the Czech Republic. As before, the magnitudes of $\gamma_{1}$ and $\gamma_{2}$ are economically small. So, it is questionable whether the presence of long-run relationships can bring about important differences in the copula estimates based on the conditional variances of the VECM-GARCH and differenced VAR-GARCH.

Panel B shows much stronger support for long-run relations using CEE and UK returns. $\gamma_{1}$ is significant for four CEE (Croatia, Hungary, Russia and Slovenia) and UK market pairs ( $p$ value $\leq 0.05) \cdot \gamma_{2}$ is negative and significant for all nine CEE and UK market pairs ( $p$ value $\leq 0.10$ ). This is our strongest result. $\gamma_{2}$ tends to be larger (in absolute value) than $\gamma_{1}$ in line with previous results. The VECM-GARCH still outperforms the Johansen technique since only Hungary and Slovenia are cointegrated, using the Johansen technique. Both $\gamma_{1}$ and $\gamma_{2}$ are significant for Croatia, Hungary, Russia and Slovenia. The CEE-UK market pairs provide stronger support for long-run relationships than the CEE-German market pairs, even if the Eurozone crisis is more strongly associated with Eurozone member states. This evidence suggests greater rebalancing between CEE and UK investors, perhaps because of greater stability in the UK stock market as well as higher level of market liquidity.

\subsection{Variance equations}

ARCH and GARCH effects are stylized features of financial prices. They are particularly pronounced in high frequency data (Baillie and Bollerslev 1989). They also have important statistical properties which are conducive to fitting copulas. Bollerslev and Engle (1993), for example, introduce the idea of co-persistence in conditional variance in a multivariate setting. Here, combinations of variables can contain a long-run component in co-persistence, which can be generalized in interpretation to cointegration, as in Engle and Granger (1987). ${ }^{21}$ If correlations and volatilities are time-varying, they affect the degree of tailedness when fitting copulas. ARCH and GARCH effects can also be viewed as providing evidence on spillover effects, regardless of the information in fundamentals (Karolyi and Stulz 1995).

\footnotetext{
${ }^{21}$ Even if the returns of one stock market exhibit persistence variance, it is possible that pairs of stock markets can exhibit common long-run persistence in their variances (Bollerslev and Engle 1993).
} 
Numerical values of the coefficients of the variance equation are not tabulated, but are available upon request. For both the VECM-GARCH and differenced VAR-GARCH, the GARCH is correctly specified for most estimates, since the estimated parameters satisfy the conditions of $\omega \geq 0 ; \alpha \geq 0 \beta \geq 0$ and $\alpha+\beta<1$ (Bollerslev 1986). These equality constraints are violated only for a very small number of markets. The sum of $\alpha+\beta$ is close to one for both VAR specifications. This suggest an integrated GARCH process (IGARCH) and the possibility of a unit root. In an IGARCH, there is persistence in variance and current information is useful for improving the forecasts of the conditional variance at all horizons (Engle and Bollerslev 1986).

\subsubsection{Coefficient of variance equations for CEE and developed markets}

Figure 1a, b shows plots of the coefficients of the variance equations [i.e. Eqs. (3a) and (3b)], under the VECM-GARCH and differenced VAR-GARCH. The plots of $\beta_{2}(\mathrm{GARCH})$ in the regressions of developed markets on CEE returns [Eq. (3b)] are at the same level for the VECM-GARCH and differenced VAR-GARCH, and are close to one. This is not the case for $\beta_{1}$ in the regressions of CEE returns on developed market returns. $\beta_{2}$ has a minimum value of $0.882(p$ value $\leq 0.01)$ for German returns on CEE returns during the GFC period (under the VECM-GARCH). $\beta_{2}$ has a minimum value of 0.705 ( $p$ value $\leq 0.01$ ) for UK returns on CEE returns during the non-crisis period. $\beta_{1}$ varies substantially across markets, especially during the non-crisis period. For the VECM-GARCH, the minimum value of $\beta_{1}$ is 0.219 (0.206) for CEE returns on German returns (CEE returns on UK returns) during the Eurozone crisis period. Both coefficients are insignificant. In addition, the maximum (minimum) value of $\beta_{1}$ is larger (smaller) than the maximum (minimum) value of $\beta_{2}$. Thus $\beta_{1}$ has a wider range than $\beta_{2}$. As such, past volatility has more variability on the current volatility of CEE returns compared to its effects on the current volatility of developed markets. The variance equations of the VAR-GARCH exhibit similar patterns.

Past news has more influence on the current volatility of CEE market returns, compared to their effects on the current volatility of developed market returns. Figure 1a, b indicates that even if past volatility has more persistence on current volatility in developed markets, past news has more persistence in CEE markets. To illustrate, using the VECM-GARCH and CEE-German returns during the non-crisis period, $\alpha_{1}$ has the largest value of 0.276 ( $p$ value $\leq 0.01$ ) for Romania, whereas, $\alpha_{2}$ has the largest value of 0.113 ( $p$ value $\leq 0.01$ ) for Ukraine. Similarly, $\beta_{1}$ has the largest value of 0.971 ( $p$ value $\leq 0.01$ ) for Slovenia, whereas $\beta_{2}$ has the largest value of 0.925 ( $p$ value $\leq 0.01$ ) for Poland. Although differences in the coefficient values may be insignificant, they illustrate variation across the types of markets. Indeed, for non-crisis period, average $\beta_{1}$ and $\beta_{2}$ coefficients across the nine CEE markets are 0.778 and 0.911 , respectively. Average $\alpha_{1}$ and $\alpha_{2}$ values are 0.126 and 0.072 , respectively. We suggest that the larger values of $\alpha_{1}$ compared to $\alpha_{2}$ may reflect the lower level of liquidity in CEE markets. For example, liquidity constraints in CEE markets can cause investors to delay rebalance their portfolios on the immediate arrival of news. This in turn, may increase the volatility of CEE returns causing $\beta_{1}$ to have a wider range than $\beta_{2}$. Since we find that average $\alpha_{1}$ and $\alpha_{2}$ values are much small than average $\beta_{1}$ and $\beta_{2}$ values, this result indicates that GARCH is more important in capturing volatility persistence than past news (see Ding and Granger 1996).

The time invariance measure of the conditional covariances are defined by $\lambda_{1}$ and $\lambda_{2}$. $\lambda_{2}$ is always larger than $\lambda_{1}$. Figure 1a, b shows that $\lambda_{2}$ is close to one; $\lambda_{1}$ is close to zero in most cases and sometimes insignificant. The larger $\lambda_{2}$ values suggest that the conditional 
covariances depend more on their past values than on residual innovations. The DCC estimates also vary across markets. They are larger during the crisis periods, in line with prior work (Braun et al. 1995; Dimitriou et al. 2013). However, we do not dwell too much on the DCC results due to their limitations. ${ }^{22}$

\subsubsection{Comparison across VAR specifications and correlated conditional variances}

Earlier, we argued that failure to account for long-run conditions would affect estimates of the conditional variances. To test this prediction, we plot the coefficients of the variance equations for both the VECM-GARCH and VAR-GARCH. Figure $2 a, b$ shows that the coefficients are similar under both VAR specifications. The difference in the VAR specifications do not contribute to observable differences in the coefficient values. It appears therefore that the main advantage of the VECM-GARCH is that it allows us to capture long-run equilibrium conditions and facilitates an interpretation of long-run and short-run dynamics. ${ }^{23}$ We suggest that the slow speed of adjustment to long-run conditions limits the ability of the VECM-GARCH to generate variance parameters that are distinguishable from those of the VAR-GARCH.

A final consideration is whether pairs of large conditional variances are correlated. While Figs. 1 and 2 provide plots of the DCC estimates, we want to observe the patterns in the pairs of conditional variances in greater detail. The plots of the conditional variances, i.e. $h_{1 t}^{2}$ and $h_{2 t}^{2}$, are not shown. However, using the VECM-GARCH, we observe a tendency for some observations in the plots to exceed their \pm 1.96 confidence bands. Overshooting is especially strong during the September to October 2008 period. These months had substantial market upheavals, including the Lehman Brother's collapse, on September 15, 2008. Pairs of $h_{1 t}^{2}$ and $h_{2 t}^{2}$ co-moved, especially during the crisis periods. The plots for $h_{2 t}^{2}$ appear more variable than those of $h_{1 t}^{2} ; h_{2 t}^{2}$ also appears to lead $h_{1 t}^{2}$. In general, the plots have important features for our copula estimates. We find similar patterns under the VAR-GARCH.

\section{Testing the dependence structure using copulas}

This section presents the copula estimates obtained from the VECM-GARCH (see Tables 5 and 6). We focus on the copula estimates from the VECM-GARCH since the idea of steady-state equilibrium is appealing under this specification. Since we are concerned with data structure, we use the AIC to determine the goodness-of-fit of the copula functions, even if it is prone to overfitting. ${ }^{24}$ This allows us to rank the fit of the copula functions (Dias and Embrechts 2010). The results are presented below.

\footnotetext{
${ }^{22}$ Using $s$ as the estimate for the centered conditional correlation, Aielli (2008, p. 290) find a positive bias when $s<0$ and a negative bias when $s>0$.

23 A further advantage of error-correction-type models is that they enhance super consistency of the regression estimates (see Stock 1987). Granger (1986, p. 226) also argues that error-correction type models "should produce better short-run forecasts and will certainly produce long-run forecasts that hold together in economically meaningful ways".

24 Specifically, we use the AIC, the BIC and the Log-likelihood ratio.
} 


\section{a}

Panel A. Coefficients of variance equations for CEE and German returns during the non-crisis period

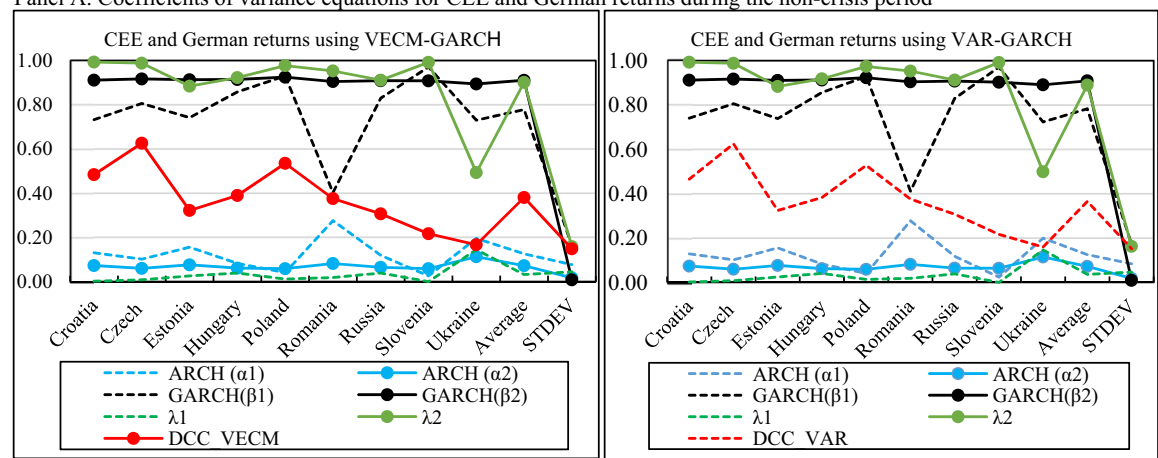

Panel B. Coefficients of variance equations for CEE and German returns during the GFC period

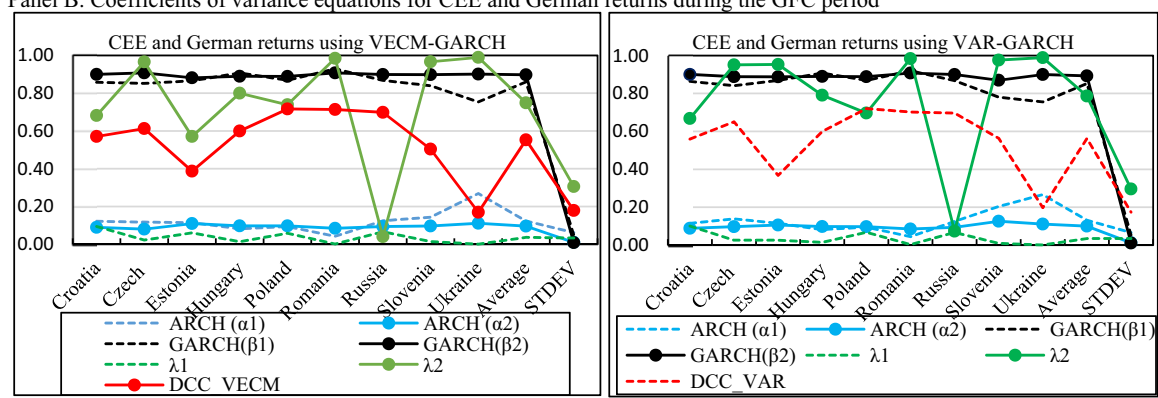

Panel C. Coefficients of variance equations for CEE and German returns during the Eurozone Crisis period
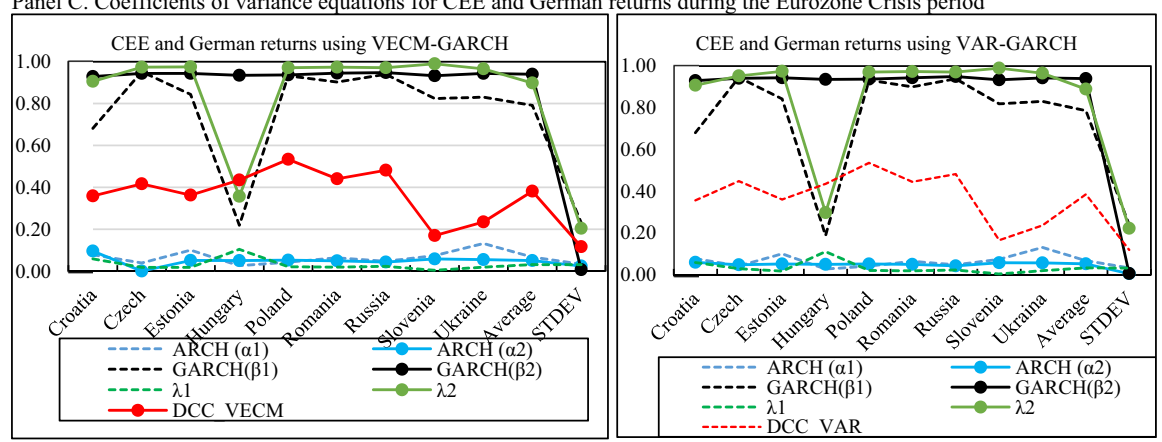

Fig. 1 a VECM-GARCH and VAR-GARCH variance coefficients for CEE and German returns. $\operatorname{ARCH}\left(\alpha_{1}\right)$, $\operatorname{GARCH}\left(\beta_{1}\right)$ and $\lambda_{1}$ are the variance coefficients based on regressions of CEE returns on German returns. $\operatorname{ARCH}\left(\alpha_{2}\right), \operatorname{GARCH}\left(\beta_{2}\right)$ and $\lambda_{2}$ are based on the regression of German returns on CEE returns. VARGARCH in the panels refers to the differenced VAR-GARCH. Plots of the constants are not shown since they are economically small. b VECM-GARCH and VAR-GARCH variance coefficients for CEE and UK returns. $\operatorname{ARCH}\left(\alpha_{1}\right), \operatorname{GARCH}\left(\beta_{1}\right)$ and $\lambda_{1}$ are the variance coefficients based on regressions of CEE returns on UK returns. $\operatorname{ARCH}\left(\alpha_{2}\right), \operatorname{GARCH}\left(\beta_{2}\right)$ and $\lambda_{2}$ are based on the regression of UK returns on CEE returns. VAR-GARCH in the panels refers to the differenced VAR-GARCH. The DCC observations for Ukraine and Hungary exceed \pm 1 in Panels B and C, respectively. These data points are not shown to avoid distortion in the plots. Plots of the constants are not shown since they are economically small

\subsection{Copula estimates using CEE and German returns}

Our results for CEE and German returns are summarized as follows. The T-V SJC copula dominates all other copula functions, based on the AIC, although performance is 
b

Panel A. Coefficients of variance equations for CEE and UK returns during the non-crisis period

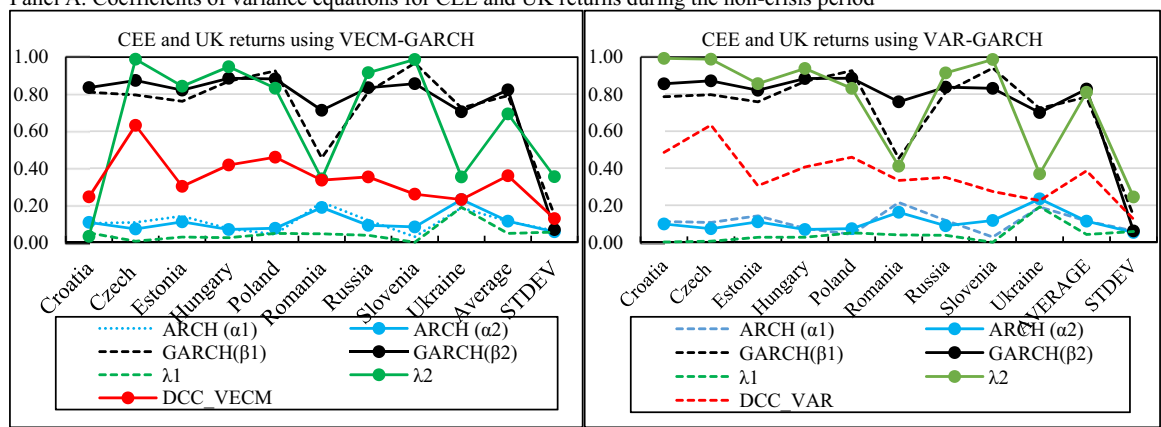

Panel B. Coefficients of variance equations for CEE and UK returns during the GFC period
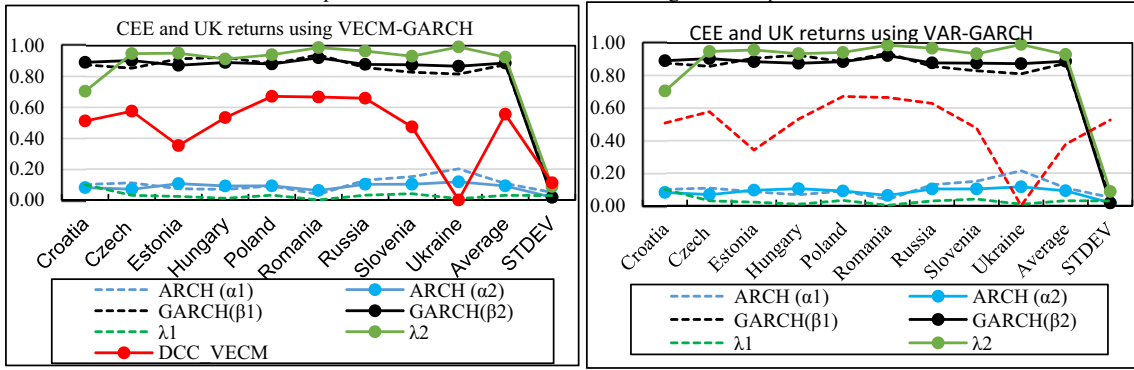

Panel C. Coefficients of variance equations for CEE and UK returns during the Eurozone Crisis period

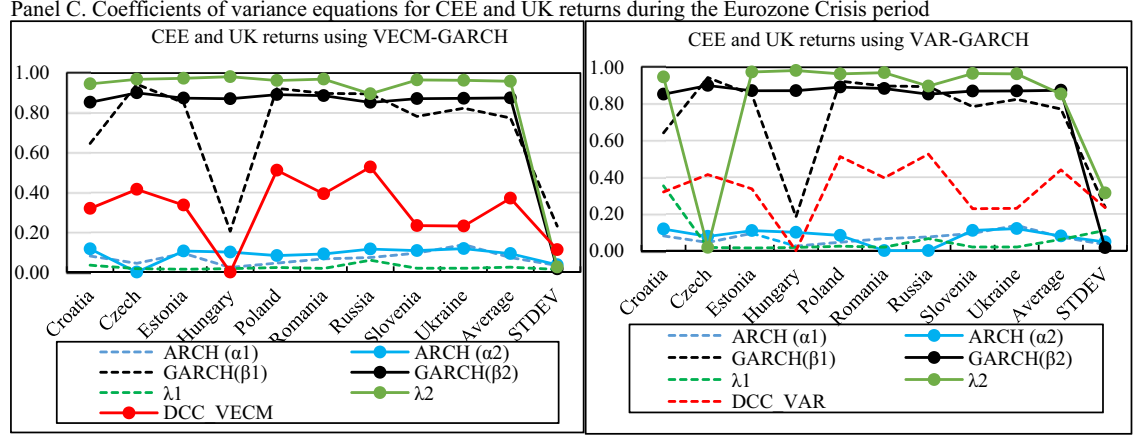

Fig. 1 (continued)

similar with T-V Student $t$ copula for the GFC period. The T-V SJC copula generates very few significant copula coefficients when we apply model selection criteria.

\subsubsection{Goodness-of-fit of copulas for CEE and German returns}

Table 5 shows the copula estimates for CEE and German returns. The T-V SJC copula provides the best fit for six market pairs, during the non-crisis period, using the AIC. The T-V Student $t$ provides the best fit for the remaining market pairs (Table 5, Panel A). For the GFC period, the performance of the T-V Student $t$ and the T-V SJC copulas is similar (Panel B). The T-V SJC outperforms the T-V Student $t$ during the Eurozone crisis period (Panel C). It is worth noting that the AIC always favors the T-V Student $t$ 


\section{a}

Panel A. Coefficients of variance equations for CEE and German returns during the non-crisis period

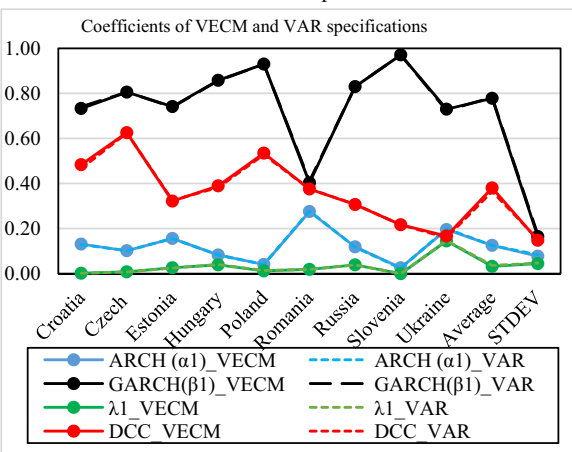
Coefficients of VECM and VAR specifications
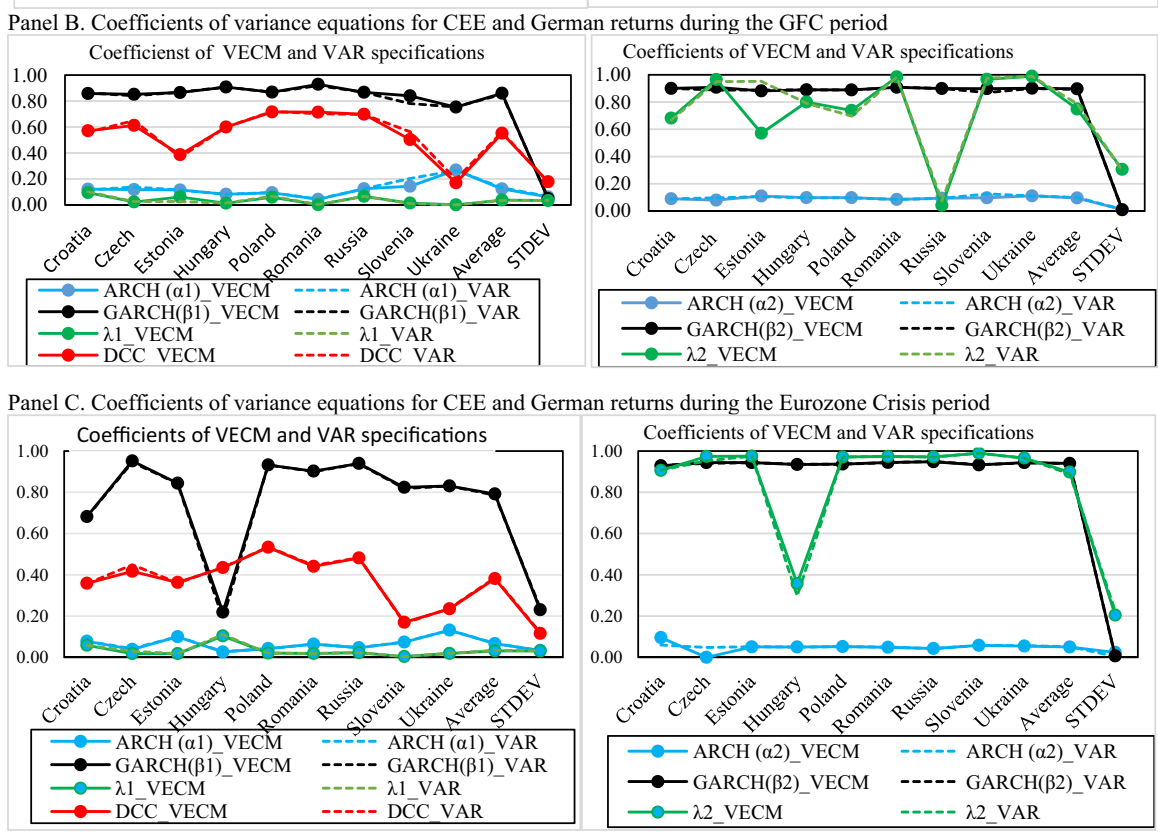

Fig. 2 a Comparison of VECM-GARCH and VAR-GARCH variance coefficients for CEE and German returns. The figure shows plots of the coefficients of the variance equations. $\alpha_{1}$ and $\alpha_{2}$ are the coefficients of $\mu_{1 t-1}$ and $\mu_{2 t-1}$, respectively. $\beta_{1}$ and $\beta_{2}$ are the coefficients of $h_{1 t-1}^{2}$ and $h_{2 t-1}^{2}$ respectively. VECM and VAR denote the coefficients for the VECM-GARCH and differenced VAR-GARCH, respectively. $\lambda_{1-V E C M}$ and $\lambda_{1-V A R}$ are the invariance coefficients. DCC_VECM and DCC_VAR are the dynamic conditional correlations for the VECM-GARCH and differenced VAR-GARCH, respectively. Plots of the constants are not shown since they are economically small. b Comparison of VECM-GARCH and VAR-GARCH variance coefficients for CEE and UK returns. The figure shows plots of the coefficients of the variance equations. $\alpha_{1}$ and $\alpha_{2}$ are the coefficients of $\mu_{1 t-1}$ and $\mu_{2 t-1}$, respectively. $\beta_{1}$ and $\beta_{2}$ are the coefficients of $h_{1 t-1}^{2}$ and $h_{2 t-1}^{2}$ respectively. VECM and VAR denote the coefficients for the VECM-GARCH and differenced VARGARCH, respectively. $\lambda_{1}$ VECM and $\lambda_{1}$ VAR are the invariance coefficients. DCC_VECM and DCC_VAR are the dynamic conditional correlations for the VECM-GARCH and differenced VAR-GARCH, respectively. The DCC observations for Ukraine and Hungary exceed \pm 1 in Panels B and C, respectively. These data points are not shown to avoid distortion in the plots. Plots of the constants are not shown since they are economically small 
b

Panel A. Coefficients of variance equations for CEE and UK returns during the non-crisis period Coefficients of variance equations for VECM and VAR
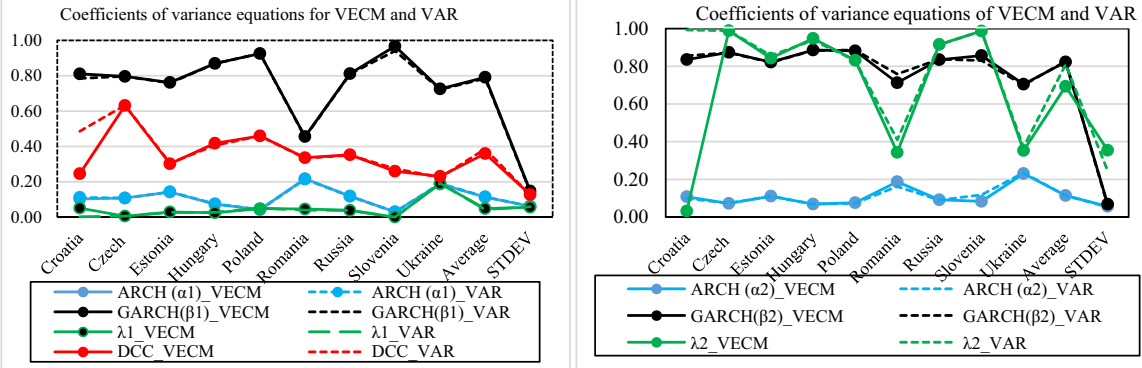

Panel B. Coefficients of variance equations for CEE and UK returns during the GFC period
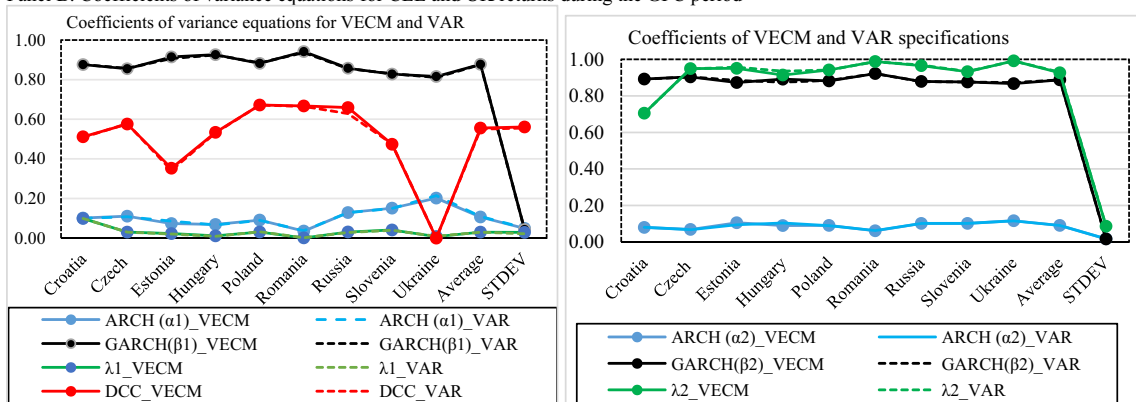

Panel C. Coefficients of variance equations for CEE and UK returns during the Eurozone Crisis period
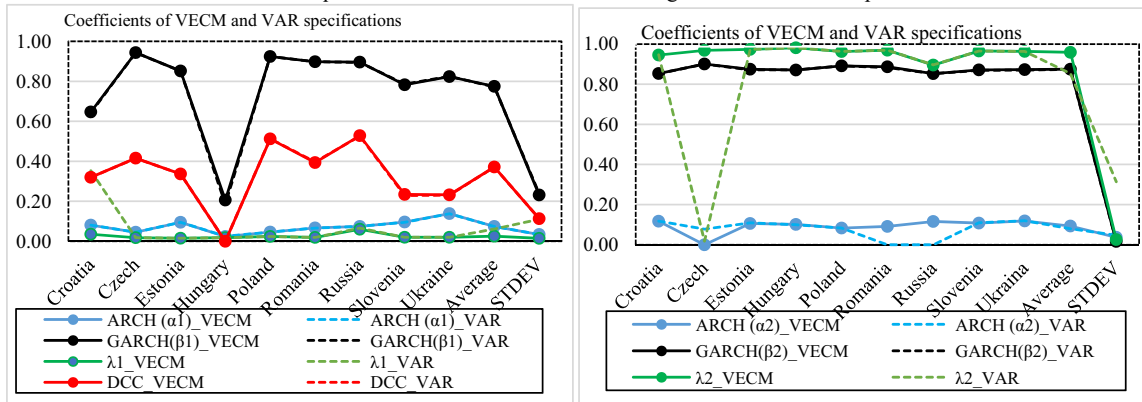

Fig. 2 (continued)

copula for the pair of German and UK returns. The other copulas perform badly across the sub-periods. The basic T-V Clayton exclusively displays lower tail dependence whereas, the Gaussian copula displays symmetric dependence. As none of these features completely characterize our data (see Table 1), we do not dwell too much on these copulas. The VAR-GARCH favors the T-V SJC copula slightly more often than the VECMGARCH, perhaps reflecting considerations regarding model specification.

Jondeau and Rockinger (2006) report that the skewed T-V Student $t$ provides a good or better fit than the Gaussian copula for four major European stock index returns. ${ }^{25}$ They do not estimate the T-V SJC copula. While the statistical features of our Student $t$ does not explain its comparable performance with the SJC copula during the GFC

${ }^{25}$ Using high frequency FX rate returns, Breymann et al. (2003) find that the Student $t$ copula outperforms the Gaussian copula. However, Boero et al. (2010) find that the constant SJC copula provides a better fit to daily exchange rate returns, which is in line with the results for our T-V SJC copula. 


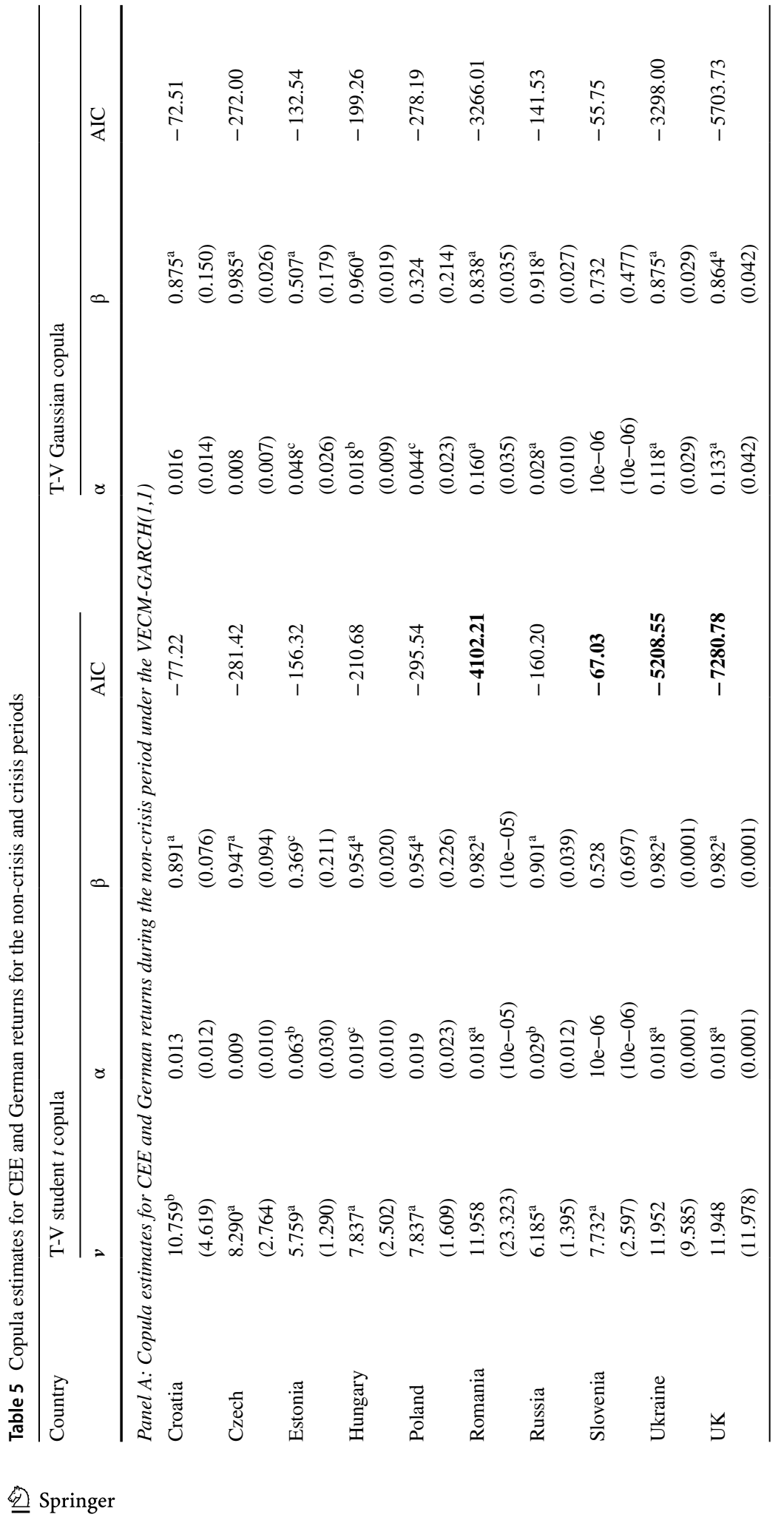




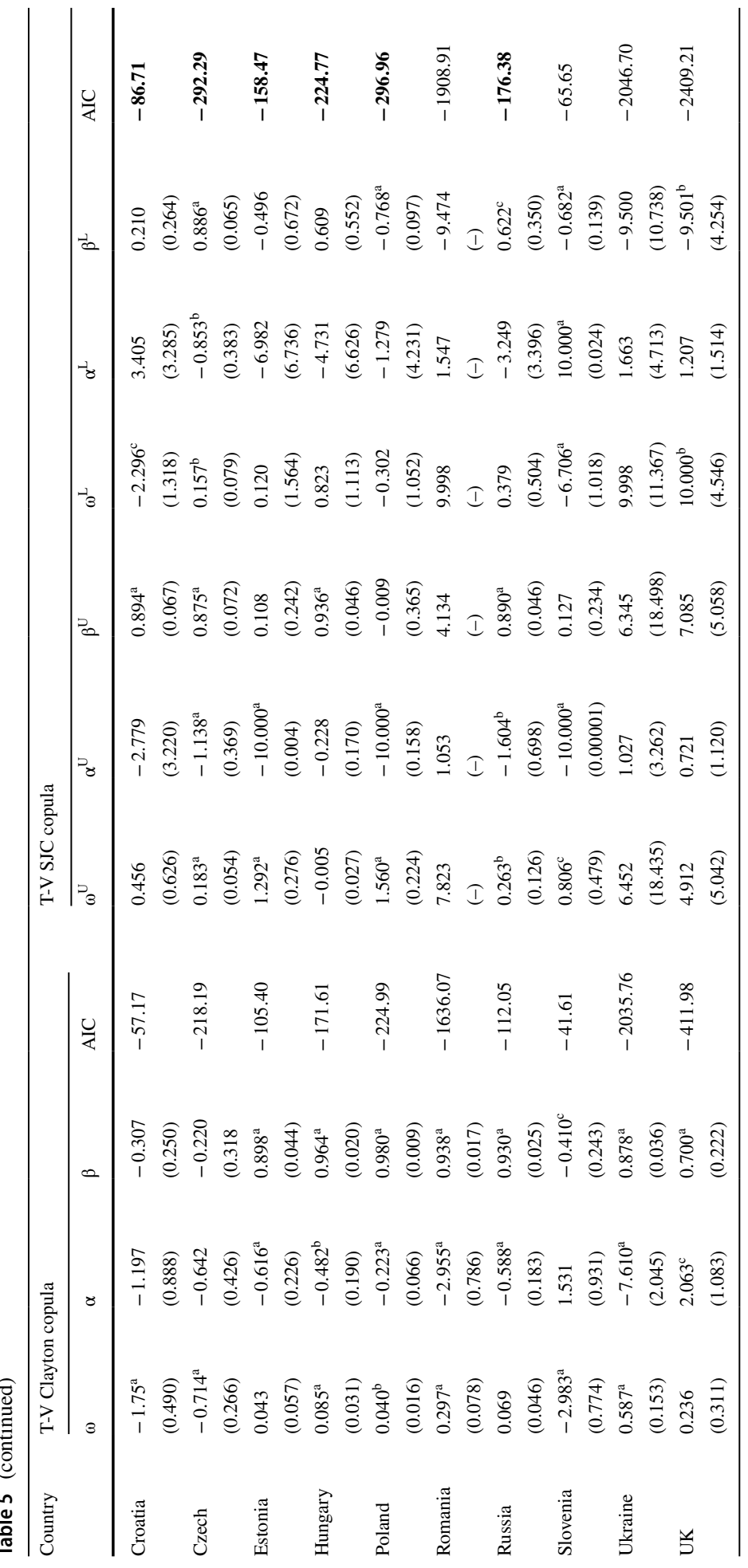




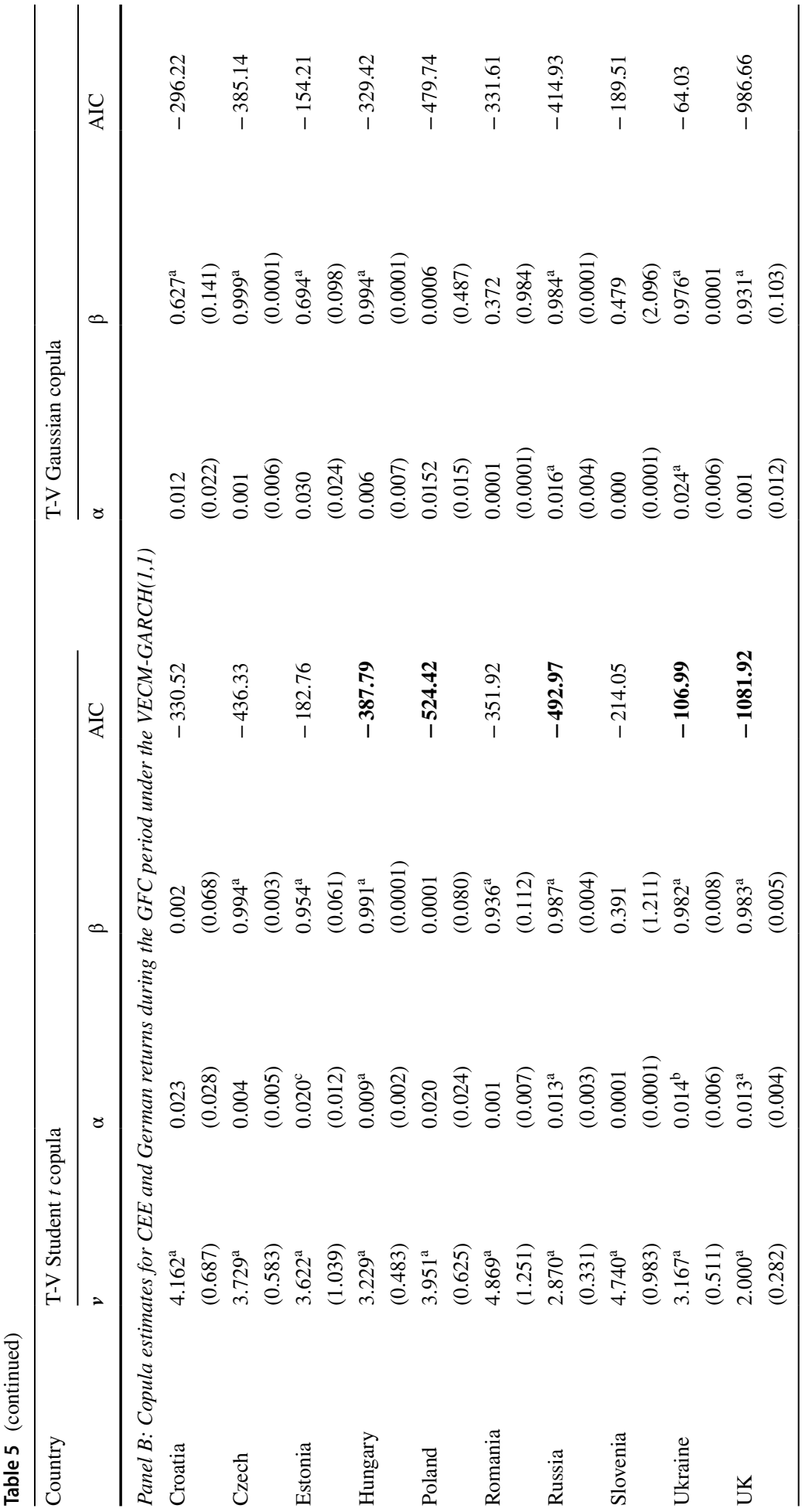




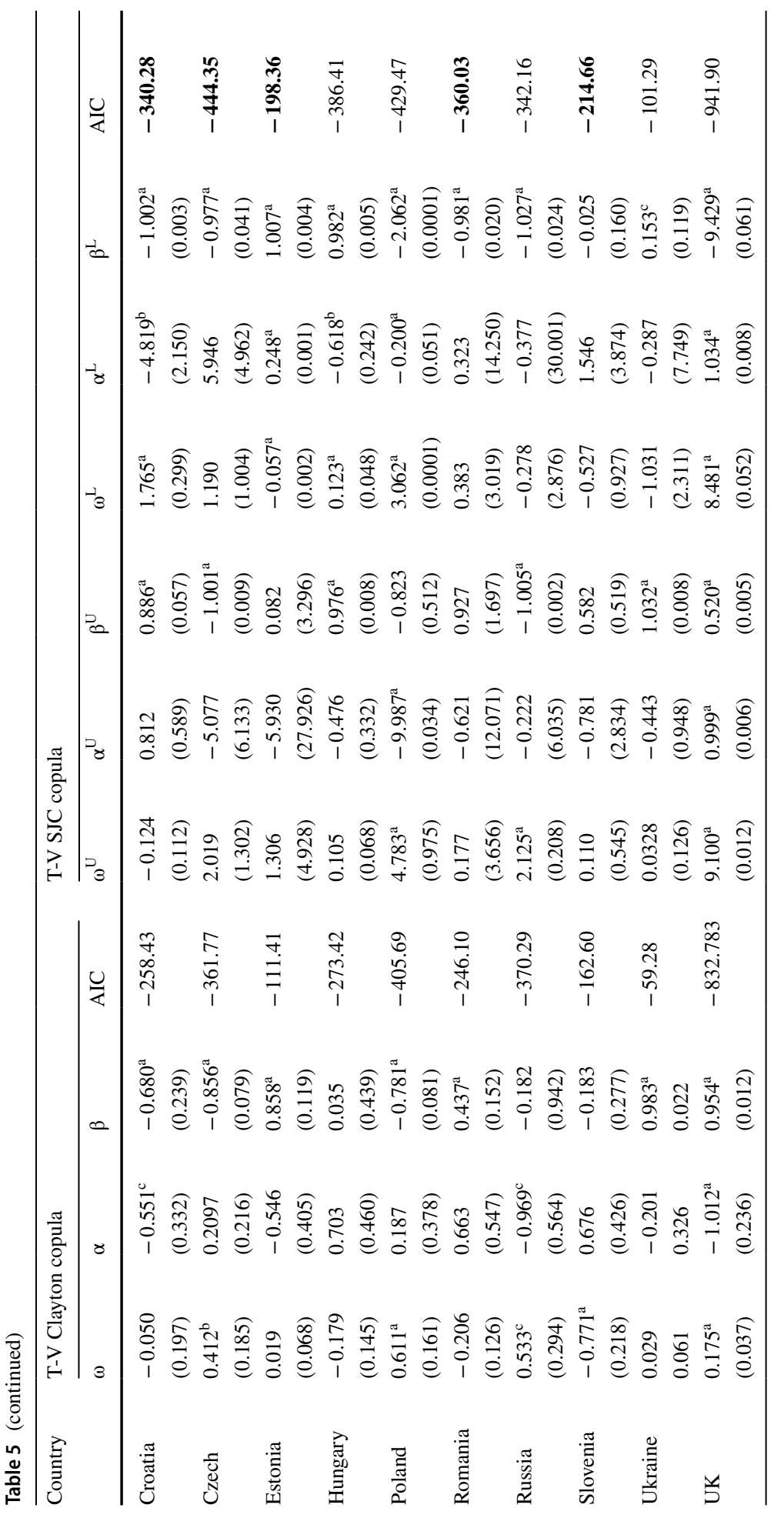




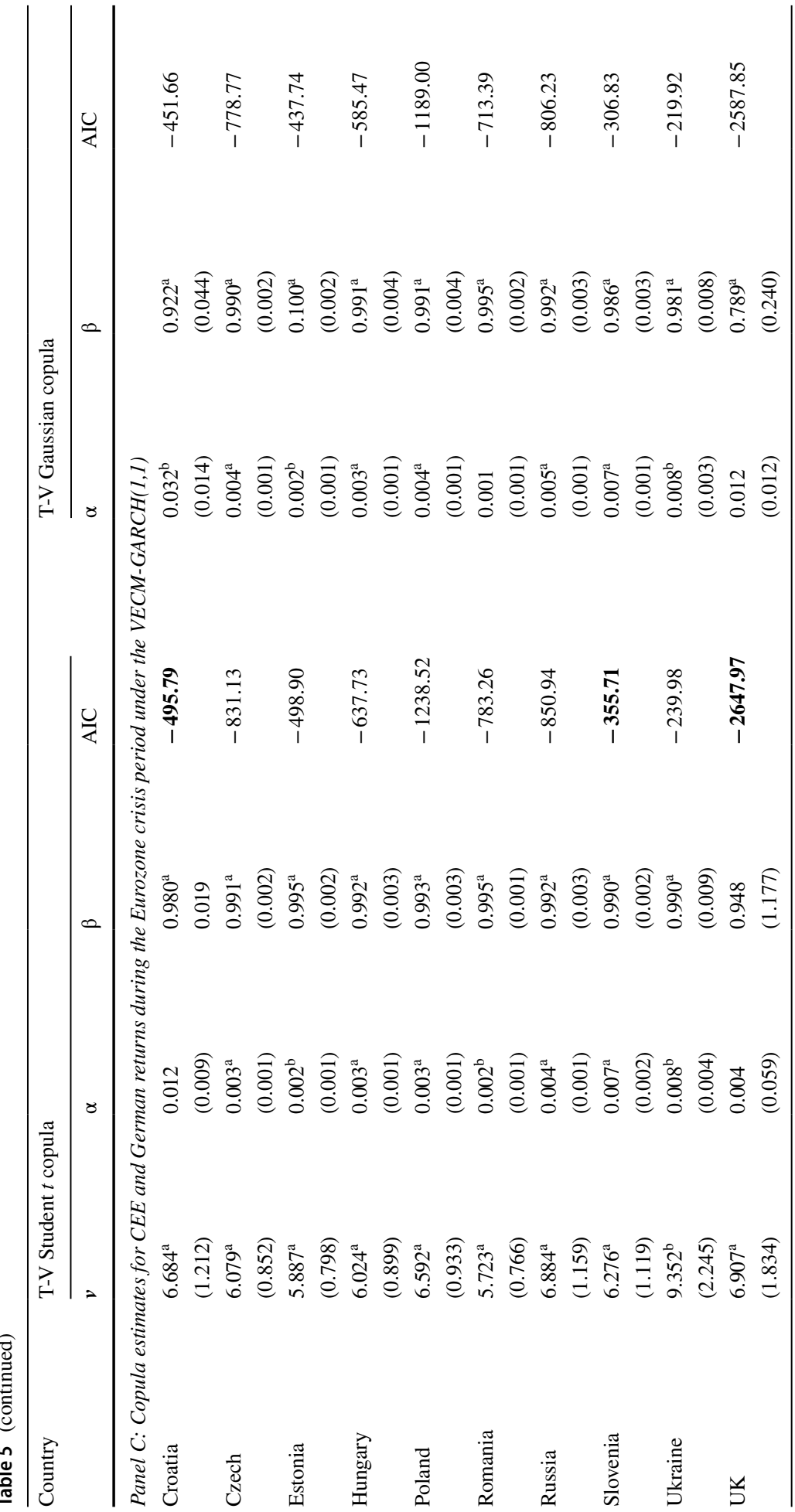




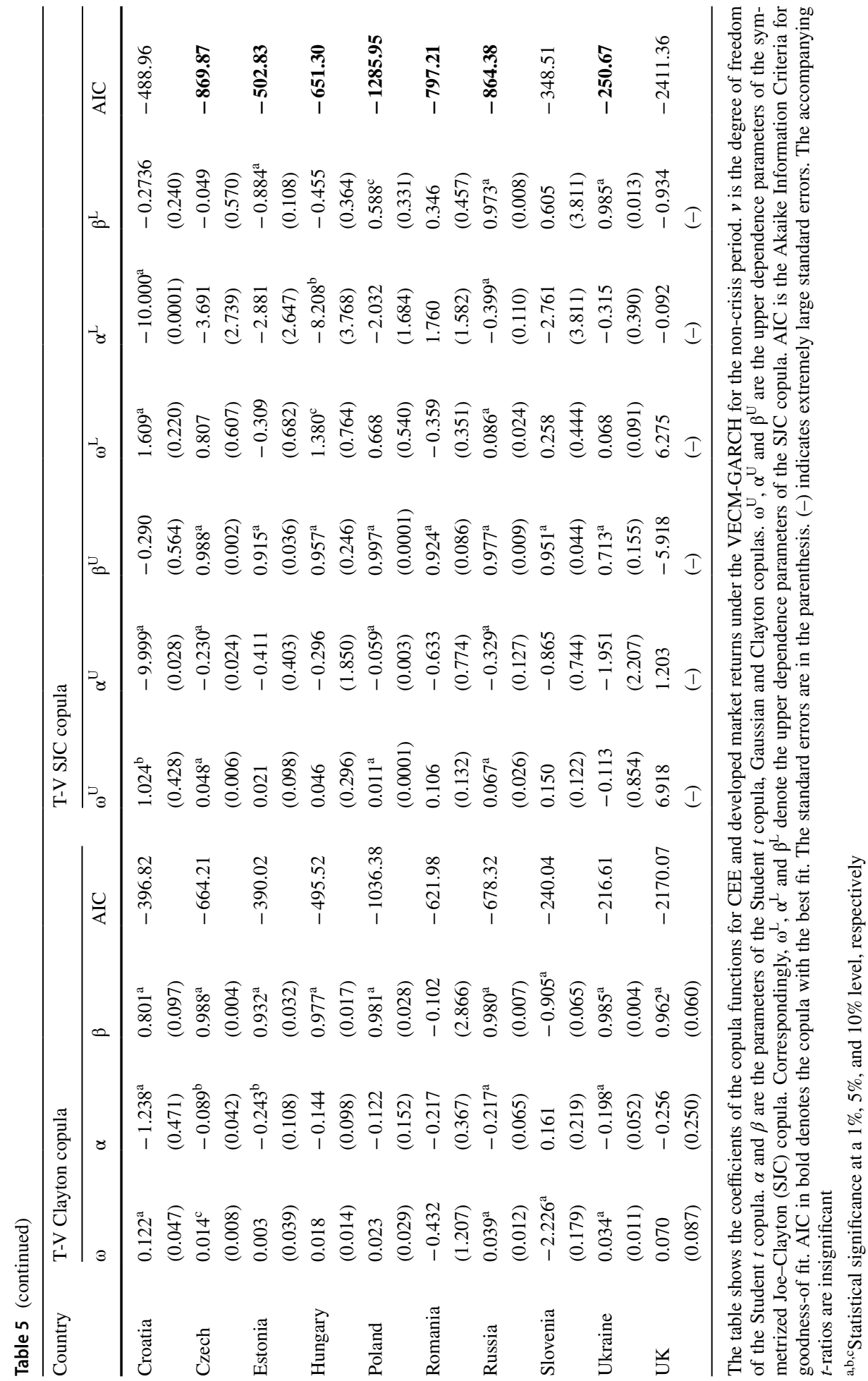




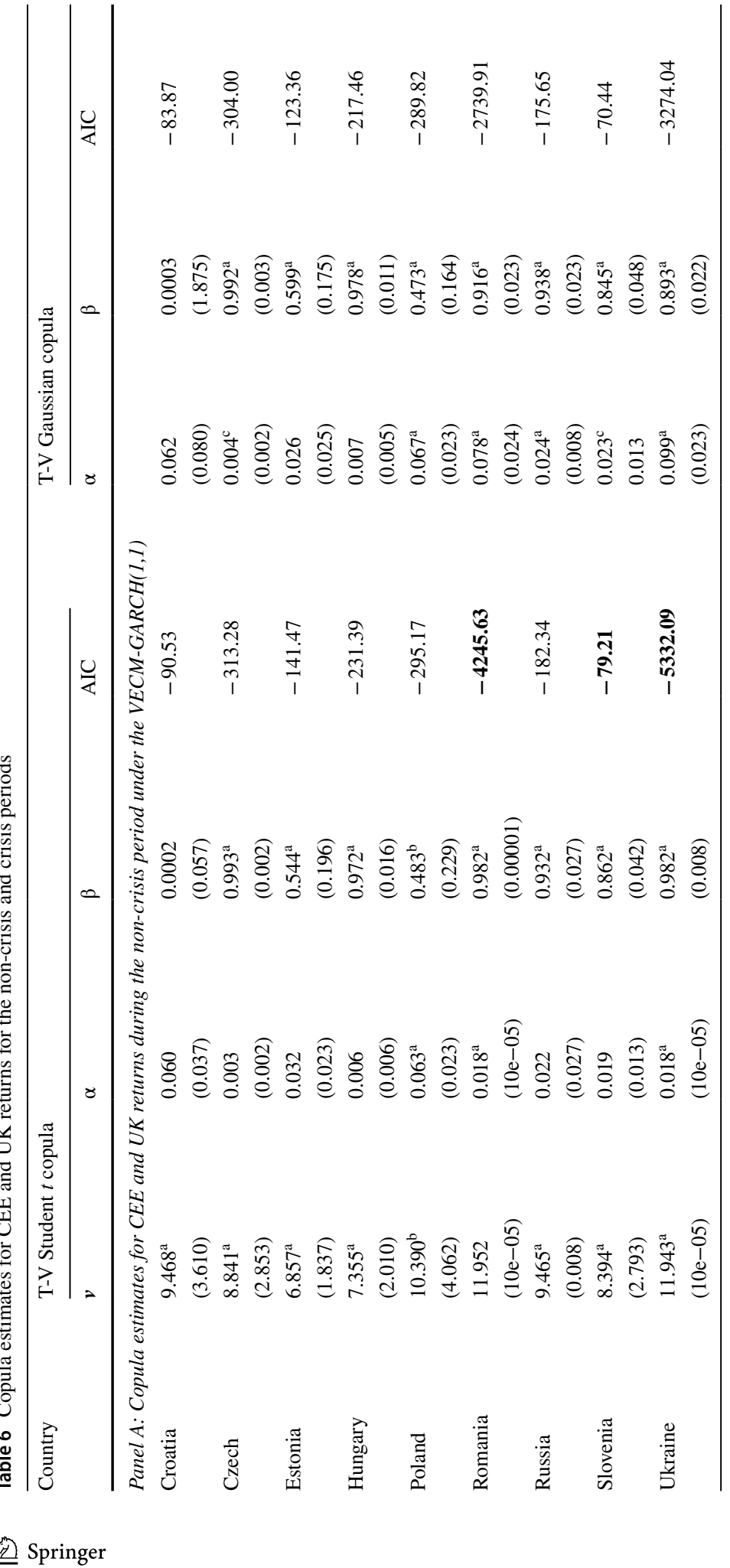




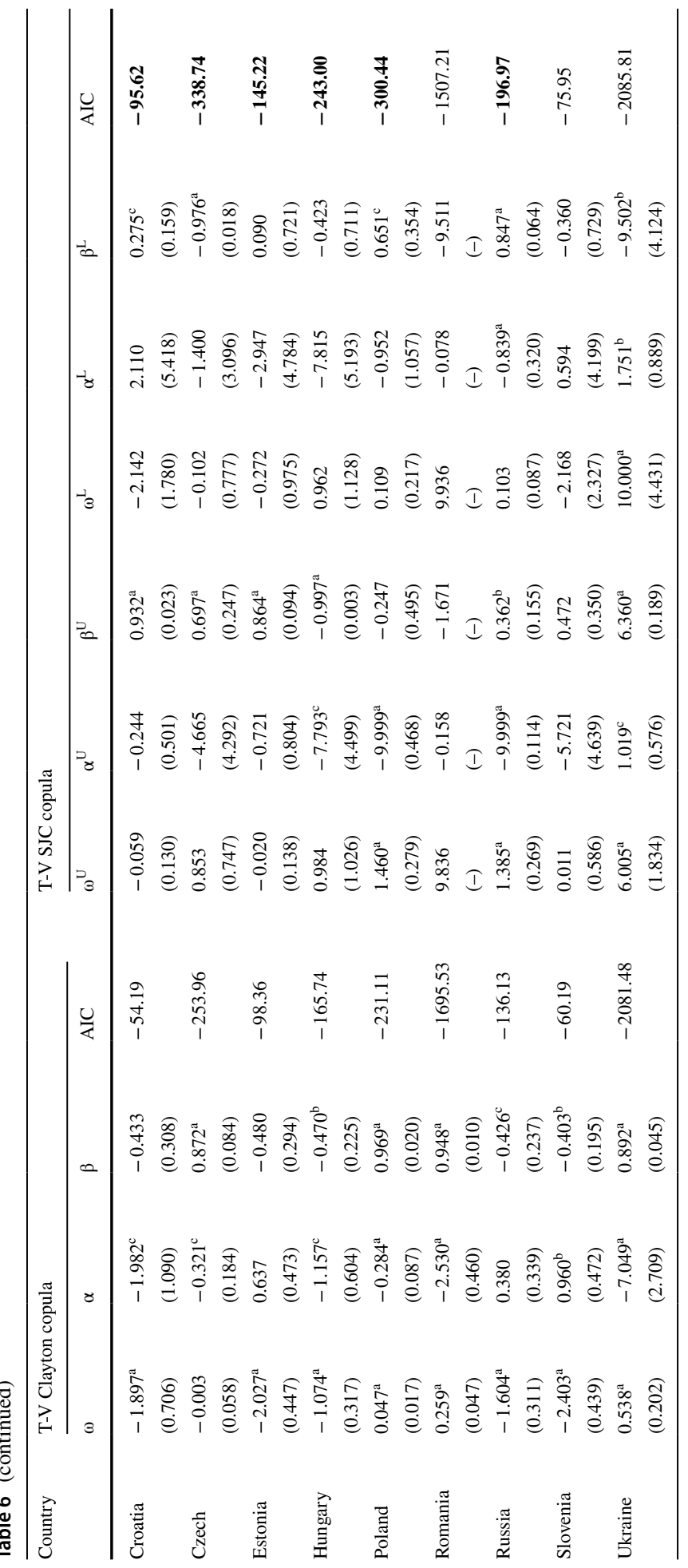




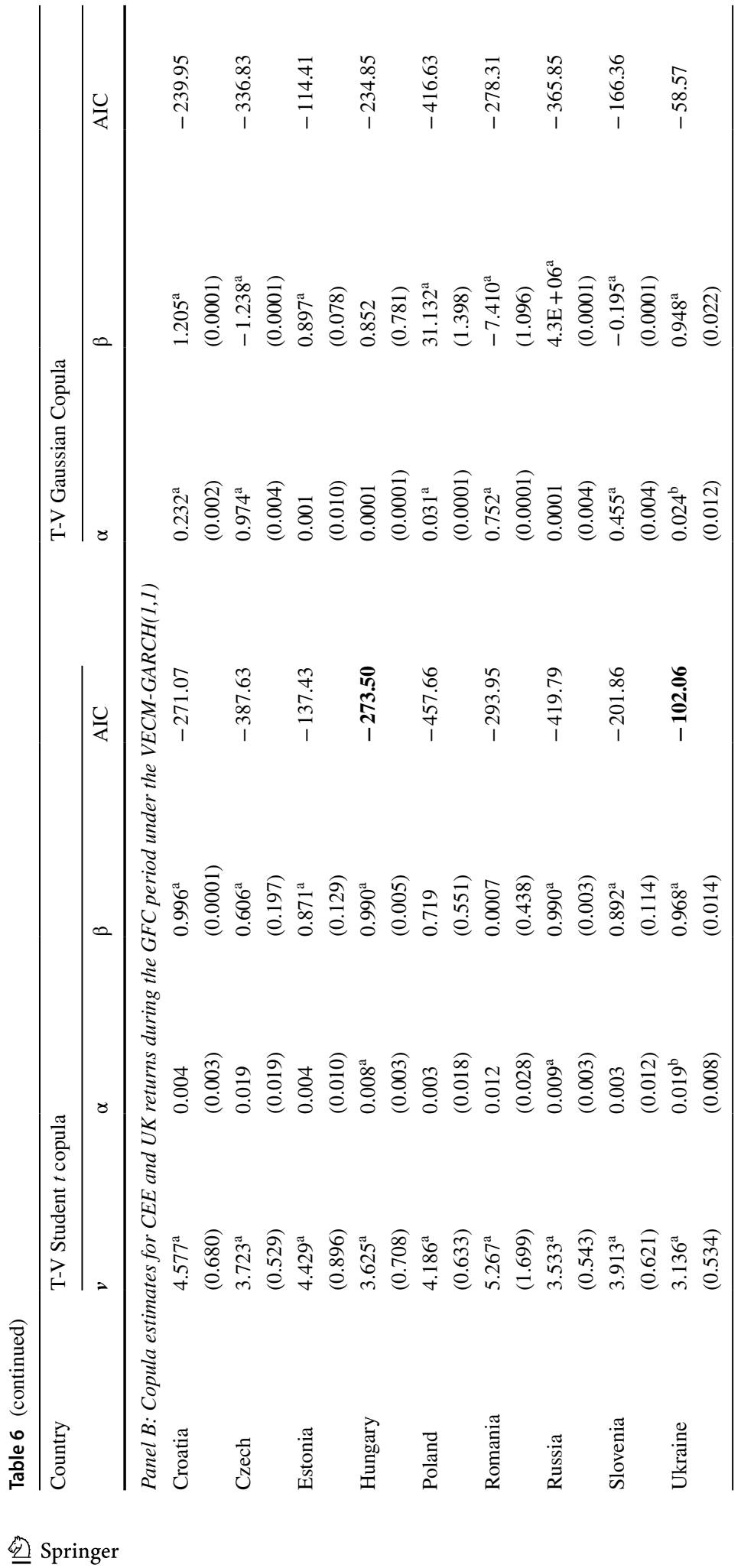




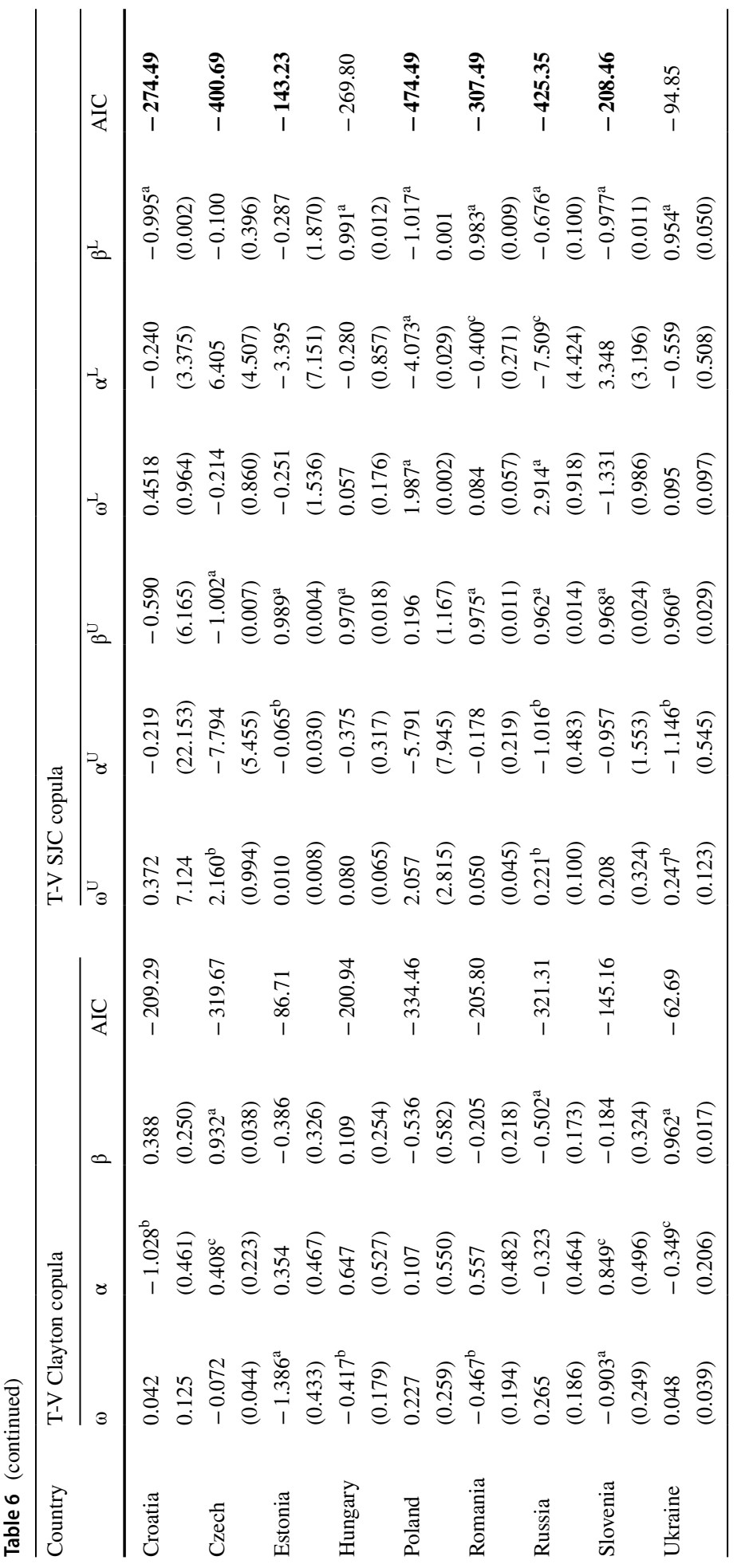




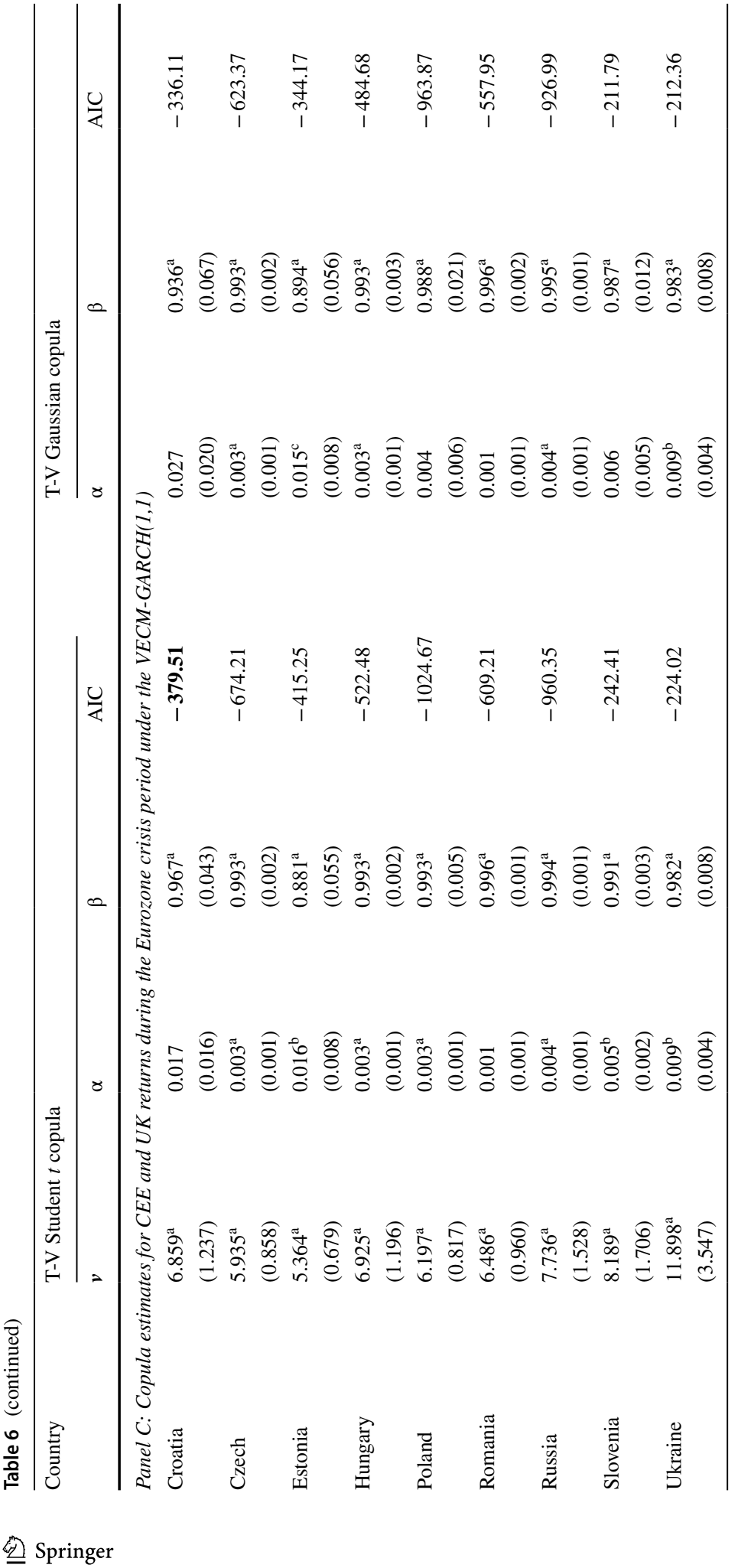




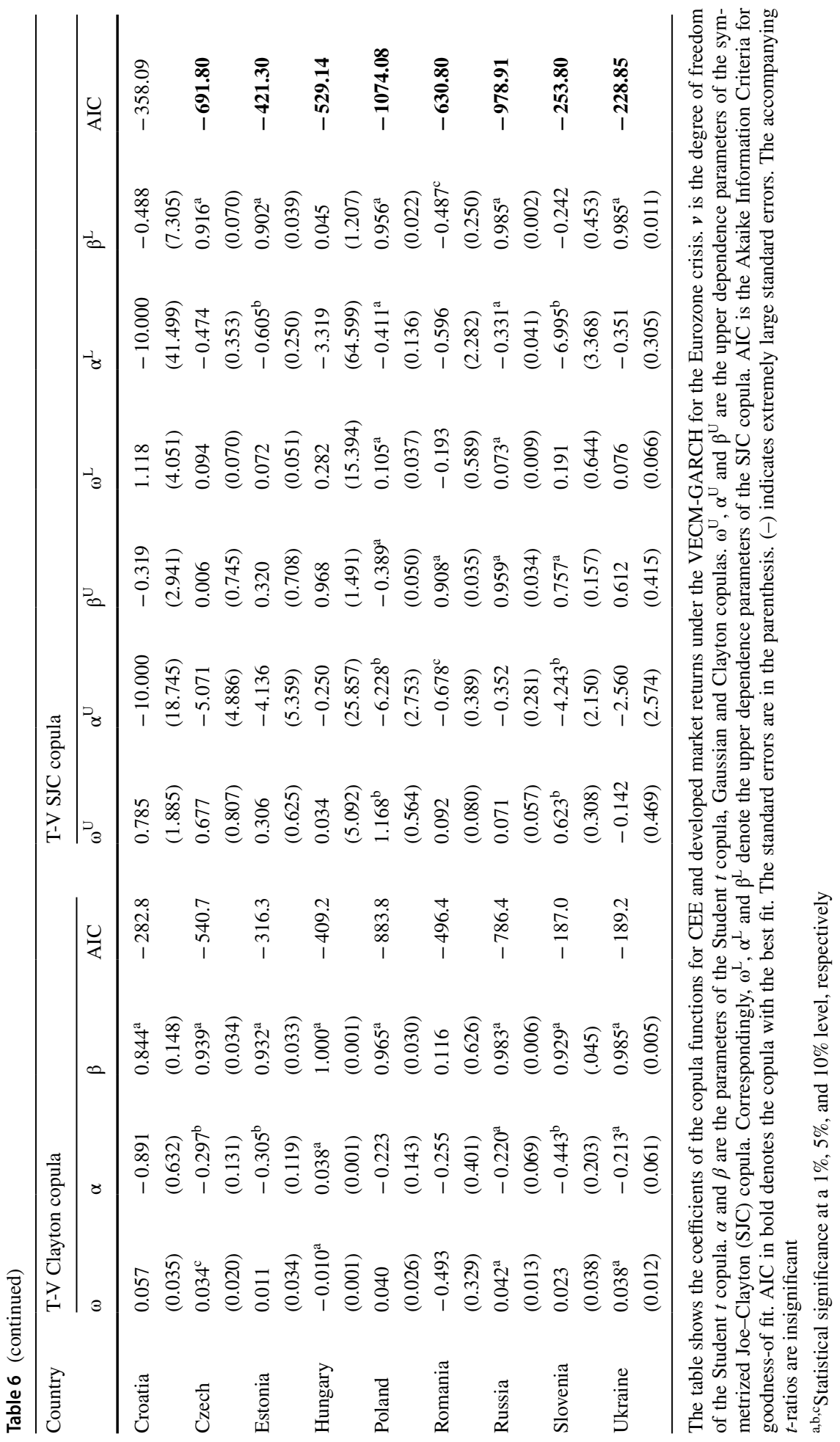


period (under the VECM-GARCH), the SJC copula performs better overall. The advantage of the SJC copula is that it allows both upper and lower tail dependence to range freely from zero to one, such that the extreme tails of the joint distribution are independent (Patton 2006). Indeed, the presence of skewness and kurtosis, rules out the Student $t$ and Gaussian copulas as good performers.

\subsubsection{Degrees of freedom and T-V Student t copula}

Ignoring model selection criteria, the persistence parameter, $\beta$ of the T-V Student $t$ copula is several times larger than the variation parameter, $\alpha$ (see Table 5). This result holds across all VAR specifications and sample periods. For instance, for the non-crisis period (see Table 5, Panel A), the Russian-German market pair has $\alpha=0.029$ ( $p$ value $\leq 0.05$ ), $\beta=0.901$ ( $p$ value $\leq 0.01$ ) with degrees of freedom, $v=6.185$ ( $p$ value $\leq 0.01)$. In contrast, $\alpha=0.013, \beta=0.987$ and $v=2.870$ (all with $p$ value $\leq 0.01$ ) for the same market pair, during the GFC period (Table 5, Panel B). Notice also that the increase in $\beta$ during the GFC period is associated with a decline in $v$. We discuss this feature below. Overall, between seven and nine market pairs have lower $\alpha$ values during both crisis periods, compared to the non-crisis period. However, the $\alpha$ values are significantly lower during the crisis periods for no more than two market pairs, using a simple $t$-test. Similarly, between five and nine market pairs have higher (more positive) $\beta$ values during both crisis periods, compared to the non-crisis period. The $\beta$ values are significantly higher during the crisis periods for no more than three market pairs. Thus, the evidence for significant decreases in $\alpha$ during the crisis periods is weak. The evidence for significantly stronger dependence in $\beta$ during the crisis periods is also weak. These results are weaker, even if we rule in model selection criteria.

The value of $v$ decreases during the crisis periods compared to the non-crisis period. The decreases in $v$ are weakly associated with increases in $\beta$ during the crisis periods. Decreases in $v$ are more severe for the GFC period compared to the Eurozone crisis period. However, except for two market pairs (Poland-Germany and Russia-Germany), the lower $v$ 's during the GFC are insignificant. The differences in the $v$ 's for the non-crisis and Eurozone crisis periods are also insignificant. It is useful to note, however, that four market pairs have significantly larger $v$ 's for Eurozone crisis period compared to the GFC period, even if the differences in the $v$ 's for non-crisis and Eurozone crisis periods are insignificant.

The patterns in $v$ and $\beta$ question what happens to dependence during different economic regimes. While we have ignored goodness-of-fit in the above test, we suggest that during crisis periods, greater uncertainty in economic conditions gives rise to heavier tail behavior than during tranquil periods, to impact both $v$ and $\beta$. This argument suggests that there was less heavy tail behavior during the Eurozone crisis period compared to the GFC period, assuming that a lower $v$ is reliably associated with more uncertainty and heavier tail behavior. Recall that the multivariate Student $t$-distribution approaches the Gaussian distribution for $\boldsymbol{v} \rightarrow+\infty$, which, in turn, depicts a more symmetric distribution. This consideration strengthens our interpretation. That is, we argue that a lower (higher) $v$ is associated with a heavier-tailed (lower tailed) distribution. Indeed, Embrechts et al. (2002) show that the Student $t$ copula delivers upper tail asymptotic dependence, the strength of which increases as $v$ decreases, and as the marginal distributions get heavier-tailed. As such, $v$ will be lower during crisis periods, compared to tranquil periods in line with our results. However, our results also suggest that upper tail asymptotic dependence, if present, is more pronounced 
during the GFC period compared to the Eurozone crisis period. Perhaps, this reflects the greater severity of the GFC.

\subsubsection{The T-V Student $t$ copula and the non-crisis and crisis periods}

Ignoring model selection criteria, the T-V Student $t$ generates six significant $\alpha$ coefficients and nine significant $\beta$ coefficients, during the non-crisis period (Table 5, Panel A). Fewer $\alpha$ and $\beta$ coefficients are significant during the GFC period (Table 5, Panel B). In contrast, eight $\alpha$ and nine $\beta$ coefficients are significant during the Eurozone crisis period (Table 5, Panel C). Thus, for the Eurozone crisis period, CEE and German returns exhibit only a small increase in the number of significant $\alpha$ coefficients compared to the non-crisis period, whereas fewer $\alpha$ and $\beta$ coefficients are significant during the GFC period. Longin and Solnik (2001) report that the correlations in returns are higher during extreme events. However, we find that persistence parameter $(\beta)$ is not substantially different across the subperiods. Of course, using sub-periods would reduce the power of the T-V Student $t$ copula. However, our approach is consistent with prior related studies (Patton 2006; Boero et al. 2010), noting also that model misspecification could also adversely affect prior empirical results. Thus, while we follow prior studies and assume that the GARCH process follows the Student $t$ distribution (Junker and May 2005), it may not provide the best fit for the GARCH process (see Sect. 3.1). Poon et al. (2004) also report that volatility clustering cannot fully explain tail dependence.

\subsubsection{T-V SJC copula and sub-period performance}

In this section, we examine the level of tail dependence for each sample period, using the T-V SJC copula. This is effectively a test of which part of the joint distribution has higher dynamics and tail dependence. Recall, that the T-V SJC copula is our preferred copula function based on the AIC. $\alpha^{U}$ and $\alpha^{L}$ capture the upper and lower tail dynamics, respectively. $\beta^{U}$ and $\beta^{L}$ capture upper and lower dependence, respectively. Ignoring whether or not the coefficients are significant, Table 5 shows that $\alpha^{L}$ tends to be higher (more positive) than $\alpha^{U}$, and $\beta^{L}$ tends to be lower than $\beta^{U}$ during the non-crisis and GFC periods. For the Eurozone crisis period, both $\alpha^{L}$ and $\beta^{L}$ tend to be lower than $\alpha^{U}$ and $\beta^{U}$, respectively. There is therefore a greater tendency to observe higher dynamics, as well as lower (less positive or more negative) joint negative dependence $\left(\beta^{L}\right)$ than upper joint dependence $\left(\beta^{U}\right)$ in each sub-period. However, the differences between the pairs of $\alpha^{L}$ and $\alpha^{U}$, and the pairs of $\beta^{L}$ and $\beta^{U}$ are often insignificant. Indeed, the simple $t$-test is significant in no more than three comparisons of $\alpha^{L}$ and $\alpha^{U}$ for any sub-period. Similarly, the $t$-test is significant in no more than four comparisons of $\beta^{L}$ and $\beta^{U}$ in any sub-period. These results point more towards a symmetric distribution since $\beta^{U}$ often equals $\beta^{L}$ for the same sub-period. Our result contrasts with prior work that reports asymmetric dependence is stock returns (Ang and Chen 2002). Jondeau and Rockinger (2006) report however, that while joint negative extremes create stronger dependence than joint positive extremes, large joint positive and negative extremes of the same magnitude have the same effect on subsequent correlations. This may explain some of our results. 


\subsubsection{T-V SJC copula and change in dependence across sub-periods}

We now compare the performance of the T-V SJC copula across the sub-periods. The focus is still on the VECM-GARCH. We use the non-crisis period as a benchmark on this occasion. Compared to the non-crisis period, four market pairs have significantly lower $\beta^{U}$ and $\beta^{L}$ values during the GFC period (Table 5, Panels A and B). $\beta^{U}\left(\beta^{L}\right)$ is significant higher for three (one) market pairs of the Eurozone crisis period compared to the non-crisis period (Table 5, Panels A and C). These results provide weak support for increases in asymmetric dependence during crisis periods compared to the non-crisis period.

We next test for asymmetric dependence between the GFC and Eurozone crisis, since the severity of the particular crisis may affect the level of dependence. Using the T-V SJC copula, $\alpha^{L}$ and $\alpha^{U}$ exhibit no demonstrable differences across the two sub-periods. At best, three market pairs have significantly higher $\beta^{U}$ coefficients during the GFC period compared to the Eurozone crisis period. In addition, five market pairs (Croatia, Poland, Romania, Russia, UK) have significantly higher $\beta^{L}$ during the Eurozone crisis period. This is our strongest result for lower tail dependence, but the evidence is still weak.

Overall, our results contradict the majority of prior studies that suggest stronger dependence during crisis periods (Gjika and Horvath 2013). Our findings complement Baruník and Vácha's (2013) result that CEE and Euro markets are loosely connected.

\subsection{Copula estimates using CEE and UK returns}

We replicate the above results for CEE and UK markets. The T-V SJC copula still dominates almost all other copulas across the VAR specifications and sub-periods. No more than five CEE-UK market pairs exhibit significant increases in lower tail dependence across our comparisons. On the practical side, our results suggest that there are important opportunities for international portfolio diversification using CEE returns. Below, we focus on the copula estimates from the VECM-GARCH.

\subsubsection{Goodness-of-fit of copulas based on CEE and UK returns}

Panel A of Table 6 shows that the T-V SJC copula provides the best fit to six of the nine market pairs of the non-crisis period. The T-V Student $t$ provides the best fit for the remaining market pairs of the non-crisis period. The T-V SJC copula also outperforms the other copula functions at other crisis periods, especially for the Eurozone crisis period (see Panels A to C). Under the T-V Student $t, \alpha$ is significant for between three and seven market pairs across the sub-periods, ignoring model selection criteria. $\beta$ is significant for between seven and nine market pairs. The Eurozone crisis period contains the largest number of significant $\alpha$ and $\beta$ coefficients (Panel C). The better fit of the T-V SJC copula is associated with fewer significant coefficients. These results are in line with those of CEE and German returns.

\subsubsection{Degrees of freedom and T-V Student $t$ copula}

Similar to the CEE and German results, Table 6 shows that $\beta$ is several times larger than the variation coefficient, $\alpha$. As before, the $v$ parameter is smaller for the crisis periods 
compared to the non-crisis period. The $\beta$ 's of the GFC period are significantly higher than those of the non-crisis period in only two comparisons. Conversely, the $\beta$ 's of the GFC are significantly lower than those of the non-crisis period in two comparisons. Pair-wise comparisons of the non-crisis and Eurozone crisis periods generate fewer significant differences. Ignoring model selection criteria, our best result for the T-V Student $t$ copula, is that five market pairs exhibit significantly higher $\beta$ values during the Eurozone crisis, compared to the non-crisis period. We are still unable to make a meaningful connection between $\alpha$ and $\beta$ over the sub-periods.

\subsubsection{T-V SJC copula and sub-period performance}

We now focus on tail dependence using the T-V SJC copula. Table 6 shows that compared to the non-crisis period, $\alpha^{U}$ and $\beta^{U}$ tend to be higher for the GFC periods (Panels A and B). Both $\alpha^{L}$ and $\beta^{L}$ tend to be lower for the GFC period. We find the opposite result in comparisons of the non-crisis and Eurozone crisis periods. The differences between the pairs of coefficients across sub-periods tend to be insignificant. At best, only five pair-wise comparisons of $\beta^{L}$ are significantly higher during the Eurozone crisis period compared to the non-crisis period. As before, the evidence in support of asymmetric dependence is weak. Three factors may contribute to this result. First, as indicated above, using a sub-period approach reduces the degree of variability in the data. An alternative approach would be to estimate the copulas over the full sample period, but prior studies do not recommend this approach (Lamoureux and Lastrapes 1990), as the underlying GARCH structure would be affected. Second, tail dependence is more likely to prevail in markets that are integrated. Finally, Patton (2006) recommends using the average of the last ten observations to capture variation in tail dependence. This effectively assumes an ARMA(1,10)-type process. While he considers this approach to be robust, his chosen lag length is unlikely to be suitable in all settings. While Bartram and Wang (2015) find support for lower tail dependence, using industry returns, their finding holds mostly for industries in Euro-area countries. Even if there may be weaknesses in their use of the Gaussian copula, it appears that support for asymmetric dependence is more pronounced when markets are integrated. Thus, Cavaglia et al. (2000) and Moerman (2008) argue for an industry approach rather than a country approach to exploit the diversification benefits of stock returns across countries.

\section{Additional tests and discussion}

We perform two additional tests in this section. First, we estimate the (time-varying) BEKK (Engle and Kroner 1995) to validate our VAR estimates and copula results. We use the bivariate diagonal BEKK as opposed to the full BEKK, since it does not suffer from some of the biases of the full BEKK (see Allen and McAleer 2018). ${ }^{26}$ Second, we estimate

\footnotetext{
${ }^{26}$ Chang and McAleer (2017) show that the full BEKK has no underlying stochastic process, asymptotic properties or even regularity conditions. The conditional variances of the full BEKK are lower in the left tail and higher in the right tail of the distribution compared to the conditional variances in the tails of the diagonal BEKK (Allen and McAleer 2018).
} 
an IV-GMM model of financial development to assess the impacts of legal and macroeconomic variables on financial development. ${ }^{27}$ Bartram and Wang (2015) adopt a related approach to explain variation in return dependence.

\subsection{BEKK estimation}

The diagonal BEKK is estimated for both VAR specifications, under the Student $t$ distributional assumption (as before). These results are not tabulated. The error-correction coefficients are negative and significant, in line with previous results. Also in line with our previous results, lagged volatility $(\mathrm{GARCH})$ has larger coefficients than past news. The T-V SJC copula dominates the T-V Student $t$ in goodness-of fit. We still do not find overwhelming support for increases or decreases in dependence across our sub-periods.

\subsection{Instrumental variable-Generalized Method of Moments (IV-GMM) estimation}

Large markets have more informative prices (Wurgler 2000). More informative prices facilitate higher liquidity, lower transaction costs and enhance co-movement. Price informativeness also facilitates more effective portfolio rebalancing. La Porta et al. (1997) indicate that legal rights protection predicts differences in ownership structure and financial development, being lower in developing countries. The strength of the legal environment (country-level corporate governance) influences tunnelling and investor behavior (Johnson et al. 2000), particularly around financial crises. Stringent legal systems constrain market activity, economic progress and innovation (Acharya and Subramanian 2009). Macroeconomic variables, such as reserves and terms of trade, also predict the severity of crisis events (see, Frankel and Saravelos 2012). An important test is whether the legal and macroeconomic environments of CEE countries are so strong to restrict market integration around crisis events. We test this prediction, using the ratio of market capitalization to GDP (MKCAP_ GDP) as a measure of financial development (see Wurgler 2000). This measure captures the idea that more competitive markets have better institutions and allocate capital more effectively. Our test is performed using a set of IV-GMM regressions. The basic model is,

$$
\begin{aligned}
\text { MKCAP }_{G D P i, t}= & \alpha+\sum_{C} \beta_{C} \text { Crisis }_{C, i, t}+\sum_{l} \beta_{l} \text { Legal }_{l, i, t}+\sum_{m} \beta_{m} \text { Control }_{m, i, t}+\sum_{k} \theta_{k} \text { Income level }_{k} \\
& +\sum_{j} \gamma_{j} \text { Year }_{j}+\varepsilon_{i, t} .
\end{aligned}
$$

MKCAP_GDP is the measure of financial development, defined as before. Crisis $_{C, i, t}$ denotes the crisis dummy variables. Legal $l_{l, i, t}$ denotes the legal measure $l$ of country $i$ in year $t$. The legal measures are: i) the Worldwide Governance Indicators (WGIs) of legal measures as in Kaufmann et al. (2011); and, ii) Quality of Government as in Houqe et al. (2012), which captures the reliability of financial reporting which tends to be higher in countries with high quality governments. We do not use Djankov et al.'s (2008) Anti-Self-Dealing

\footnotetext{
27 We thank two anonymous reviewers for suggesting additional tests along these lines. One of the reviewers suggested that cultural factors may contribute to variation in dependence. Data on cultural factors are difficult to construct in our setting. Prior studies show a connection between cultural factors and the legal environment (Franck 1999).
} 


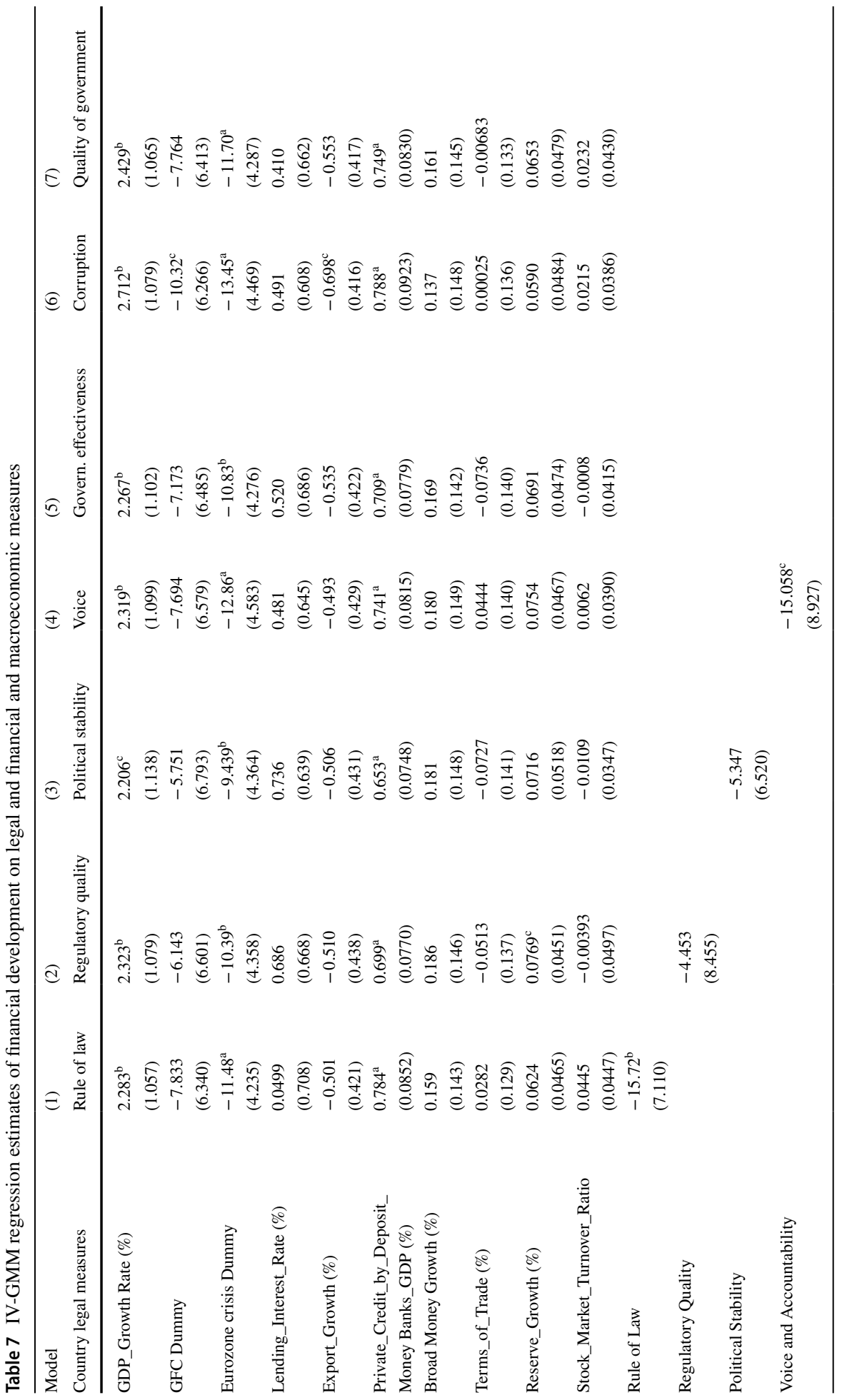




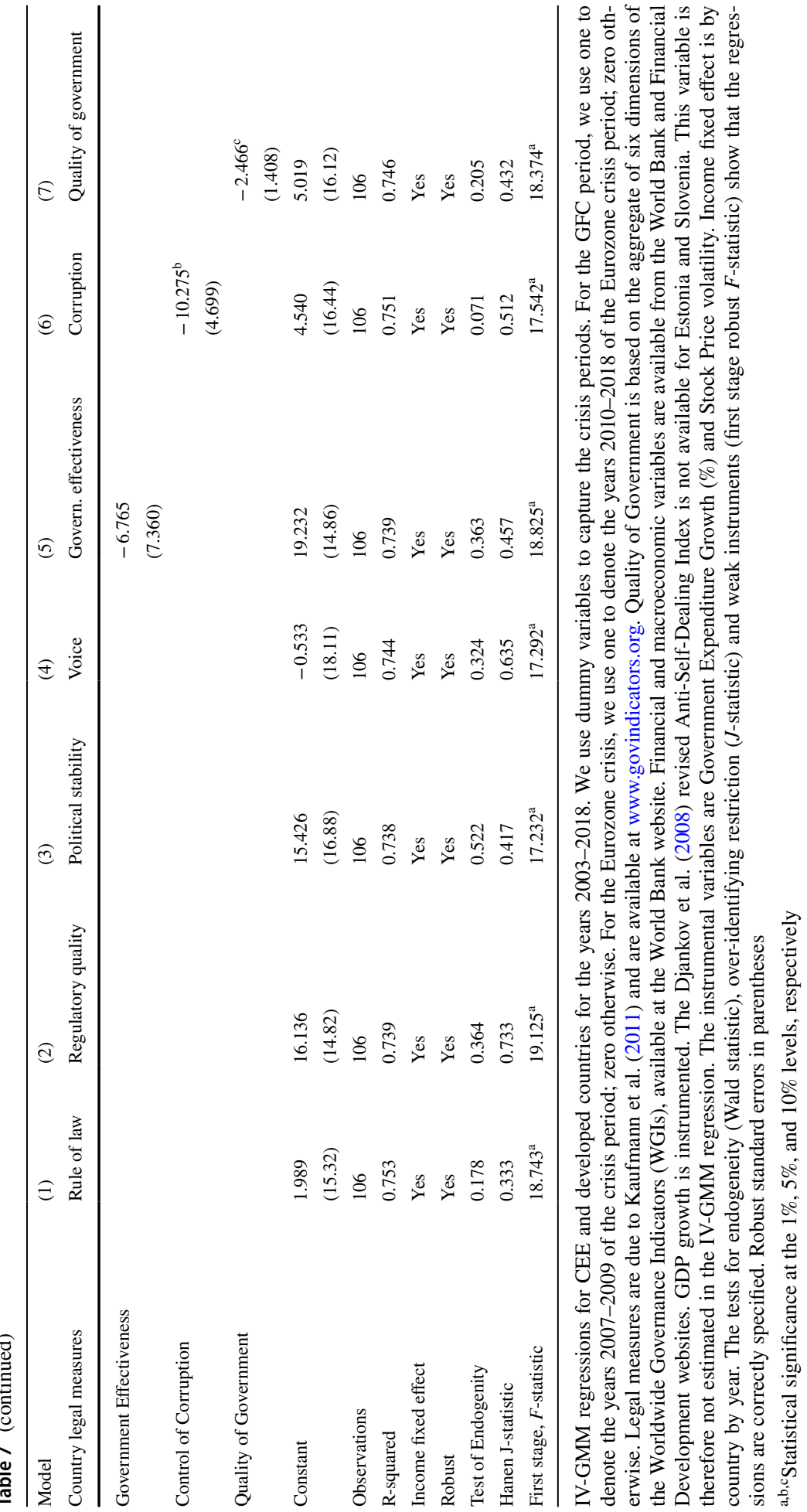


index of investor protection since it is unavailable for Estonia and Slovenia. Control ${ }_{m, i, t}$, denotes $m$ control variables. Year $_{j}$ is a dummy variable with a value of 1 for year $j$; 0 otherwise. $\theta_{j}$ and $\gamma_{j}$ capture income group and year effects, respectively. $\varepsilon_{i, t}$ is the disturbance term. We use robust standard errors for the IV-GMM estimation.

Table 7 shows that the IV-GMM model is well-specified, since there are no endogeneity and over-identification concerns ( $p$ value $\geq 0.10$ ). We also have good instruments as determined by the First stage $F$-statistic ( $p$ value $\leq 0.01$ ). The table shows that the crisis coefficients, especially for the Eurozone crisis, are negatively related to financial development. Only the GFC dummy in the Corruption model (Model 6) is negative and significant ( $p$ value $\leq 0.10)$. These results do not explain the observed variation in our VECM-GARCH, except to suggest that the financial markets were more isolated from the impacts of the GFC compared to the Eurozone crisis. The legal environment also has negative effects on financial development. A unit increase in the legal measures of Voice, Corruption and Quality of Government decreases financial development by between 2 and $15 \%$. The negative effects of the legal environment can cause CEE and the developed markets to be segmentation. This may explain the absence of strong market dependence in copula estimates. That is, differences in the legal environment can cause markets to be less responsive to global events. Recall that Eurozone crisis dummy indicates stronger negative effects on financial development compared to the negative effects of the GFC. Being in the Eurozone also implies compliance to strict rules on financial regulation which can adversely affect financial development in some markets. Indeed, Acharya and Subramanian (2009) argue that strong legal environments can actually restrict economic progress.

\section{Conclusion}

We investigate stock return volatility and the dependence of a set of CEE and developed stock markets. We argue that long-run conditions in the VECM-GARCH would limit divergence in pairs of market returns and lead to more reliable estimates of asymmetric dependence compared to the differenced VAR-GARCH. While we find support for long-run equilibrium conditions, the markets experienced a slow response to long-run equilibrium adjustments. We suggest that this slow adjustment process contributes to the inability of our VECM-GARCH to outperform the differenced VAR-GARCH, in terms of our copula results. Thus, the main advantages of the VECM-GARCH over the VAR-GARCH are that the VECM-GARCH allows an interpretation of steady-state equilibrium conditions which can be inferred by theory, and it facilitates improvements in estimation consistency. Of our four copula functions, the T-V SJC copula provides the best overall fit above all our other copula functions, including the T-V Student $t$. We do not find overwhelming evidence for upper or lower tail dependence. Our strongest results indicate increases in lower tail dependence: i) for five of our CEE-German market pairs during the Eurozone crisis period compared to the GFC period; and, ii) for five CEE-UK market returns in the Eurozone crisis period compared to the non-crisis period. Given the number of comparisons we perform, the evidence on asymmetric dependence is weak. We suggest that dependence between CEE and the developed markets is more symmetric than asymmetric, contrary to prior results. This means that the coordinated economic and financial policies of EU members have not brought about the desired level of market integration. On the other hand, CEE markets still provide opportunities for portfolios diversification. The legal environment 
has a decreasing effect on financial development which in turn may limit dependence in returns. This finding is consistent with Baruník and Vácha's (2013) for the Euro area.

Our results also make the case for using copula functions in tests of market dependence since such an approach generates more reliable results compared to the commonly used DCC approach. However, we do not suggest that using T-V copulas is the only reliable approach to test for market dependence nor do we suggest that stock market returns are the only variables of interest. For example, recently Poshakwale and Mandal (2017) show that international interest rates, inflation uncertainty and dividend yields are important drivers of return comovements and that they can be used to predict contagion effects. Indeed $\mathrm{Wu}$ (2000) find that strong inter-trade and liberalization among countries are an important source of contagion. However, given our results, we emphasize the need to ensure that the variables are correctly modelled to satisfy the data generating process. As a related estimation approach, it would be useful to consider tests that capture local dependence. Tjøstheim and Hufthammer (2013) introduce such an approach that approximates an arbitrary bivariate return distribution based on the Gaussian bivariate distribution family. Using this approach, Støve et al. (2014) report that normal copula best describes the nonlinear dependence structure of returns around crisis periods, using the local Gaussian correlations assumption. We doubt however, whether the Gaussian bivariate distribution is the best distributional assumption. Alternatively, future research could consider our time series modeling approach but using switching-parameter copulas (see Rodriguez 2007). Rocco (2014) provides a review of other extreme value approaches that can be applied to our data.

Acknowledgements We acknowledge the financial support from the NASDAQ OMX Nordic Foundation. We are grateful to participants of the British Accounting \& Finance Association 2018, Birmingham, UK, for comments on a previous version of the paper. We are also very grateful to Dr. Manthos Vogiatzoglou for making his dynamic MATLAB tool box 3.0 available, in order to compute the copula functions. We are also grateful for his support. The remaining errors are the authors' responsibility.

Funding We acknowledge the financial support from the NASDAQ OMX Nordic Foundation.

Data availability Dynamic Copula Toolbox. https://papers.ssrn.com/Sol3/papers.cfm?abstract_id=2956888. Accessed 9 Nov 2018.

\section{Compliance with ethical standards}

Conflict of interest The authors declare that they have no conflict of interest.

Open Access This article is licensed under a Creative Commons Attribution 4.0 International License, which permits use, sharing, adaptation, distribution and reproduction in any medium or format, as long as you give appropriate credit to the original author(s) and the source, provide a link to the Creative Commons licence, and indicate if changes were made. The images or other third party material in this article are included in the article's Creative Commons licence, unless indicated otherwise in a credit line to the material. If material is not included in the article's Creative Commons licence and your intended use is not permitted by statutory regulation or exceeds the permitted use, you will need to obtain permission directly from the copyright holder. To view a copy of this licence, visit http://creativecommons.org/licenses/by/4.0/. 


\section{Appendix I}

Stock markets with significant error-correct terms or cointegration

\begin{tabular}{|c|c|c|c|c|c|c|c|}
\hline & \multicolumn{3}{|c|}{$\begin{array}{l}\mathrm{CEE} \text { and German stock } \\
\text { markets }\end{array}$} & \multicolumn{3}{|c|}{ CEE and UK stock market } & \multirow[t]{2}{*}{ Year joining EU } \\
\hline & Johansen & $\mathrm{ECT}_{1, t-1}$ & $\mathrm{ECT}_{2, t-1}$ & Johansen & $\mathrm{ECT}_{1, t-1}$ & $\mathrm{ECT}_{2, t-1}$ & \\
\hline \multicolumn{8}{|c|}{$\begin{array}{l}\text { Panel A: non-crisis } \\
\quad \text { period }\end{array}$} \\
\hline Croatia & & & $\mathrm{Y}$ & & & $\mathrm{Y}$ & July 2013 \\
\hline Czech Republic & & & & & & & May 2004 \\
\hline Estonia & & $\mathrm{Y}$ & $\mathrm{Y}^{*}$ & & $\mathrm{Y}$ & & May 2004 \\
\hline Hungary & $\mathrm{Y}$ & $\mathrm{Y}$ & & $\mathrm{Y}$ & $\mathrm{Y}$ & & May 2004 \\
\hline Poland & $\mathrm{Y}$ & & $\mathrm{Y}$ & & & $\mathrm{Y}$ & May 2004 \\
\hline Romania & & & & & & & Jan 2007 \\
\hline Russia & & & $\mathrm{Y}$ & & & $\mathrm{Y}$ & \\
\hline Slovenia & $\mathrm{Y}$ & & & $\mathrm{Y}$ & & $\mathrm{Y}$ & May 2004 \\
\hline \multicolumn{8}{|l|}{ Ukraine } \\
\hline UK & & & & N/A & N/A & N/A & Jan 1973 \\
\hline Total Sig. cases & 3 & 2 & 4 & 2 & 2 & 4 & \\
\hline \multicolumn{8}{|c|}{$\begin{array}{l}\text { Panel B: global financial } \\
\text { crisis period }\end{array}$} \\
\hline Croatia & $\mathrm{Y}$ & $\mathrm{Y}$ & & $\mathrm{Y}$ & $\mathrm{Y}$ & & July 2013 \\
\hline Czech Republic & & $\mathrm{Y}$ & & & $\mathrm{Y}$ & $\mathrm{Y}$ & May 2004 \\
\hline Estonia & & & $\mathrm{Y}$ & & $\mathrm{Y}$ & & May 2004 \\
\hline Hungary & & & & & & $\mathrm{Y}$ & May 2004 \\
\hline Poland & & $\mathrm{Y}^{*}$ & $\mathrm{Y}$ & & & $\mathrm{Y}$ & May 2004 \\
\hline Romania & & $\mathrm{Y}$ & $\mathrm{Y}$ & & $\mathrm{Y}$ & & Jan 2007 \\
\hline Russia & & $\mathrm{Y}$ & & & $\mathrm{Y}$ & & \\
\hline Slovenia & & & $\mathrm{Y}$ & & & & May 2004 \\
\hline Ukraine & & & $\mathrm{Y}$ & & & $\mathrm{Y}$ & \\
\hline UK & $\mathrm{Y}$ & & & N/A & N/A & N/A & Jan 1973 \\
\hline Total Sig. cases & 2 & 5 & 5 & 1 & 5 & 4 & \\
\hline \multicolumn{8}{|c|}{$\begin{array}{l}\text { Panel C: Eurozone crisis } \\
\text { period }\end{array}$} \\
\hline Croatia & & & $\mathrm{Y}$ & & $\mathrm{Y}$ & $\mathrm{Y}$ & July 2013 \\
\hline Czech Republic & & & $\mathrm{Y}$ & & & $\mathrm{Y}$ & May 2004 \\
\hline Estonia & & & $\mathrm{Y}$ & & & $\mathrm{Y}$ & May 2004 \\
\hline Hungary & & $\mathrm{Y}$ & $\mathrm{Y}$ & $\mathrm{Y}$ & $\mathrm{Y}$ & $\mathrm{Y}$ & May 2004 \\
\hline Poland & & & & & & $\mathrm{Y}$ & May 2004 \\
\hline Romania & $\mathrm{Y}$ & $\mathrm{Y}$ & & & & $\mathrm{Y}$ & Jan 2007 \\
\hline Russia & & $\mathrm{Y}$ & $\mathrm{Y}$ & & $\mathrm{Y}$ & $\mathrm{Y}$ & \\
\hline Slovenia & $\mathrm{Y}$ & & & $\mathrm{Y}$ & $\mathrm{Y}$ & $\mathrm{Y}$ & May 2004 \\
\hline Ukraine & $\mathrm{Y}$ & & & & & $\mathrm{Y}$ & \\
\hline UK & & & & N/A & N/A & N/A & Jan 1973 \\
\hline Total sig. cases & 3 & 3 & 5 & 2 & 4 & 9 & \\
\hline
\end{tabular}

$Y$ denotes that the VECM-GARCH(1,1) and/or Johansen technique confirm long-run equilibrium conditions/cointegration at $p$ value $\leq 10 \%$ level. *indicates an error-correction coefficient with an unexpected positive sign. A blank indicates that neither the VECM-GARCH $(1,1)$ or Johansen technique confirms long-run equilibrium conditions/cointegration. Total sig. cases indicates the total number of statistically significant cases for each sub-period 


\section{References}

Acharya VV, Subramanian KV (2009) Bankruptcy codes and innovation. Rev Financ Stud 22:4949-4988

Ahmed R, Rhee SG, Wong YM (2012) Foreign exchange market efficiency under recent crisis. J Int Money Financ 31:1574-1592

Aielli GP (2008) Dynamic conditional correlation: on properties and estimation. J Bus Econ Stat 31:282-299

Aït-Sahalia Y, Cacho-Diaz J, Laeven RJA (2015) Modeling financial contagion using mutually exciting jump processes. J Financ Econ 117:585-606

Allen DE, McAleer M (2018) Theoretical and empirical differences between diagonal and full BEKK for risk management. Energies 11:1-19

Anastasopoulos A (2018) Testing for financial contagion: new evidence from the Greek crisis and yuan devaluation. Res Int Bus Financ 45:499-511

Ang A, Chen J (2002) Asymmetric correlations of equity portfolios. J Financ Econ 63:443-494

Baharumshah AZ, Wooi HC (2007) Exchange rate volatility and the Asian Financial Crisis: evidence from South Korea and ASEAN-5. Rev Pac Basin Financ Mark Polic 10:237-264

Baillie R, Bollerslev T (1989) The message in daily exchange rates: a conditional-variance tale. J Bus Econ Stat 7:297-305

Banerjee A, Dolado JJ, Galbraith JW, Hendry D (1993) Co-integration error correction and the econometric analysis of non-stationary data. Oxford University Press, Oxford

Banerjee A, Dolado J, Mestre R (1998) Error-correction mechanism tests for cointegration in a single-equation framework. J Time Ser Anal 19:267-283

Bartram SM, Wang YH (2015) European financial market dependence: an industry analysis. J Bank Financ 59:146-163

Baruník J, Vácha L (2013) Contagion among Central and Eastern European stock markets during the Financial Crisis. Czech J Econ Financ 63:443-453

Bekaert G, Hodrick RJ, Zhang X (2009) International stock return comovements. J Financ 64:2591-2626

Blanchard OJ, Dell'Ariccia G (2010) Rethinking Macroeconomic policy. J Money Credit Bank 42(Supp 1):199-215

Boero G, Silvapulle P, Tursunalieva A (2010) Modelling the bivariate dependence structure of exchange rates before and after the introduction of the euro: a semi-parametric approach. Int $\mathrm{J}$ Financ Econ $16: 357-374$

Bollerslev T (1986) Generalized autoregressive conditional heteroscedasticity. J Econ 31:307-327

Bollerslev T, Engle RF (1993) Common persistence in conditional variances. Econometrica 61:167-186

Boyer BH, Gibson MS, Loretan M (1999) Pitfalls in test for changes in correlations. Board Gov of the Fed Res Syst Int Financ Disc Pap No 597:1-25

Braun P, Nelson D, Sunier A (1995) Good news bad news volatility and betas. J Financ 50:1575-1603

Brechmann EC, Hendrich K, Czado C (2013) Conditional copula simulation for systemic risk stress testing. Insur Math Econ 53:722-732

Breymann W, Dias A, Embrechts P (2003) Dependence structures for multivariate high-frequency data in finance. Quant Financ 3:1-14

Brunsden J, Khan M (2018) Eurozone hails Greece's exit from bailout as end of crisis Eurozone hails Greece's exit from bailout as end of crisis in Brussels. FT: August 20. Accessed 9 Nov 2018

Caporale GM, Hunter J, Menla AF (2014) On the linkages between stock prices and exchange rates: evidence from the banking crisis of 2007-2010. Int Rev Financ Anal 33:87-103

Caporin M, McAleer M (2013) Ten things you should know about the dynamic conditional correlation representation. Econometrics 1:115-126

Cavaglia S, Brightman C, Aked M (2000) The increasing importance of industry factors. Financ Anal J $56: 41-54$

Chambet A, Gibson R (2008) Financial integration economic instability and trade structure in emerging markets. J Int Money Financ 27:654-675

Chang CL, McAleer M (2017) The fiction of full BEKK working paper; TI 2017-015/III Tinbergen Institute discussion paper SSRN: Rochester, NY, USA

Chollete L, Heinen A, Valdesogo A (2009) Modeling international financial returns with a multivariate regime-switching copula. J Financ Econ 7:437-480

Cubillos-Rocha JS, Gomez-Gonzalez JE, Melo-Velandia LF (2019) Detecting exchange rate contagion using copula functions. N Am J Econ Financ 47:13-22

de Boef S, Granato J (1999) Testing for cointegrating relationships with near-integrated data. Polit Anal 8:99-117

De Souza LV (2008) Foreign investment in Russia. ECFIN Ctry Focus 5:1-6 
Dias A, Embrechts P (2010) Modeling exchange rate dependence dynamics at different time horizons. J Int Money Financ 29:1687-1705

Dias JG, Ramos SB (2014) The aftermath of the subprime crisis: a clustering analysis of world banking sector. Rev Quant Financ Acc 42:293-308

Dimitriou D, Kenourgios D, Simos T (2013) Global financial crisis and emerging stock market contagion: a multivariate FIAPARCH-DCC approach. Int Rev Financ Anal 30:46-56

Ding Z, Granger CWJ (1996) Modeling volatility persistence of speculative returns: a new approach. J Econ 73:85-215

Djankov S, La Porta R, Lopez-de-Silanes F, Shleifer A (2008) The law and economics of self-dealing. J Financ Econ 88:430-465

Donadelli M, Paradiso A (2014) Is there heterogeneity in financial integration dynamics? Evidence from country and industry emerging market equity indexes. J Int Financ Mar Inst Money 32:184-218

Durante F, Jaworski P (2010) Spatial contagion between financial markets: a copula-based approach. Appl Stoch Models Bus Ind 26:551-564

ECB (2012) Area cross-border financial flows. ECB Mon Bull Feb 105-118. https://www.ecbeuropaeu/ pub/pdf/other/art3_mb201202en_pp105-118en.pdf. Accessed 9 July 2019

Embrechts P, McNeil A, Straumann D (2002) Correlation and dependency in risk management: properties and pitfalls. In: Dempster M, Moffatt H (eds) Risk management: value at risk and beyond. Cambridge University Press, Cambridge, pp 176-223

Engle RF (2002) Dynamic conditional correlation: a simple class of multivariate generalized autoregressive conditional heteroscedasticity models. J Bus Econ Stat 20:339-350

Engle RF, Bollerslev T (1986) Modelling the persistence of conditional variance. Econ Rev 5:1-50

Engle RF, Granger CWJ (1987) Co-integration and error correction: representation estimation and testing. Econometrica 55:251-276

Engle RF, Kroner KF (1995) Multivariate simultaneous generalized ARCH. Econ Theo 11:122-150

Erb CB, Harvey CR, Viskanta TE (1994) Forecasting international equity correlations. Financ Anal J 50:32-45

Fantazzini D (2009) The effects of misspecified marginals and copulas on computing the value at risk: a Monte Carlo study. Comput Stat Data Anal 53:2168-2188

Fermanian JD, Malongo M (2018) On the stationarity of dynamic conditional correlations models. Econ Theor 33:636-663

Franck TM (1999) The legal culture and the culture culture. Am Soc Int Law Proc 93:271-278

Frankel J, Saravelos G (2012) Can leading indicators assess country vulnerability? Evidence from the 2008-09 global financial crisis. J Int Econ 87:216-231

Frieden J, Walter S (2017) Understanding the political economy of the Eurozone Crisis. Annu Rev Polit Sci 20:1-19

Gilmore CG, McManus GM (2002) International portfolio diversification: uS and Central European equity markets. Emerg Mark Rev 3:69-83

Gjika D, Horvath R (2013) Stock market comovements in Central Europe: evidence from asymmetric DCC model. Econ Mod 33:55-64

Goetzmann WN, Li L, Rouwenhorst KG (2005) Long-term global market correlations. J Bus 78:1-38

Granger CW (1986) Developments in the study of cointegrated economic variables. Oxf Bull Econ Stat 48:213-228

Guidi F, Ugur M (2014) An analysis of South-Eastern European stock markets: evidence on cointegration and portfolio diversification benefits. J Int Financ Mark Inst Money 30:119-136

Heston SL, Rouwenhorst KG (1994) Does industrial structure explain the benefits of international diversification? J Financ Econ 36:3-27

Horváth R, Lyócsa Š, Baumöhl E (2018) Stock market contagion in Central and Eastern Europe: unexpected volatility and extreme co-exceedance. Eur J Financ 24:391-412

Houqe MN, Monem RM, van Zij1 T (2012) Government quality auditor choice and adoption of IFRS: a cross country analysis. Adv Int Acc 28:307-316

Jawadi F, Louhichi W, Cheffou AI (2015) Testing and modelling jump contagion across international stock markets: a nonparametric intraday approach. J Financ Mark 26:64-84

Johansen S (1988) Statistical analysis of cointegrating vectors. J Econ Dyn Control 12:231-254

Johnson S, Boone P, Breach A (2000) Corporate governance in the Asian Financial Crisis. J Financ Econ 58:141-186

Jondeau E, Rockinger M (2006) The copula-GARCH model of conditional dependencies: an international stock market application. J Int Money Financ 25:827-853

Junker M, May A (2005) Measurement of aggregate risk with copulas. Econ J 8:428-454 
Kalemli-Ozcan S, Papaioannou E, Peydró JL (2010) What lies beneath the euro's effect on financial integration? Currency risk legal harmonization or trade? J Int Econ 81:75-88

Karolyi GA, Stulz RM (1995) Why do markets move together? an investigation of U.S.-Japan stock return comovements. J Financ 51:951-986

Kaufmann D, Kraay A, Mastruzzi M (2011) The Worldwide Governance Indicators: methodology and analytical issues. Hague J Rule Law 3:220-246

Kenourgios D, Samitas A, Paltalidis N (2011) Financial crises and stock market contagion in a multivariate time-varying asymmetric framework. J Int Financ Mark Inst Money 21:92-106

Kwabi F, Faff R, Marshall A, Thapa C (2016) Sub-optimal international portfolio allocations and the cost of capital. J Multinatl Financ Manag 35:41-58

La Porta R, Lopez-de-Silanes F, Shleifer A, Vishny R (1997) Legal determinants of external finance. J Financ 52:1131-1150

Lamoureux CG, Lastrapes WD (1990) Persistence in variance structural change and the GARCH model. J Bus Econ Stat 8:225-234

Lane PR, Milesi-Ferretti GM (2007) Capital flows to Central and Eastern Europe. Emerg Mark Rev 8:106-123

Longin F, Solnik B (2001) Extreme correlation of international equity markets. J Financ 56:649-676

Lucey BM, Voronkova S (2008) Russian equity market linkages before and after the 1998 crisis: evidence from stochastic and regime-switching cointegration tests. J Int Money Financ 27:1303-1324

MacKinnon JG, Haug AA, Michelis L (1999) Numerical distribution functions of likelihood ratio tests for cointegration. J Appl Econ 14:563-577

Mensah JO, Premaratne G (2017) Dependence patterns among Asian banking sector stocks: a copula approach. Res Int Bus Financ 41:516-546

Moerman GA (2008) Diversification in euro area stock markets: country versus industry. J Int Money Financ 27:1122-1134

Mollah S, Quoreshi S, Zafirov G (2016) Equity market contagion during Global and Eurozone crises. J Int Financ Mark Inst Money 41:151-167

Patton AJ (2006) Modelling asymmetric exchange rate dependence. Int Econ Rev 47:527-556

Perron P (1989) The Great Crash the oil price shock and the unit root hypothesis. Econometrica 57:1361-1401

Poon SH, Rockinger M, Tawn J (2004) Extreme-value dependence in financial markets: diagnostics models and financial implications. Rev Financ Stud 17:581-610

Poshakwale SS, Mandal A (2017) Sources of time varying return comovements during different economic regimes: evidence from the emerging Indian equity market. Rev Quant Financ Acc 48:859-892

Pragidis C, Aielli GP, Chionis D, Schizas P (2015) Contagion effects during financial crisis: evidence from the Greek sovereign bonds market. J Financ Stab 18:127-138

Rocco M (2014) Exteme value theory for finance: a survey. J Econ Surv 28:82-108

Rodriguez JC (2007) Measuring financial contagion: a copula approach. J Empir Financ 14:401-423

Sklar A (1959) Functions de repartition an dimensions at leurs marges. Publications de L'mstitut de Statistique De L'université de Paris 8:229-231

Stock JH (1987) Asymptotic properties of least squares estimators of cointegrating vectors. Econometrica 55:1035-1056

Støve B, Tjøstheim D, Hufthammer KO (2014) Using local Gaussian correlation in a nonlinear re-examination of financial contagion. J Empir Financ 25:62-82

Su E (2017) Measuring and testing tail dependence and contagion risk between major stock markets. Comput Econ 50:325-351

Syllignakis MN, Kouretas GP (2011) Dynamic correlation analysis of financial contagion: evidence from the Central and Eastern European markets. Int Rev Econ Financ 20:717-732

Syriopoulos T, Roumpis E (2009) Dynamic correlations and volatility effects in the Balkan equity markets. J Int Financ Mark Inst Money 19:565-587

Tjøstheim D, Hufthammer KO (2013) Local Gaussian correlation: a new measure of dependence. J Econ 172:33-48

Vogiatzoglou M (2016) Dynamic copula toolbox. https://papers.ssrn.com/Sol3/papers.cfm?abstract_ $\mathrm{id}=2956888$. Accessed 9 Nov 2018

Voronkova S (2004) Equity market integration in Central European emerging markets: a cointegration analysis with shifting regimes. Int Rev Financ Anal 13:633-647

Wu C (2000) International trade relations and the contagious effects of the Asian Financial Crisis. Rev Pac Basin Financ Mark Polic 3:367-399 
Wu C, Chen C-n, He Y (2003) The Performance of East Asian economies and financial markets since the 1997 Financial Crisis. Rev Pac Basin Financ Mark Polic 6:113-140

Wurgler J (2000) Financial markets and the allocation of capital. J Financ Econ 58:187-214

Publisher's Note Springer Nature remains neutral with regard to jurisdictional claims in published maps and institutional affiliations. 